Aluminum extrusion with a deformable die

W. A. Assaad 
This research was carried out under projectnumber MC4.05221/A in the framework of the Strategic Research program of the Materials innovation institute (M2i).

Committee members:

Chairman:

Prof. dr. F. Eising

University of Twente, CTW

Promoter:

Prof. dr. ir. J. Huétink

University of Twente, CTW

Assistant promoter:

Dr. ir. H.J.M. Geijselaers

University of Twente, CTW

Members:

Prof. dr. ir. D. J. Schipper

University of Twente, CTW

Prof. dr. ir. F. J. A. M. van Houten

Prof. ir. L. Katgerman

University of Twente, CTW

Prof. ir. F. Soetens

Technical University of Delft

Technical University of Eindhoven

ISBN 978-90-365-3113-9

1st printing November 2010

Keywords: Aluminum extrusion, flat die, measuring die deflection, sharp corner, material flow simulation, condensation, substructuring, coupled analysis

This thesis was prepared with $\mathrm{LTT}_{\mathrm{E}} \mathrm{X}$ by the author and printed by PrintPartners Ipskamp, Enschede, from an electronic document.

Copyright (c) 2010 by W. Assaad, Enschede, The Netherlands

All rights reserved. No part of this publication may be reproduced, stored in a retrieval system, or transmitted in any form or by any means, electronic, mechanical, photocopying, recording or otherwise, without prior written permission of the copyright holder. 


\section{ALUMINUM EXTRUSION WITH A DEFORMABLE DIE}

\section{DISSERTATION}

to obtain

the degree of doctor at the University of Twente, on the authority of the rector magnificus, prof. dr. H. Brinksma, on account of the decision of the graduation committee to be publicly defended

on Wednesday, $24^{\text {th }}$ of November 2010 at $13: 15$ hrs

by

Wissam Ali Assaad

born on the $7^{\text {th }}$ of March 1977

in Saida, Lebanon 
This thesis has been approved by the promoter:

Prof. dr. ir. J. Huétink

and

by assistant promoter:

Dr. ir. H.J.M. Geijselaers 


\section{Summary}

In aluminum extrusion, a work-piece (billet) is pressed through a die with an opening that closely resembles the desired shape of a profile. By this process, long profiles with an enormous variety of cross-sections can be produced to serve different markets such as building, construction and transport industry. When the shape of a profile does not conform to the specifications defined by the customer, it is considered as scrap. The reason for the shape deviations may be related to unknown aluminum flow through the die or unknown deformation of the die. Subsequently the die requires correction or replacement. Here, not only aluminum but also time and energy are lost. Currently this is the state of the art in extrusion die design. Dies are designed by so called trial and error. The material flow in the die and the deformation of the die can also be predicted by numerical simulations. Computer capacities are more and more increasing and improvements on finite element methods with respect to mesh management, material modeling and solution of the systems of equations are going on. This means that in the traditional trial and error design process extrusion trials can be replaced with numerical simulations. This saves time, energy and the amount of scrap.

The part in the die opening that determines the shape of the profile is called the bearing. At the entrance of the bearing the aluminum flow has to round a sharp corner with a very small radius. Discretization of this radius will increase the total number of degrees of freedom in the simulation. Since a sharp change in the flow direction occurs at the corner, an approximation must be applied which avoids material loss and locking. As an approximation the corner is modeled by a single node to which a conditional normal is specified. The direction of this normal is determined such that the material flow is conserved. This approximation gives good results also in terms of extrusion force. It can be applied to different types of elements and it consumes little additional time in the preprocessing stage of the numerical simulation.

Three different methods are followed to simulate the material flow and the die deformation: a decoupled, a coupled and a semi-coupled method.

In the decoupled method, the material flow and die deformation simulations are solved separately. Although it gives a good prediction of the extrusion force and 
die deformation, it fails in predicting the exit velocity when the die is weak. The reason is that the exit velocity changes when the die deforms. In the coupled method, the material flow and die deformation are solved simultaneously. An Arbitrary Langrangian Eulerian formulation is applied to the aluminum. New mesh management options suitable for the aluminum extrusion simulations are implemented. They include centering and relocating the billet's nodes at the bearing to their corresponding die's nodes. The results show the influence of the die deformation on the exit velocity. The computational costs are however very high. The reason is that the die has to be deformed before steady state can be reached.

Two different procedures are studied to decrease the computational time: statically condensed tool and substructuring without condensation. Substructuring without condensation doesn't save computational time because the largest portion of the time is spent in the solver. The simulation with a statically condensed tool even shows a much higher computational time because the condensed stiffness matrix of the tool becomes dense.

In the semi-coupled method, the simulation is solved iteratively. The first iteration is similar to the decoupled method. Then, the simulation of the aluminum flow through the deformed die is performed. This procedure is repeated until the change in the extrusion force drops below a certain threshold. The computational time consumed in this method is negligible in comparison to that spent in the coupled method. It shows promising results. Since the simulations with the coupled method take a long time to reach the steady state due to the tool deformation, the semi coupled method will be a solution.

In addition actions have been taken to speed up the aluminum flow simulations. These include specifying the appropriate step size, employment of proportional increment, termination of the simulation when it reaches the steady state and selection of the appropriate solver. A significant decrease in the computational time has been realized.

The results of the numerical calculation of the deformation of the die are validated by an experiment. The experiment is conducted on a press owned by Boal Group. A U-shaped profile is extruded and the extrusion parameters are recorded. In addition, the die deflection is measured by applying a laser beam on a reflecting surface. The experiment was conduced in two rounds at different dates and with different extrusion parameters. Its setup is relatively simple yet it still gives realistic results and it is reproducible. 


\section{Samenvatting}

In het extrusieproces van aluminium wordt stafmateriaal door een matrijs met een opening geduwd. De vorm van deze opening komt overeen met de gewenste vorm van het profiel. Met het extrusieproces kunnen lange profielen worden geproduceerd met een enorme variteit in dwarsdoorsneden voor verschillende toepassingsgebieden, zoals de bouw-, contructie- of transportindustrie.

Indien de vorm van een gextrudeerd profiel niet voldoet aan de specificaties zal het worden afgekeurd. Deze vormafwijkingen kunnen worden veroorzaakt door onbekend stromingsgedrag van het aluminium of door de vervorming van de matrijs. Vervolgens zal de matrijs moeten worden aangepast of in zijn geheel moeten worden vervangen. In dit geval gaat niet alleen aluminium verloren, maar ook tijd en energie. Op dit moment is de stand van zaken in het ontwerpproces van extrusiematrijzen dat de matrijzen worden ontworpen met een trial-and-error proces.

De materiaalstroming in de matrijs, en de vervorming van deze matrijs, kunnen ook vooraf worden bepaald met numerieke simulaties. De rekencapaciteit van computers neemt toe en zo ook de ontwikkeling van de eindige elementen methode. Met name is dit het geval op het gebied van mesh-management, materiaalmodellering en vergelijkingoplossers. Dit betekent dat in het trial-and-error ontwerpproces, 'trial' extrusies kunnen worden vervangen door numerieke simulaties. Dit bespaart tijd, energie en uitval.

De opening in de matrijs bepaalt de vorm van het profiel en wordt ook wel de bearing genoemd. Aan het begin van de bearing moet het aluminium rond een scherpe hoek met een kleine radius stromen. Wanneer deze radius gedetaileerd gediscretiseerd wordt, neemt het aantal vrijheidsgraden in het model aanzienlijk toe. Aangezien het stromingsveld een grote richtingsverandering heeft bij deze hoek, is een benadering nodig die geen materiaalverlies of element-locking tot gevolg heeft. Een benadering is opgesteld, waarbij deze hoek wordt gemodelleerd met een enkele knoop waarop een normaalvector is gedefinieerd die de rand beschrijft. De richting van de normaalvector wordt ingesteld zodanig dat het materiaalvolume behouden blijft. Deze aanpak heeft als voordelen dat hij goede resultaten geeft voor de berekende extrusiekracht, kan worden gebruikt voor verschillende elementtypes en dat de benodigde preprocessing 
tijd voor de numerieke simulatie gering is.

Drie verschillende methodes zijn bestudeerd om de materiaalstroming en de matrijsvervorming te simuleren. Er is een ontkoppelde, een gekoppelde en een gedeeltelijk gekoppelde methode onderzocht.

In de ontkoppelde methode worden de materiaalstroming en de matrijsvervorming apart berekend. Hoewel dit een goede benadering geeft voor de extrusiekracht en de vervorming van de matrijs, is voor relatief slappe matrijzen de benaderde uitgangssnelheid onnauwkeurig.

In de gekoppelde methode worden de materiaalstroming en de matrijsvervorming simultaan berekend. Een gemengd Euler-Lagrangiaanse beschrijving (ALE) wordt gebruikt voor het aluminium. Nieuwe opties om de beweging van de mesh te controleren zijn gemplementeerd. Een van de opties is om in de bearing de knopen van het aluminium te centreren en te herplaatsen aan de hand van de corresponderende knopen op de matrijs. De resultaten tonen aan dat de matrijsvervorming een invloed heeft op het stromingsprofiel bij de uitgang van de matrijs. De benodigde rekentijd voor deze strategie is echter hoog. De belangrijkste reden hiervoor is dat de matrijs moet worden vervormd voordat een stationaire stroming wordt bereikt.

Om de rekentijd te reduceren zijn twee verschillende procedures bestudeerd. De eerste procedure is het statisch condenseren van de gereedschappen en de tweede procedure is het substructureren van de gereedschappen zonder condensatie. Substructureren zonder condenseren geeft geen winst in rekentijd aangezien het merendeel van de tijd wordt gebruikt voor het oplossen van de vergelijkingen. De simulatie met het statisch gecondenseerde gereedschap geeft een nog hogere rekentijd omdat de gecondenseerde stijfheidsmatrix van het gereedschap een hoge dichtheid krijgt.

In de gedeeltelijk gekoppelde methode wordt de simulatie iteratief opgelost. Voor de eerste iteratie is deze methode gelijk aan de ontkoppelde methode. Daarna wordt de simulatie van de aluminiumstroming door de matrijs berekend, waarbij de vervorming van de matrijs in rekening is gebracht. Deze procedure wordt herhaald totdat de verandering in de extrusiekracht daalt onder een bepaalde drempel. De rekentijd van deze methode is verwaarloosbaar in vergelijking met de gekoppelde methode en de resultaten zijn veelbelovend. De simulaties met de gekoppelde methode nemen veel tijd in beslag om een stationaire toestand te bereiken door de gereedschapsvervorming. De gedeeltelijk gekoppelde methode is hiervoor een oplossing.

Daarnaast is actie ondernomen om de rekenduur van de stromingssimulaties te verkorten. Het kiezen van een geschikte stapgrootte, het gebruiken van een proportioneel increment, het beindigen van de simulatie als de stationaire toestand is bereikt en het kiezen van een geschikte vergelijkingoplosser zijn bestudeerd. Een significante reductie van de rekentijd is gerealiseerd. 
De resultaten van de simulatie van de matrijsvervorming zijn gevalideerd met een experiment. Het experiment is uitgevoerd op een extrusiepers van de Boal Groep. Een U-profiel is gextrudeerd en de extrusieparameters zijn geregistreerd. Bovendien is de matrijsvervorming gemeten door met een laserstraal op een reflecterend oppervlak te schijnen. Het experiment is uitgevoerd in twee sessies op verschillende tijdstippen, met verschillende procesinstellingen. Het experiment is relatief eenvoudig, maar geeft toch realistische resultaten en is bovendien reproduceerbaar. 



\section{Contents}

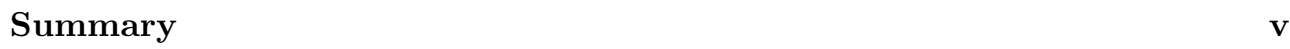

Samenvatting vii

1 Introduction 1

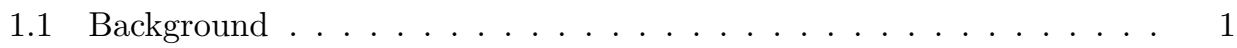

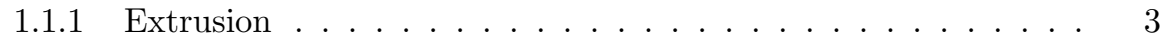

1.1.2 Performance of an aluminum extrusion plant . . . . . . . . 5

1.2 Finite element methods in aluminum extrusion . . . . . . . . . . . 6

1.3 Outlook of the thesis . . . . . . . . . . . . . 7

2 Modeling a sharp corner in aluminum extrusion 9

2.1 Introduction . . . . . . . . . . . . . . . . . . 9

2.2 Related work . . . . . . . . . . . . . . . . . . . 10

2.3 Specifying a conditional normal at a sharp corner . . . . . . . . . . 16

2.3.1 Representation of the conditional normal in aluminum extrusion simulation . . . . . . . . . . . . . . . 17

2.4 Specifying a conditional normal to a sharp corner after modifying the geometry . . . . . . . . . . . . . . . 18

2.5 Three-dimensional examples . . . . . . . . . . . . . . . . . . 22

2.6 Summary and conclusion ................... 23

3 Measuring the deflection of a flat die 25

3.1 Introduction . . . . . . . . . . . . . . . . . 25

3.2 Literature review . . . . . . . . . . . . . . . . . . 25

3.3 Experimental setup . . . . . . . . . . . . . . . . . . . 26

3.3.1 Extrusion of the profile . . . . . . . . . . . . . 27

3.3.2 Determination of the angular deflection . . . . . . . . . . . . 29

3.3.3 Reflecting surface . . . . . . . . . . . . . . . . . 30

3.3.4 Laser source. . . . . . . . . . . . . . . . . . . . . . . . . . . . . . . . . . 31

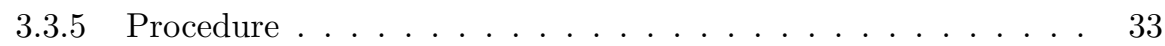

3.3.6 Extrusion cycle . . . . . . . . . . . . . . . . . 34

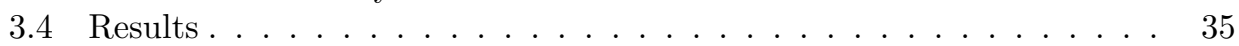


3.4.1 Experimental results of the $1^{\text {st }}$ round . . . . . . . . . . . . 35

3.4 .2 Experimental results of the $2^{\text {nd }}$ round . . . . . . . . . . . 41

3.5 Summary and conclusion ................... 41

4 Calculation of the die deflection by the decoupled method 45

4.1 Introduction . . . . . . . . . . . . . . . . . . . . . . . . . . . . 45

4.2 Decoupled method . . . . . . . . . . . . . . . . . . . . . . . . . . . . . . . . 45

4.3 Case study . . . . . . . . . . . . . . . . . . . . . . . 46

4.3.1 Material flow simulation . . . . . . . . . . . . . . 46

4.3.2 Tool simulation .................... 53

4.3.3 Comparison between experimental and numerical results . . . . 57

4.4 Summary and conclusion . . . . . . . . . . . . . . . 61

5 Calculation of die deflection by the coupled method 63

5.1 Introduction . . . . . . . . . . . . . . . . . . . 6 . . . . . . . 63

5.2 A coupled method ..................... 64

5.3 Procedures of the coupled method . . . . . . . . . . . . . . 65

5.3 .1 Full-scale model . . . . . . . . . . . . . . . . . . 67

5.3.2 Substructuring without condensation . . . . . . . . . . 70

5.3.3 Statically condensed tool . . . . . . . . . . . . . . 72

5.4 Case study . . . . . . . . . . . . . . . . . . . . 73

5.5 A semi-coupled method . . . . . . . . . . . . . . 76

5.6 Summary and conclusion . . . . . . . . . . . . 78

6 Applications $\quad 81$

6.1 Introduction . . . . . . . . . . . . . . . . . . . . . 81

6.2 Extrusion benchmark 2007 . . . . . . . . . . . . . . 82

6.2.1 Finite element simulation . . . . . . . . . . . . . 82

6.2 .2 Results ......................... 83

6.2.3 Achievements since $2007 \ldots \ldots . \ldots . \ldots . \ldots 84$

6.3 Extrusion benchmark 2009 . . . . . . . . . . . . . . . 85

6.3.1 Finite element simulation . . . . . . . . . . . . . . 86

6.3.2 Results ..................... 87

7 Conclusion $\quad 91$

7.1 Modeling a sharp corner in aluminum extrusion . . . . . . . . . . . . . 91

7.2 Measuring the deflection of a flat die . . . . . . . . . . . . . . . . . . 91

7.3 Calculating the deflection of the die . . . . . . . . . . . . . 92

8 Recommendations for further development $\quad 93$

$\begin{array}{ll}\text { A Tool parts } & 95\end{array}$

$\begin{array}{ll}\text { B Results of the } 1^{\text {st }} \text { round } & 99\end{array}$

$\begin{array}{ll}\text { C Material parameters } & 101\end{array}$

C.1 Aluminum alloys ...................... 101 
C.2 Tool steel . . . . . . . . . . . . . . . . . . . . . . 101

$\begin{array}{ll}\text { References } & 102\end{array}$ 



\section{Introduction}

\subsection{Background}

Aluminum is not found in nature as a free element because of its chemical reactivity. Most of it is found in the form of bauxite; gray or white clay stone whose main constituent is aluminum hydroxide. Bauxite is washed, crushed and dissolved in caustic soda at high temperature and pressure. The resulting solution contains sodium aluminate and undissolved bauxite residues containing iron, silicon and titanium. The residues are removed and the clear sodium aluminate solution is pumped into a huge tank called the precipitator where pure alumina particles sink to the bottom. After the chemically combined water is driven off, a pure alumina is obtained in the form of white powder. Finally, alumina is separated into aluminum and oxygen by the Hall-Heroult smelting process. This is a continuous process and it requires a very high electric current. Aluminum is formed at about $900 \mathrm{C}^{\circ}$, while it melts at $660 \mathrm{C}^{\circ}$. Aluminum is produced with $99.7 \%-99.8 \%$ purity.

The recyclability of aluminum is one of its main benefits because the recycled aluminum only requires $5 \%$ of the energy needed to make new aluminum. The quality and properties of the recycled aluminum are similar to those of new aluminum. The recycled aluminum originates from old scrap and new scrap. Old scrap is the discarded material after it has been used by the consumer. New scrap is the material which results during the manufacturing of products.

Aluminum can be mixed with other elements to form alloys with different properties. The alloying elements include magnesium, silicon, iron, copper, manganese, chromium, zirconium, vanadium, lead and titanium.

Aluminum alloys are processed in many different ways depending on the intended application. For example, aluminum alloys can be cast in an infinite variety of shapes, rolled into plates and sheets and extruded to form profiles with different crosssections. 
Figure 1.1 shows the percentage of aluminum metal formed by each process where $26.4 \%$ is formed by extrusion.

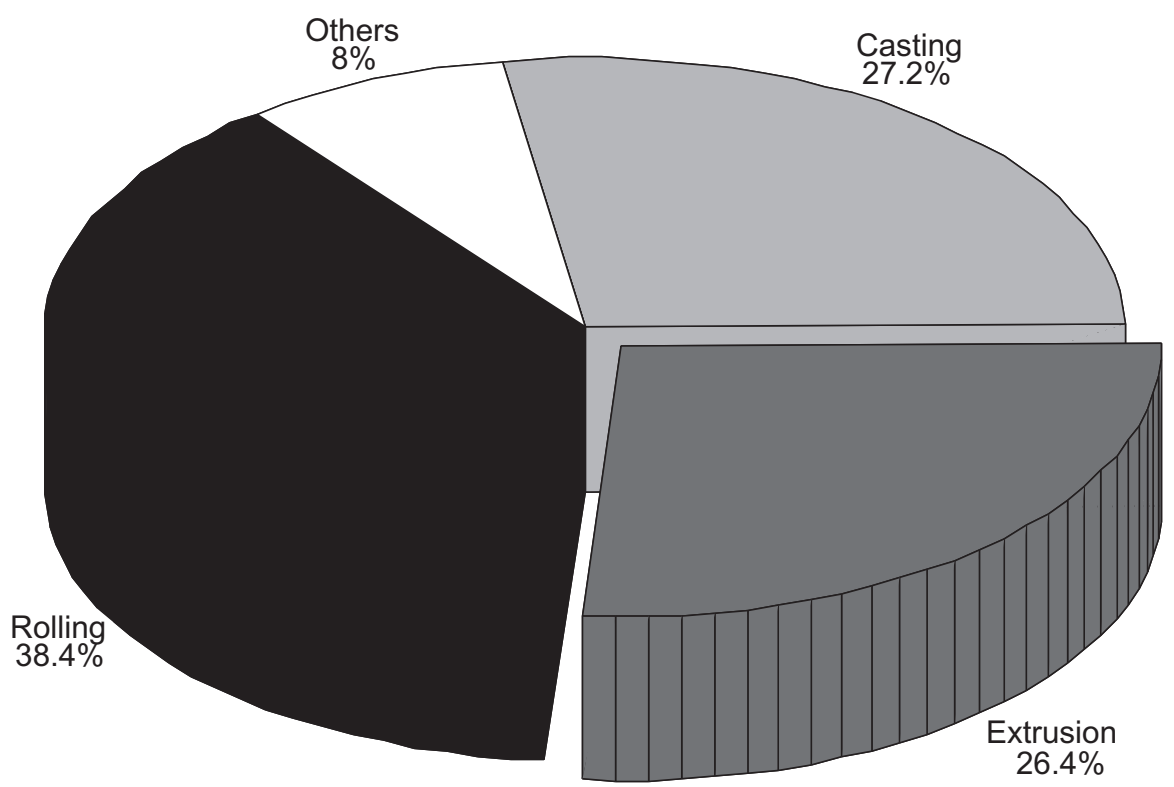

Figure 1.1: Distribution of aluminum processes in West and Central Europe in 2006 (EAA)

The alloy classes range from 1000 to 7000 series. The 6000 series alloys have magnesium $(\mathrm{Mg})$ and silicon $(\mathrm{Si})$ as main alloying elements and they are designated by magnesium silicide $\left(\mathrm{Mg}_{2} \mathrm{Si}\right)$. They are most commonly used in extrusion due to the following qualities: good corrosion resistance, surface finish, formability and medium strength [15]. Accordingly, these qualities make them suitable for decorative architectural sections and structural applications. These alloys are classified into three main categories according to the content of aluminum silicide. $1 \%, 0.8 \%$ and $0.7 \%$ aluminum silicide correspond to high strength, general purpose and high extrudability, respectively [40].

Extruded products are utilized in different sectors where figure 1.2 displays the size of the market in each sector. The transport sector makes up $17 \%$ of all extrusion products.

In the transport sector, the growing demand for vehicles with less energy consumption and less emissions makes aluminum a good candidate for replacing heavier metals such as steel and copper because of its high strength, stiffness-to-weight ratio, formability, corrosion resistance and recycling potential. Regarding trucks, busses, rail and marine transport, the reduction in their weight allows them to carry heavier loads without 


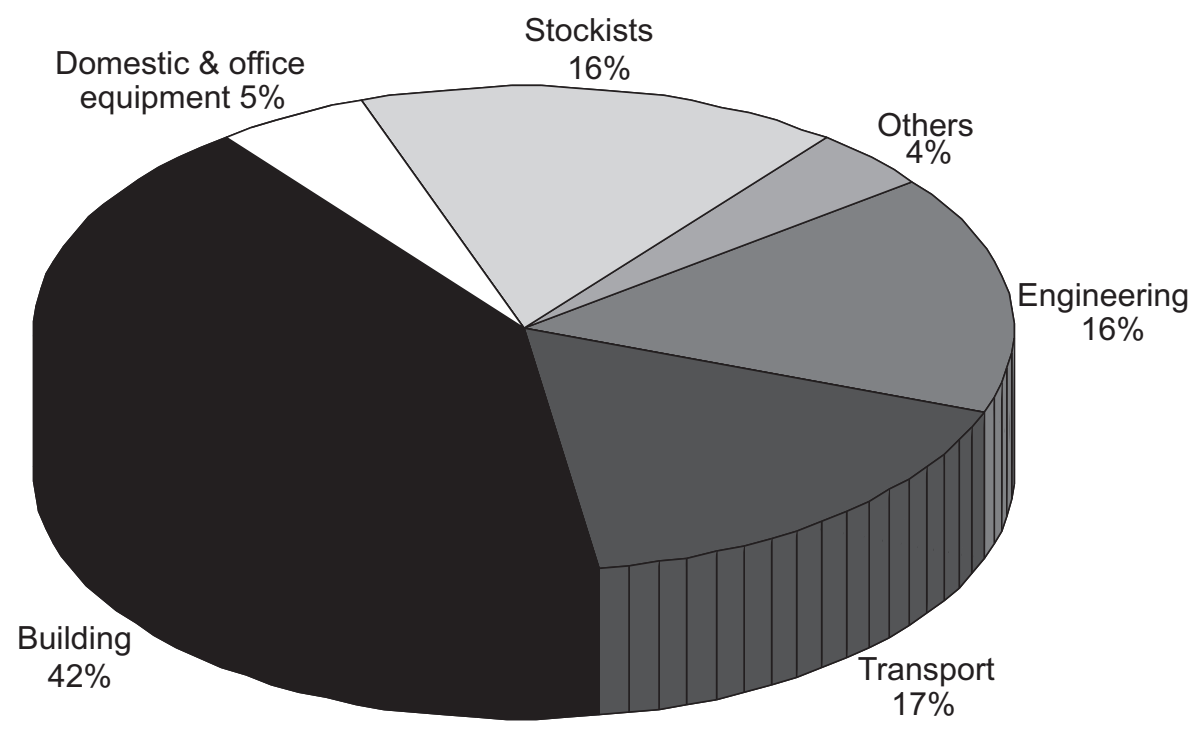

Figure 1.2: Market of extruded products in Europe in 2006 (EAA)

exceeding the weight limit and lowers the number of trips. Regarding road vehicles, the weight reduction leads to fuel savings and a reduction in carbon dioxide emissions during their lifetime.

\subsubsection{Extrusion}

Extrusion is a forming process in which a workpiece (billet) is pressed through a die with an opening in the shape of the desired crosssection. The billet deforms plastically and starts flowing through the die opening under indirect compressive loads. The process can be hot or cold depending on the alloy and the method used. In hot extrusion, the billet is preheated to a temperature between $400 \mathrm{C}^{\circ}$ and $500 \mathrm{C}^{\circ}$ before entering the container in order to facilitate its plastic deformation. There are two basic methods of the extrusion process: direct and indirect extrusion.

Direct extrusion shown in figure 1.3 is the most commonly used method. In this method, the billet is placed into the container and pressed by oil pressure exerted on the ram. The container and the die remain stationary. During extrusion the material flows in the direction of the ram movement. A friction force results due to the relative motion between the billet and the walls of the container. This friction force leads to a high ram pressure and it shears off the outer layer of the billet.

In indirect extrusion the die is mounted at the front of a hollow stem and moves relative to the container as shown in figure 1.4. The main advantages of this method 


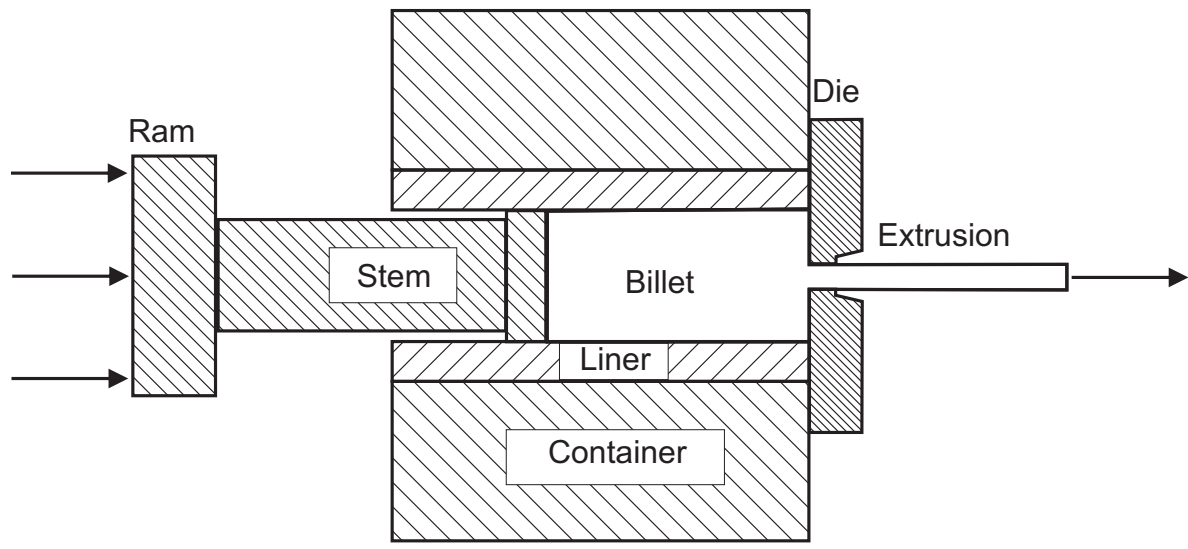

Figure 1.3: Direct extrusion process

are related to the absence of the relative motion between the billet and the container. They include lower extrusion load and no heat generation due to the absence of friction related shearing. Therefore, profiles with smaller crosssections can be formed, a higher extrusion speed can be applied and the service life of the liner of the container is increased. But there are disadvantages to this method that make its application not as broad as that of the direct extrusion method. The profile has to travel the whole distance of the hollow stem before it is quenched. The profile crosssection is limited by the hollow stem. The more uniform flow due to the lack of friction between the billet and the container will lead to the invasion of impurities in the extrusion [40].

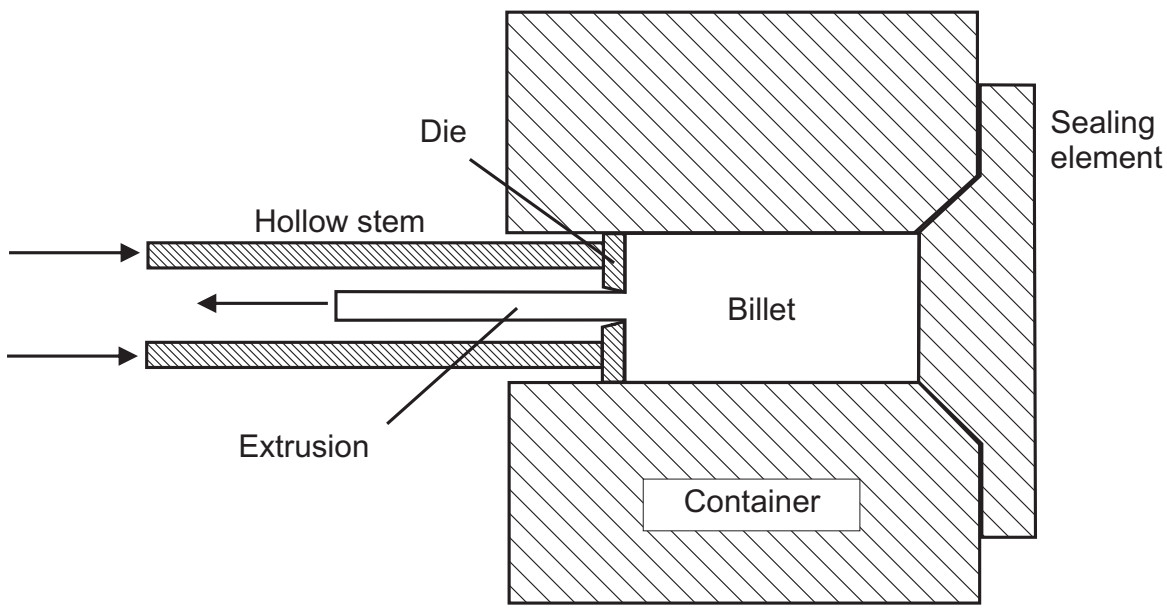

Figure 1.4: Indirect extrusion process 
The thesis only treats examples of the direct extrusion method.

Two types of profiles are extruded: solid and hollow profiles. A solid profile is bounded by a single curve and a flat die is employed in extruding it, whereas a hollow profile is bounded by two or more curves and a porthole die is utilized in extruding it [29]. Examples of solid and hollow profiles are shown in figure 1.5.
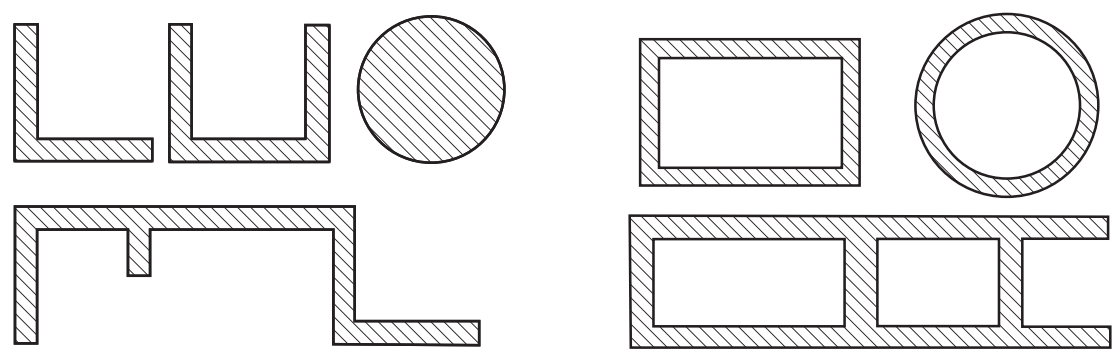

Figure 1.5: Examples of solid profiles (left) hollow profiles (right)

\subsubsection{Performance of an aluminum extrusion plant}

In aluminum extrusion the margin is low and the competition between extrusion companies is fierce. The profit can be increased by improving the productivity and recovery. The productivity is defined by the quantity of good extrusions produced per unit time [38]. The recovery is defined as the ratio of the weight of the good extrusions to the weight of the billets. Figure 1.6 reveals the division of a single billet into three parts including the recoverable part, the butt end and the scrap.

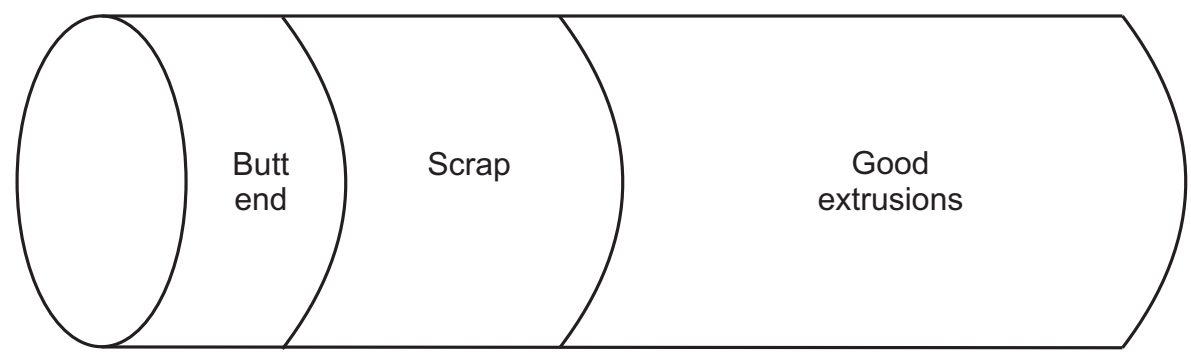

Figure 1.6: The recovery of a billet

The recoverable part is the part of the billet which is mapped to the good extrusions. The butt end is the remaining part of the billet where the extrusion process is stopped 
in order to prevent oxide and other metallic or non-metallic inclusions from flowing into the extrusions. Its thickness is kept to 10 to $15 \%$ of the billet length [38]. The scrap is classified into two categories: unavoidable and avoidable.

The unavoidable part includes the scrap resulting from the nose piece, back-end defects, transverse and longitudinal welds. It amounts to approximately $10 \%$ of the aluminum used. The avoidable scrap results from profiles that don't meet customer specifications. This portion can be controlled either by the extruder or by the die designer. Therefore, the die design has an influence on the amount of scrap [50]. A well designed die decreases the amount of discarded profiles that don't comply with customer specifications, material lost in changing the tool, manpower, and downtime of the press.

\subsection{Finite element methods in aluminum extrusion}

The finite element method is widely used in the analysis of the aluminum extrusion process as well as in other metal forming processes. The diversity of element types, material models, formulations and solvers available in most of the commercial and non-commercial finite element codes, makes this tool suitable for investigating the aluminum extrusion process. Commercial packages include Forge, HyperXtrude, Qform and Deform. Non-commercial packages include DiekA and PressForm.

Nowadays, the demand for complicated profiles in the market makes 2D simulations unsuitable for the study of the material flow. Therefore, 3D simulations are required. In addition, aluminum extrusion is a thermo-mechanical and non-stationary process. Its complexity forces researchers and engineers to refrain from studying the entire problem and to study a simplified one instead. For example, calculations are performed with a filled rigid die, the heat transferred from the aluminum to the die, ram and container is neglected and stick-slip boundary conditions are applied between aluminum and die.

In extrusion benchmarks 2007 [21] and 2009 [31] two different die designs were simulated with different finite element packages in order to check the applicability and user's knowledge. These packages use different formulations such as Lagrangian, Eulerian or mixed in a transient or steady state analysis. Most of them show good results in comparison with the experimental results in terms of velocity distribution, extrusion force, profile temperature and die deflection. Comparing the time spent in the simulation of the two extrusion benchmarks by different finite element packages, a significant decrease in the computational time has been observed since 2007 . For some finite element packages, the decrease exceeds $500 \%$. This means that the efforts spent in the developments of the packages are paying off. But their application in the industry is still limited due to large computational time, lack of user's skills and limited accuracy of prediction [22]. 
As mentioned before, simulations of the material flow are commonly performed with a rigid tool. Therefore, the influence of the tool deformation on the material flow is not considered. In fact, the die is subjected to high mechanical and thermal loads. Under these loads, the die will be dished in [40]. The shape of the opening and velocity distribution will be modified by this deformation. Subsequently, the extruded profiles will be discarded as scrap because they don't meet customer specifications. The deformation of the die must be known during its design stage in order to design the bearings, supporting parts and its thickness. The finite element method can be applied in designing the die [33].

Since linear tetrahedron elements are unsuitable for plastic flow calculations due to volume locking, quadratic elements with selective reduced integration are used $[16,26]$. Furthermore, the quadratic tetrahedron elements are preferred for complex geometries. In this work, 3D CAD models are discretized with 10 node tetrahedron elements with translational degrees of freedom. A preprocessor was developed to create the input file of FE code DiekA. It translates the mesh, applies the boundary conditions, builds the stiffness matrix of the tool and condenses it when it is required. In addition, a postprocessor was developed to calculate the extrusion force and the velocities of the profiles.

Since hot aluminum has a rate-dependent or viscoplastic behavior, its behavior is described by Sellers-Tegart law. The law and its constants that correspond to the alloys used in the simulations are stated in appendix C. An elasto-plastic material model with Voce hardening is used to describe the behavior of the tool material [29]. The constants of the tool material are stated in appendix C.

Direct and iterative sparse solvers are employed in the simulations. The direct sparse solvers are MUMPS [30] and Sun Performance [42]. The iterative solver is Bi-CGSTAB [1]. The simulations are performed with different versions of DiekA on different machines. The machines are listed in table 1.1.

\begin{tabular}{ccccc}
\hline Machine & Processors & Processor speed & RAM & DiekA version \\
\hline HP DL145 64 bit & 1 & $2.5 \mathrm{GHz}$ & $16 \mathrm{~GB}$ & $64 \mathrm{bit}$ \\
Sun fire X4450 64 bit & 1 & $3 \mathrm{GHz}$ & $4 \mathrm{~GB}$ & $32 \mathrm{bit}$ \\
\hline
\end{tabular}

Table 1.1: Machines and DiekA versions used in the simulations

\subsection{Outlook of the thesis}

This thesis deals with the application of finite element methods in determining the velocity distribution, extrusion force and deflection of the die in a direct aluminum extrusion process. The study concentrates on a flat die with a tongue because it deforms under shear and bending loads. For example, the die used in the extrusion of 
a U-shaped profile is analyzed. In addition, an experiment is performed to measure the angular deflection of the tongue. It consists of four main chapters. Chapters two, three, four and five are based on papers which have been published elsewhere [51-53]. Finally, the extrusion benchmarks organized on the occasion of the extrusion conferences of 2007 and 2009 [21,31] are analyzed in chapter six.

Modeling a sharp corner in aluminum extrusion The bearing is the most important area in the extrusion process. Most of the deformation occurs around it. It is difficult to model in finite element simulations because of its small scale in comparison to the rest of the process. This chapter describes different models of the bearing corner and shows their problems. Finally, it shows a new equivalent bearing corner which simplifies the simulation and keeps the material flow conserved.

Measuring the deflection of a flat die Measuring the deflection of the die is difficult because of high temperatures, limited free space and because no modifications are to be made to the press. This chapter shows an experimental setup for measuring the angular deflection of the die tongue by applying a laser beam on a reflecting surface. The results are presented and explained, including extrusion force, ram speed and angular deflection during the extrusion of consecutive billets.

Calculation of die deflection by the decoupled method In this chapter, the deflection of the tool is determined by the decoupled method. In the decoupled method, a Eulerian simulation of the aluminum is performed with a rigid die. As soon as the simulation reaches its steady state, the reaction forces at the interface between the die and the billet are exported and an Updated Lagrangian simulation for the tool is performed. In addition, the procedure for decreasing the analysis time is described. It includes determination of the appropriate step size and terminating the analysis when it reaches the steady state.

Calculation of die deflection by the coupled method In this chapter, different procedures of the coupled method for calculating the die deflection are described. In the coupled method, the aluminum and the tool are calculated simultaneously with an Arbitrary Lagrangian Eulerian formulation. The procedures include a full-scale model, substructuring without condensation and a statically condensed tool. 


\section{Modeling a sharp corner in aluminum extrusion}

\subsection{Introduction}

Nowadays, finite element simulations are more frequently used in aluminum extrusion to replace costly and time-consuming factory trials. By FE simulations the velocity distribution of exit velocity and the deformation of the die can be predicted. Because there is a growing demand in the market for complex profiles, $3 \mathrm{D}$ analysis is required more often in simulating the extrusion of these complex profiles. The geometry of the extrusion dies contains a number of tiny entities that are responsible for increasing the number of degrees of freedom in the FE simulations. As a result, the simulations will consume an unacceptable computational time. Examples of the tiny entities include small fillets, chamfers and holes for screws. Suppressing these entities in some regions has no effect on the results while in other regions it has. This applies especially to the entrance of the bearing channel (bearing corner) see figure 2.1. At this location a small radius between 0.1 and $0.5 \mathrm{~mm}$ is found in practice. Disregarding this entity becomes problematic because then a sharp change in the velocity takes place around it.

In [38] it was shown by etching the crosssection of a 7075 alloy butt end that aluminum sticks at the die face. Moreover, in [36] experimental results concerning extrusion of gridded billets of 5083 alloy also show that the aluminum sticks at the die face. In [2] and [11] the appearance of sticking zones at the interface between the billet and the container wall was depicted. In [37] the split-die technique is utilized in measuring the slipping and sticking lengths in the die bearing channel. It is shown that for parallel bearing the slipping length is equal to the bearing channel length.

In this work, fully stick and fully slip boundary conditions are considered [20]. Fully stick boundary conditions are applied at the interface between die face and aluminum. 


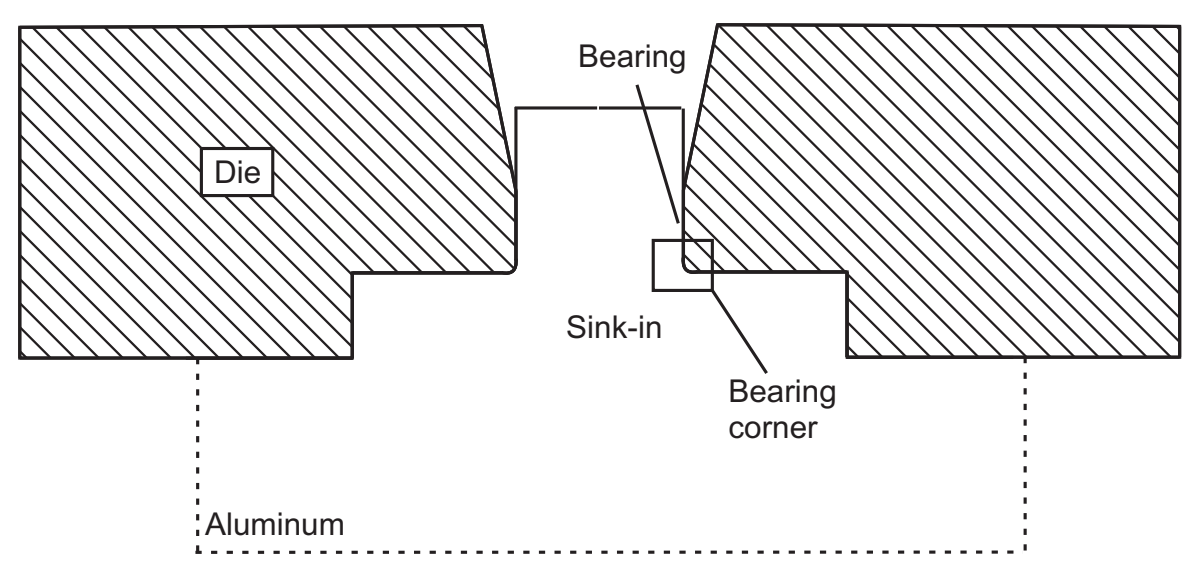

Figure 2.1: A sketch of a die showing the bearing area

Fully slip boundary conditions are applied at the interface between the die bearing channel and the aluminum. The node at the bearing corner, the intersection of the two interfaces, can have two different boundary conditions, fully stick or fully slip in the extrusion direction. If it is fully stick, its movement will be locked and the extrusion force will be overestimated. If it is fully slip in the extrusion direction then the extrusion force will be underestimated and a material flow conservation problem will appear. An equivalent model, which describes the resistance against the flow at the entrance of bearing channel, is required. The computational time must be acceptable and the material flow must be conserved. Since the stresses and strains are not necessarily to be obtained at the bearing corner, a coarser mesh can be created.

In this chapter, different models of a sharp corner or non-smooth boundary found in the literature are described and evaluated. Consequently, two new models are implemented and analyzed. In the first one, a normal is specified at the bearing corner node such that the material flow is conserved. This normal is called a conditional normal. In this model the radius of the corner is not considered. A second model is implemented where the position of the corner node is changed in order to take into consideration the shape of the round corner. Finally, an assessment of these models is performed through a comparison with a reference model where the round corner with a radius $0.5 \mathrm{~mm}$ is built and contact boundary conditions with 0.4 coefficient of friction are applied between the die and the aluminum (billet) [49]. The mesh of the $2 \mathrm{D}$ reference model is displayed in figure 2.2 .

\subsection{Related work}

In the literature, the problem of a flow around non-smooth boundaries is treated by different researchers. In [43] Sundqvist used sliding interfaces to solve fluid-structure 


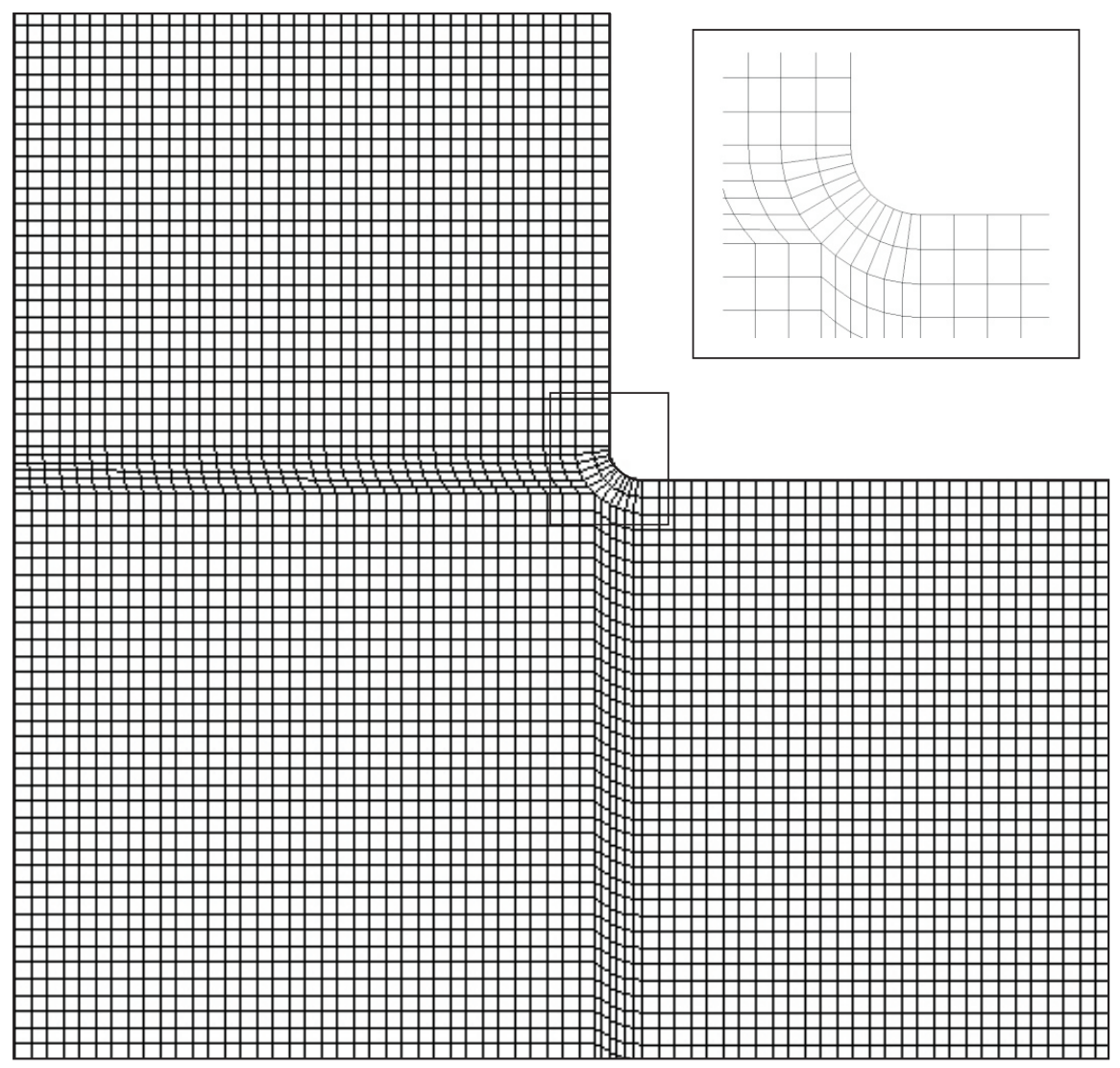

Figure 2.2: Mesh of the 2D reference model for axisymmetric extrusion

interface problems. Each node of the interface is described by two nodes: one node belongs to each face. For each pair of nodes, a local coordinate system is defined such that its basic direction is tangent to the sliding interface and the other direction is normal to the sliding interface. The two nodes are coupled in the normal direction, but a sliding is permitted in the direction of the tangent. It is assumed that the nodes have the same initial location in the global coordinate system. This procedure cannot be generalized because it requires some knowledge of the flow around the structure to determine the orientation of the local coordinate systems at these nodes.

In $[16,26]$ a similar idea is applied to construct an equivalent bearing corner in an aluminum extrusion where a triple node construction is applied. In the triple node construction, three nodes are created at the bearing corner and their degrees of freedom are connected in such a way that the nodes will move around the corner as described in figure 2.3. In this construction, the material flow is not always conserved. 
The application of this method consumes more time in preprocessing especially in 3D simulations and the extrusion force is underestimated due to the absence of shear deformation at the element boundaries.

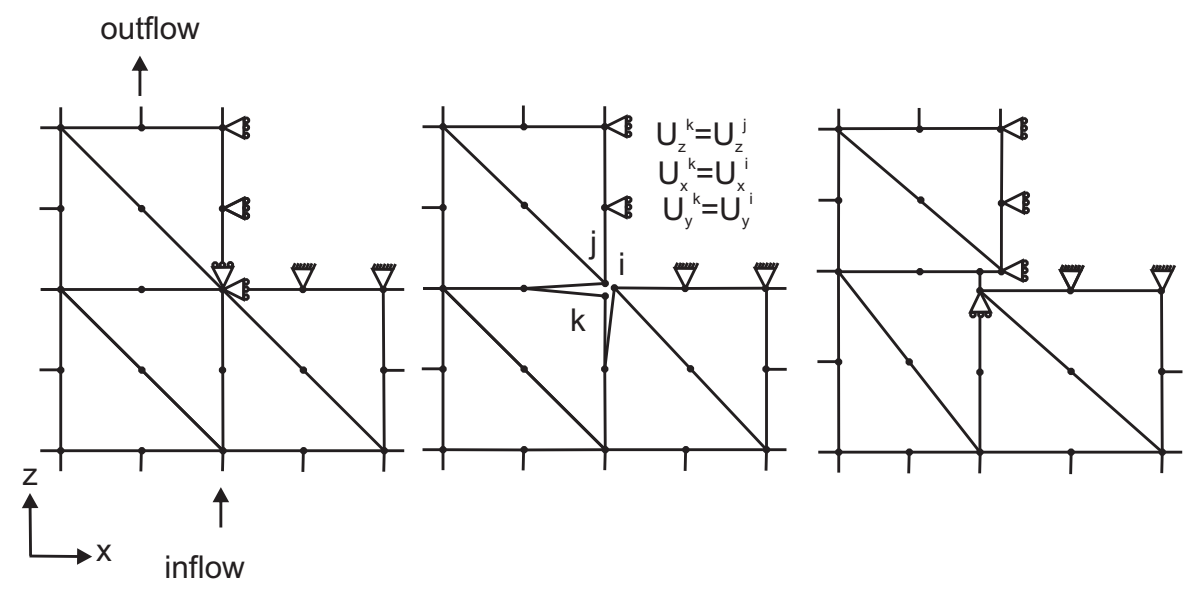

Figure 2.3: Triple node construction

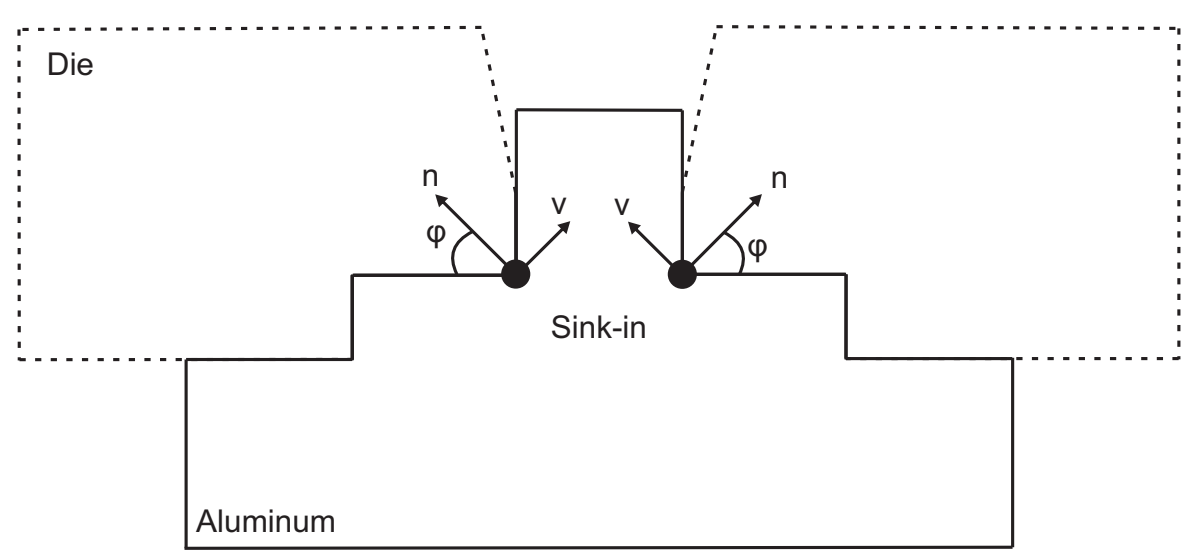

Figure 2.4: Normal at the entrance of the bearing channel

In [6] where the friction at a sharp corner is involved, a normal shown in figure 2.4 is specified. This normal is assumed to be a weighted average of the normals on the element faces connected to the node located at the sharp corner:

$$
\mathbf{n}=\frac{\sum_{i=1}^{m} w_{i} \mathbf{n}^{\mathbf{i}}}{\left\|\sum_{i=1}^{m} w_{i} \mathbf{n}^{\mathbf{i}}\right\|}
$$


where $w_{i}$ is the weight of each face. The weights are determined from the surface areas of the elements connected to the corner node.

In [5], the weights are determined such that the normal is positioned in a plane perpendicular to the average velocity of a thin layer around the sharp corner. In the last method, the normal is calculated iteratively and the direction of the normal is not constant in the whole simulation. This method increases the calculation time and it is not clear whether the material flow is conserved or not.

In [20], Koopman studies modeling the sharp corner in aluminum extrusion with a chamfer and specifying a normal with an angle $\varphi$ as illustrated in figure 2.5. Concerning the chamfer, its two end nodes can move tangentially to their adjacent sides and the nodes in the middle can move in the direction of the chamfer. Concerning the normal, the node where the normal is specified can move in the direction perpendicular to the normal. Different values of its angle $\varphi$ are considered ranging from $5^{\circ}$ to $65^{\circ}$. It is shown that the chamfer and the normal with $\varphi=45^{\circ}$ show the best results in terms of the extrusion force and the error in streamlines.

The material conservation condition is not checked when a chamfer is constructed at the bearing corner. The material conservation condition is checked at different values of $\varphi$ when a normal is specified at the bearing corner node with plane strain FE models. It is satisfied when $\varphi=45^{\circ}$ and the finite element model has a uniform mesh.

Choosing the chamfer will add two new parameters, its length and angle, that must be optimized in the preprocessing stage. Since the chamfer must be discretized with no less than two elements, the construction of the sharp corner with the chamfer requires more elements in comparison to its construction with a normal. The construction of the normal is simple and straightforward during the preprocessing stage.

In order to assess the construction of the normal with $\varphi=45^{\circ}$, it is studied in two dimensions with uniform mesh, non-uniform mesh and different element types. The element types include a 4-node plane strain and a 4-node axisymmetric. The studies are performed with different extrusion ratios. The relative error in exit velocity is shown in table 2.1 for different element types and at different extrusion ratios. This table shows that the normal with $\varphi=45^{\circ}$ is applicable for plane strain but not for axisymmetric simulations. There the error in exit velocity reaches the value of $10 \%$ at two different extrusion ratios. Therefore, a problem in material flow balance will appear during the application of the normal with $\varphi=45^{\circ}$ in axisymmtric FE simulation.

In order to illustrate the reason for the loss of material with a model discretized with axisymmetric elements, a sketch drawn in figure 2.6 shows the areas generated during the movement of the bearing corner node in the direction perpendicular to the normal. The two areas $A^{k i}$ and $A^{k j}$ are equal in the case of a uniform mesh and they 

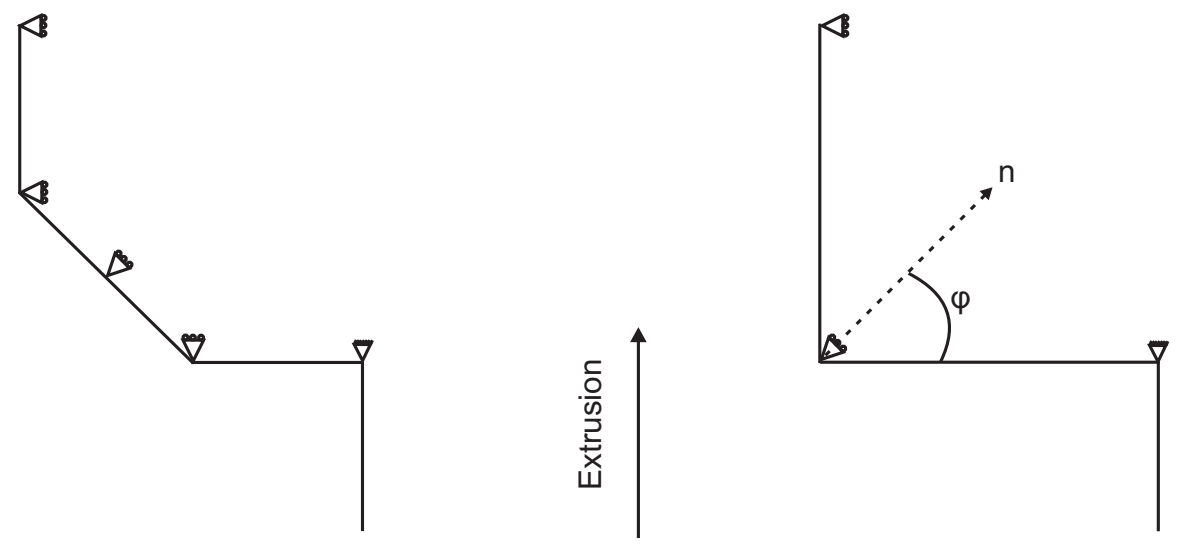

Figure 2.5: The construction of the sharp corner with a chamfer (left) and a normal (right)

\begin{tabular}{ccccc}
\hline $\begin{array}{c}\text { Element } \\
\text { type }\end{array}$ & $\begin{array}{c}\text { Extrusion } \\
\text { ratio }\end{array}$ & $\begin{array}{c}\text { Inflow } \\
\text { velocity } \\
{[\mathrm{mm} / \mathrm{sec}]}\end{array}$ & $\begin{array}{c}\text { Exit } \\
\text { velocity } \\
{[\mathrm{mm} / \mathrm{sec}]}\end{array}$ & $\begin{array}{c}\text { Relative error } \\
\text { in exit } \\
\text { velocity }\end{array}$ \\
\hline Plane strain & 3 & 1.0 & 3.0 & $0.0 \%$ \\
Axisymmetric & 9 & 1.0 & 8.1 & $-9.7 \%$ \\
Axisymmetric & 49 & 1.0 & 44.2 & $-9.7 \%$ \\
\hline
\end{tabular}

Table 2.1: Relative error in exit velocity for normal with $\varphi=45^{\circ}$ for different element types and at different extrusion ratios

are called an outflow and inflow respectively [20].

In the case of plane strain, the generated inflow and outflow volumes are equal because the area and the thickness of the inflow volume are equal to those of the outflow volume. But these volumes differ in the case of axisymmetric because each volume is calculated by the product of the area and the radius of its geometric centroid (Pappus's centroid theorem). According to the theorem the volumes are calculated by:

$$
V=2 \pi \bar{x} A
$$

Figure 2.7 shows that the radius of the geometric centroid $\left(C G^{k i}\right)$ of the outflow area $A^{k i}$ is greater than that of the geometric centroid $\left(C G^{k j}\right)$ of the inflow area $A^{k j}$. By this, the error in the outflow velocity with axisymmetric elements is clarified. Therefore, the inflow area must be increased to make the inflow and outflow volumes equal and this can be accomplished by increasing the angle $\varphi$ of the normal. For 

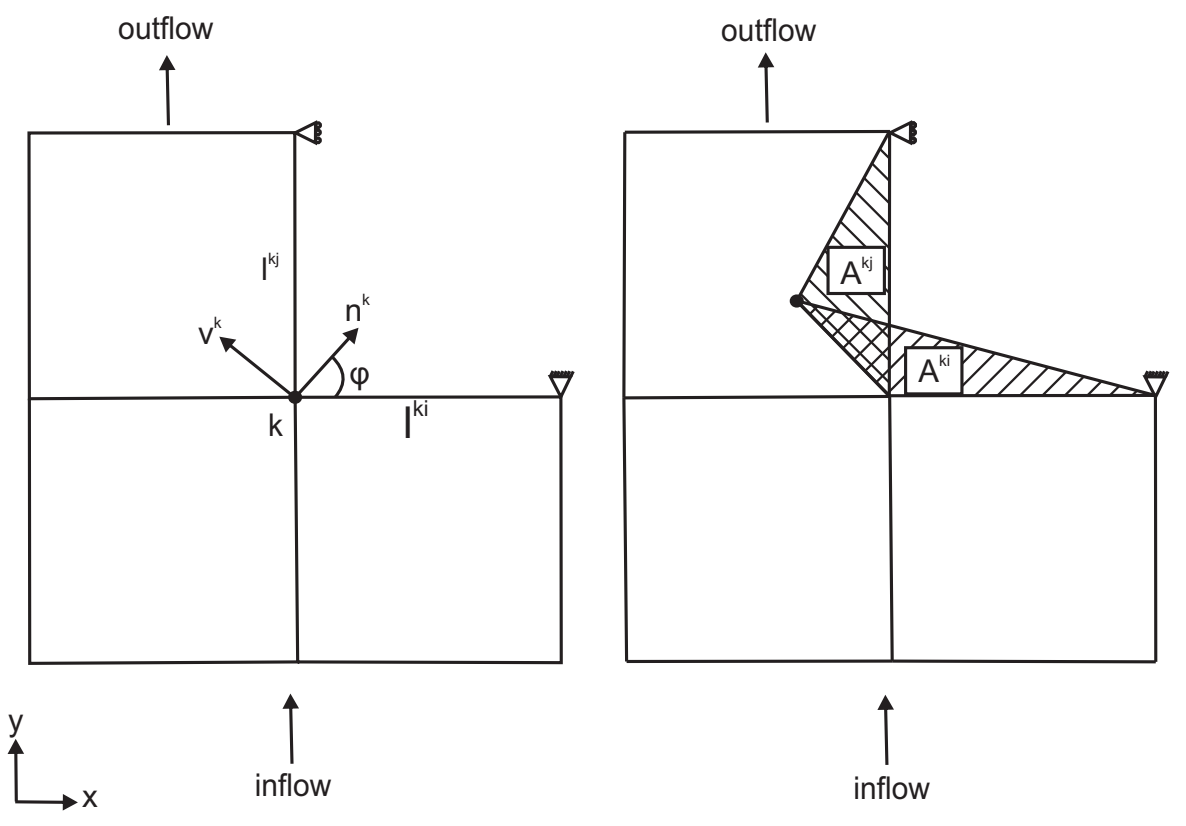

Figure 2.6: Inflow and outflow areas generated by the flow perpendicular to the normal

axisymmetric elements and uniform mesh, the normal with $\varphi=53^{\circ}$ means that the material flow conservation condition is satisfied for this specific geometry.

When an aluminum extrusion simulation is done with a filled die, the element size differs in the vicinity of the bearing corner. Therefore, the influence of this change on the performance of the normal with $\varphi=45^{\circ}$ is checked on axisymmetric elements. The errors in exit velocity and extrusion force versus the element size ratio are plotted in figures 2.8 and 2.9 respectively. The error is calculated with respect to exit velocity and extrusion force of a reference model. The element size ratio is calculated by the division of the element size in the downstream $\left(l^{k j}\right)$ by the element size in the upstream $\left(l^{k i}\right)$. Figure 2.8 shows that the error in exit velocity vanishes when the element size ratio equals 1.25 . This means that the inflow volume becomes bigger than the outflow volume to compensate for the difference in the distance traveled by the geometric centroids of the inflow and outflow areas. In addition, figure 2.9 illustrates that the extrusion force is influenced by the change in the element size ratio.

The error in applying the normal with $\varphi=45^{\circ}$, shows that the normal direction is mesh dependent. A new procedure must be generated for the choice of the direction of the normal. 


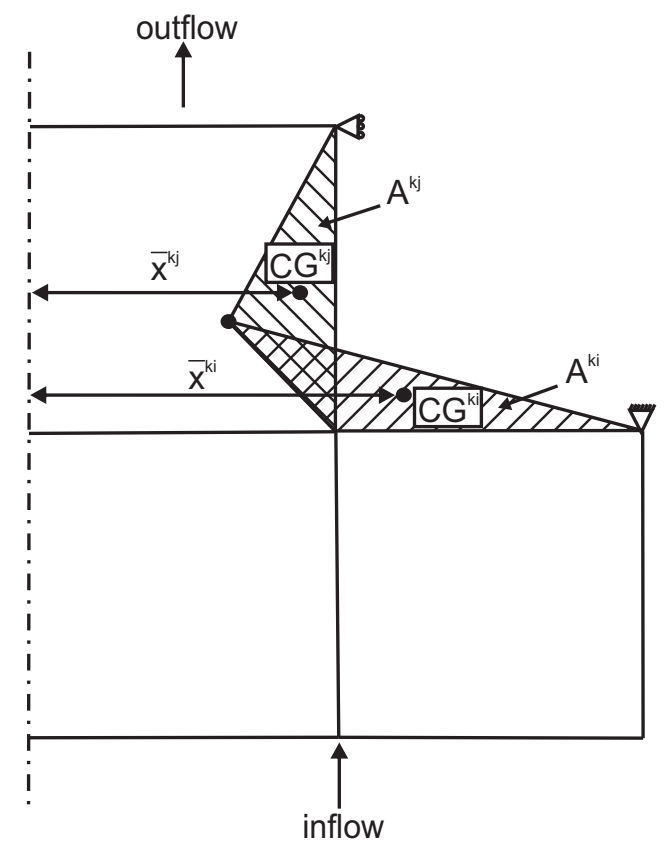

Figure 2.7: Pappus's centroid theorem

\subsection{Specifying a conditional normal at a sharp corner}

The direction of the normal specified at the bearing corner is calculated such that the net change in volume for elements connected to each corner node is zero. Then displacement constraint conditions are applied to the bearing corner node such that it moves perpendicular to that normal. The concept is similar to the one described in [6] but the determination of the direction of the normal can be performed easily and straightforwardly in the preprocessing stage. The condition of material conservation is exactly satisfied as a priori.

The direction of the normal is determined by the following equation:

$$
\sum_{i=1}^{N_{e}} \sum_{j=1}^{N_{f}} A^{i j} \mathbf{n}^{\mathbf{i} \mathbf{j}} \cdot \mathbf{v}=\mathbf{0}
$$

where $A^{i j}$ and $n^{i j}$ are the face area and its unit normal vector related to an element having the bearing corner node as one of its nodes as shown in figure 2.10. $N_{e}$ and $N_{f}$ are the number of elements intersected at the bearing corner node and number of faces intersected at this node in each element. A loop over the bearing corner nodes 


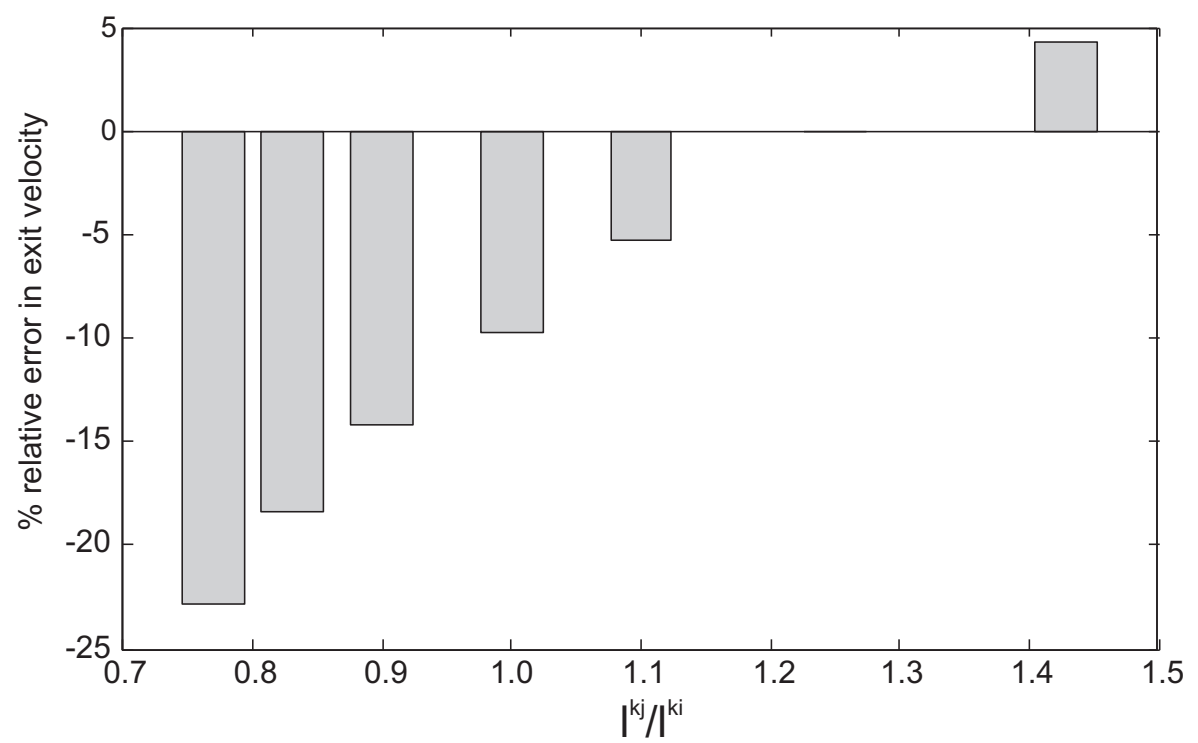

Figure 2.8: The error in exit velocity versus element size ratio with axisymmetric FE models

is performed. At each bearing corner node another loop is performed on the elements having this node in common and then the areas of the faces intersecting at this node are computed separately. Finally, the resultant of these areas is determined and it is equivalent to that of the face areas at the boundary. The implementation of this method is easier than that stated in [6] because there is no need to search and select the intersected face areas at the boundaries. This implementation can be applied to all types of elements in 2D and 3D.

\subsubsection{Representation of the conditional normal in aluminum extrusion simulation}

The normal at a sharp corner can be represented in two ways. In one way, a linear constraint equation between the velocity components of the corner node is determined from equation (2.3). The constraint equation can be manipulated in finite element codes in different methods such as transformation matrix, Lagrange multipliers and penalty. These methods are described in [34]. In the transformation matrix method, the so-called slave degrees of freedom are condensed out. It requires rearranging of the global stiffness matrix and matrix multiplications. Implementation of this method can be performed either on the global matrix as described in [14] or on the element level as described in [39]. The performance of this method depends on how efficiently it is coded because it includes a lot of matrix manipulations such as adding zeros to the global stiffness matrix, searching and sorting. The Lagrange multipliers method 


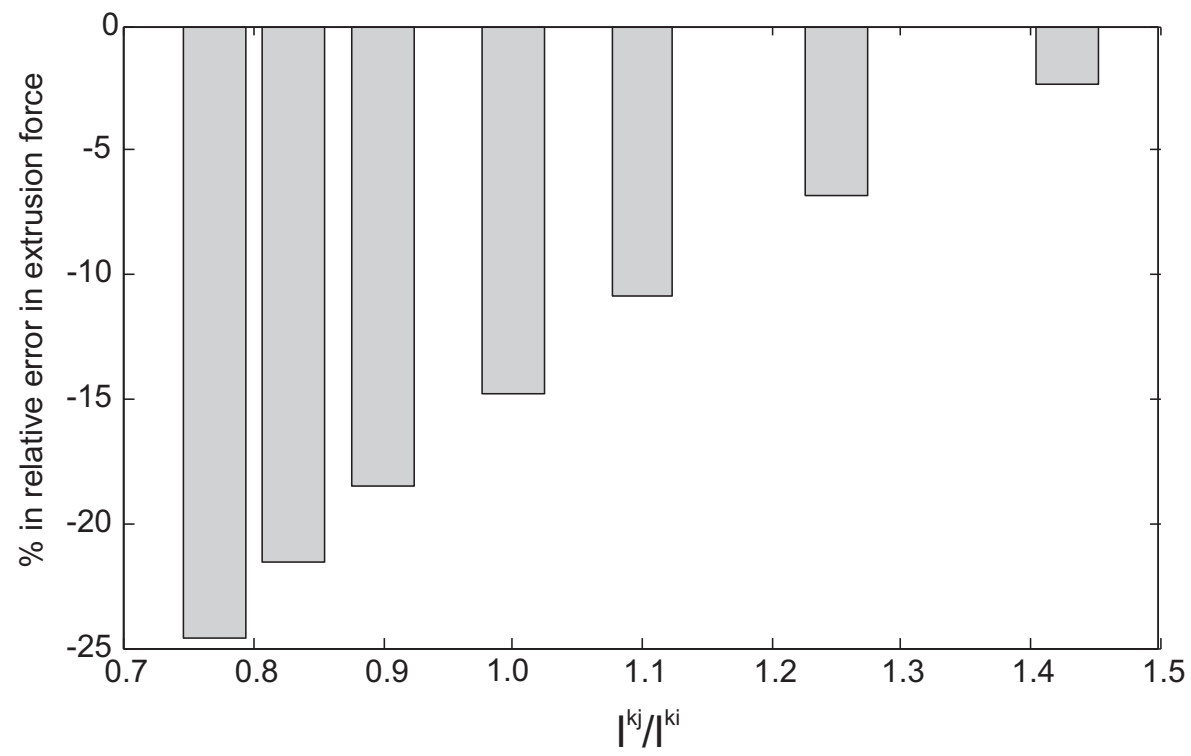

Figure 2.9: The error in extrusion force versus element size ratio with axisymmetric FE models

is not suitable because it increases the number of degrees of freedom. The penalty method is not suitable also because it causes errors due to ill-conditioning.

In the other way, a local coordinate system is defined at the corner node, rotated by an angle $\varphi$ and the movement of the corner node in the direction of the normal is suppressed as described in figure 2.11.

Both representations are examined. They give the same results and computational time.

\subsection{Specifying a conditional normal to a sharp corner after modifying the geometry}

In the aforementioned method the influence of the fillet at the bearing corner is not considered. Therefore, a new method is studied where the direction of the normal is determined after changing the location of the bearing corner node. In principle, the study of this method is started with a simple model discretized uniformly with a 4-node plane strain element.

Discrete choices of the corner node are located in a square region defined according to the element size and radius of the fillet. The position of the corner node is 


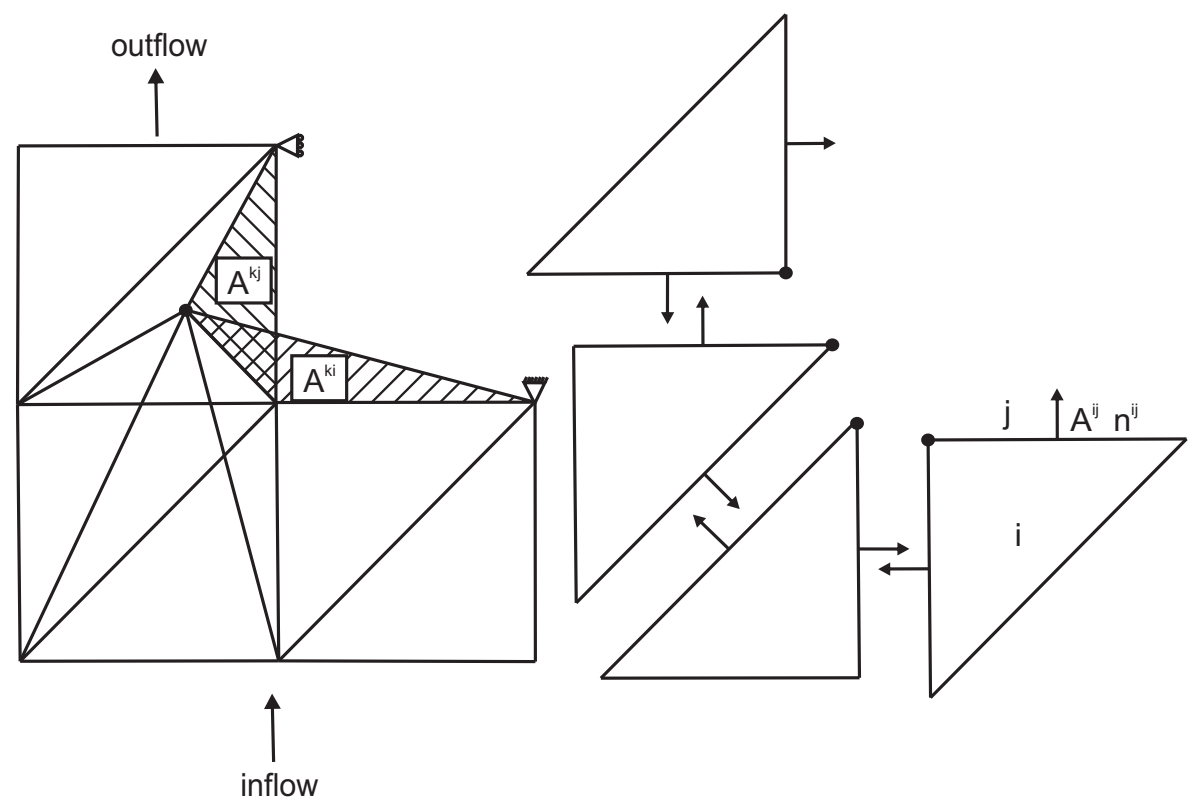

Figure 2.10: Elements around the bearing corner
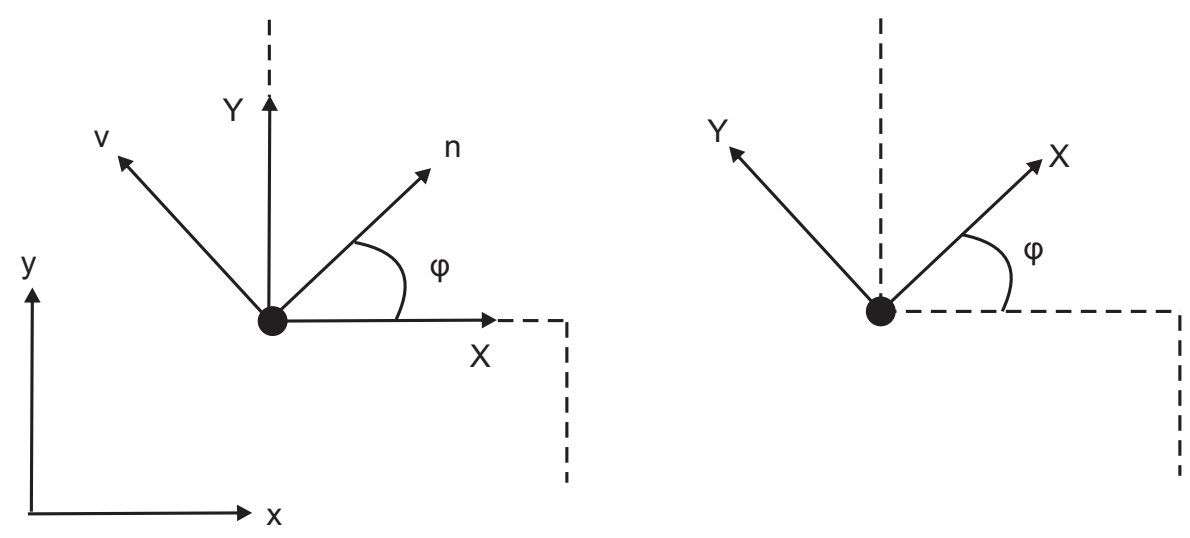

Figure 2.11: Representation of the normal by a local coordinate system

changed to different positions from $[i, j]$ to $[i+2, j+2]$ as shown in figure 2.12. Similarly to the previous method a relation between the incremental material displacement components is obtained at each position of the corner node from figure 2.13 and equation 2.4. Three areas are generated: an inflow area identified by $A^{3}$ and two outflow areas identified by $A^{1}$ and $A^{2}$. The resulting relation is nonlinear because of the formation of area $A^{2}$. Then a linearization is performed by assuming the velocity 


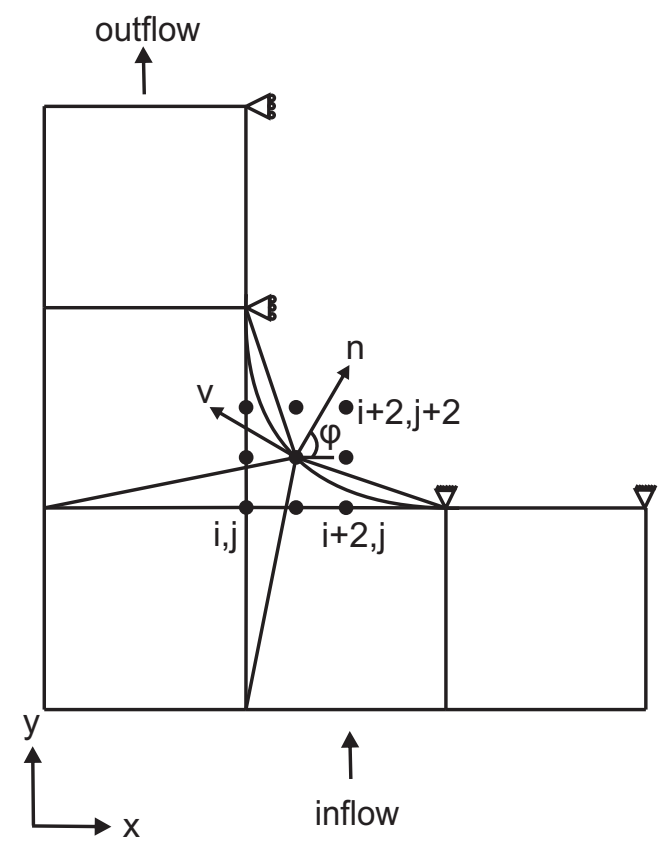

Figure 2.12: Choices of bearing corner node location

at point $\mathrm{N}$ is known and it is equal to the product of ram speed and extrusion ratio.

$$
A^{1}+A^{2}=A^{3}
$$

where $A^{1}=$ area of triangle $\mathrm{PM} P^{1}, A^{2}=$ area of triangle $\mathrm{N} P^{1} N^{1}, A^{3}=$ area of triangle $P^{1} \mathrm{PN}$.

At each position of the corner node the extrusion force and the flow conservation are checked and compared with respect to a reference model.

Figure 2.14 shows unexpected results where the extrusion force increases as the bearing corner node moves radially. As shown in figure 2.13, when the corner node moves radially the area $A^{2}$ increases. Therefore the area $A^{3}$ must compensate the increase in $A^{2}$ by increasing the horizontal component of the velocity of the node "P". Figure 2.15 shows that the flow is non-conservative at positions $[i+1, j],[i+2, j]$ and $[i+2, j+1]$ due to the linearized constraint equation. This method is not pursued any further. 


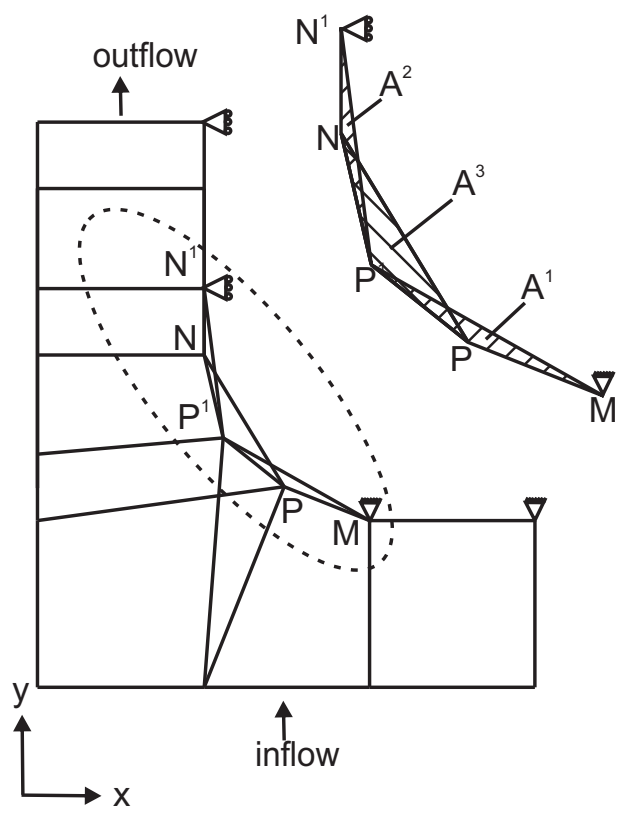

Figure 2.13: Formulation of constraint equation

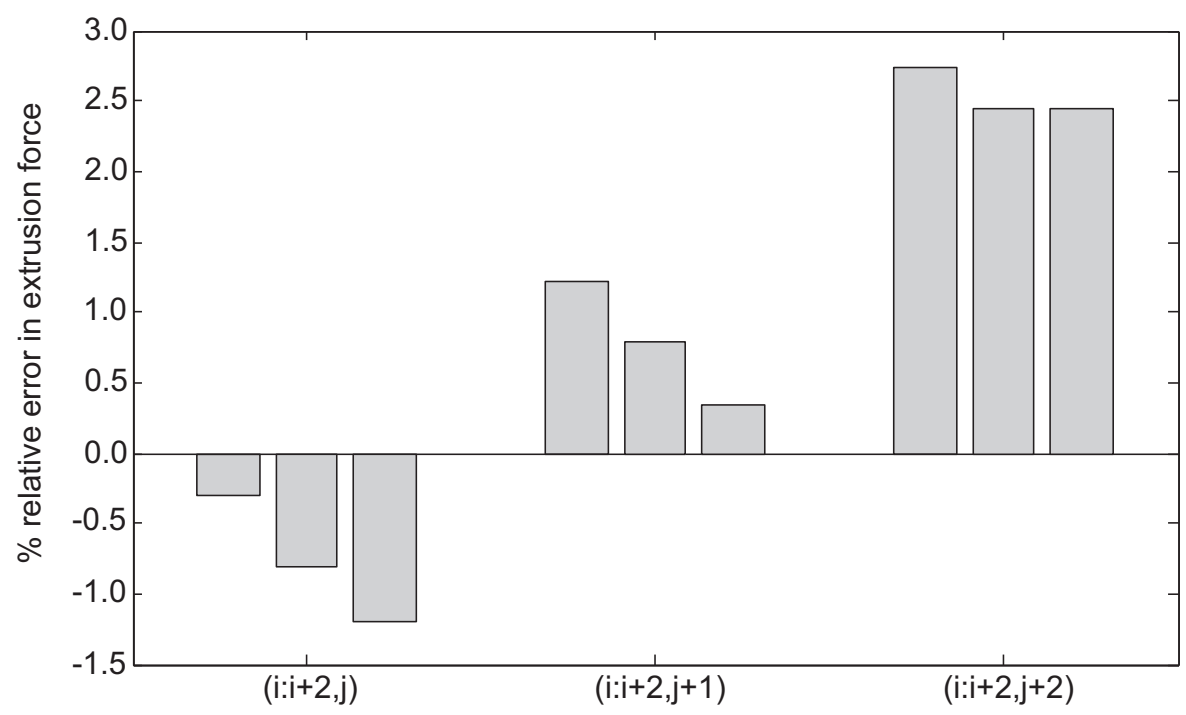

Figure 2.14: Error in extrusion force with respect to a reference model 


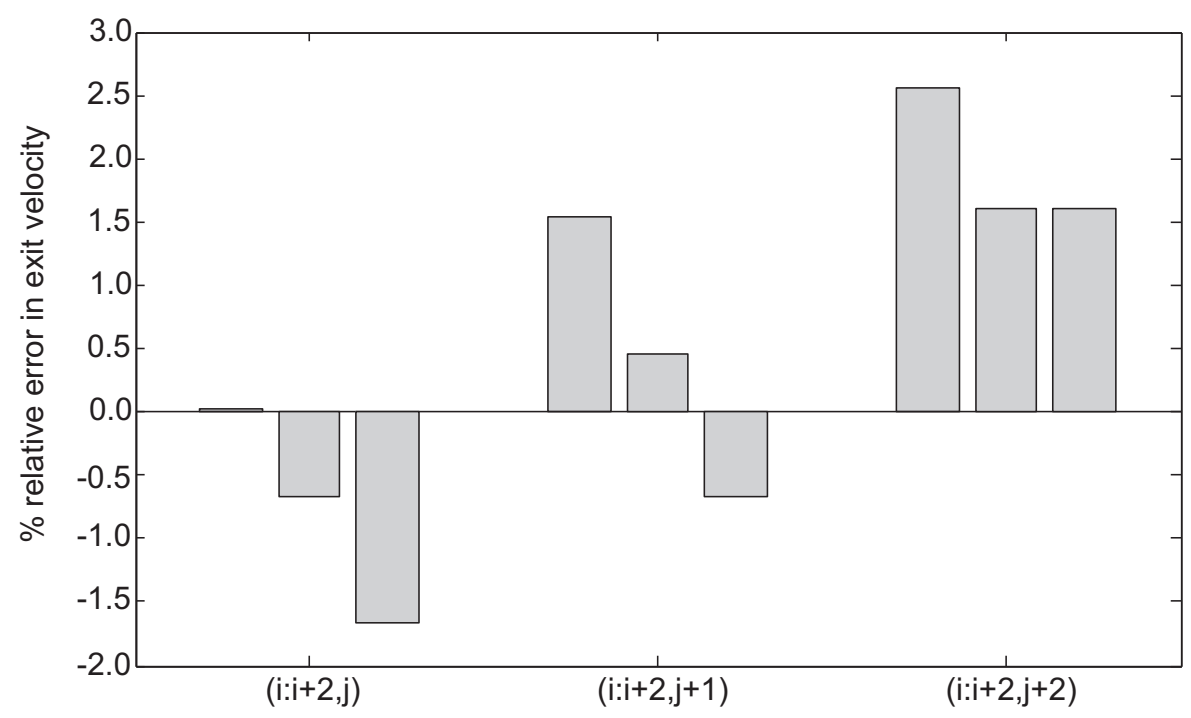

Figure 2.15: Error in outflow velocity with respect to reference model

\subsection{Three-dimensional examples}

Since the tetrahedron element is mostly used in aluminum extrusion simulations, an assessment of the bearing corner constructions including specifying a conditional normal on a sharp corner and triple node is performed with an example discretized with a 10-node tetrahedron element. The example represents the extrusion of a round bar with an extrusion ratio 9 and a ram speed with $1 \mathrm{~mm} / \mathrm{sec}$. An isothermal simulation with a Eulerian formulation is performed. Concerning the boundary conditions, the nodes in contact with the cylinder and the die face are sticking and the nodes in contact with the bearing channel are slipping freely in the extrusion direction. The percentages in relative error in extrusion force and exit velocity are calculated with respect to those of the reference model and are presented in table 2.2.

\begin{tabular}{ccccc}
\hline $\begin{array}{c}\text { Construction } \\
\text { bearing } \\
\text { corner }\end{array}$ & $\begin{array}{c}\text { Extrusion } \\
\text { force } \\
{[\mathrm{N}]}\end{array}$ & $\begin{array}{c}\text { Exit } \\
\text { velocity } \\
{[\mathrm{mm} / \mathrm{sec}]}\end{array}$ & $\begin{array}{c}\text { Relative error } \\
\text { in exit } \\
\text { velocity }\end{array}$ & $\begin{array}{c}\text { Relative error } \\
\text { in extrusion } \\
\text { force }\end{array}$ \\
\hline Triple node & $9.17 \mathrm{E} 04$ & 8.8 & $-1.7 \%$ & $-6.5 \%$ \\
Conditional normal & $9.86 \mathrm{E} 04$ & 9.0 & $0.0 \%$ & $0.4 \%$ \\
\hline
\end{tabular}

Table 2.2: Relative error in exit velocity and extrusion force for the extrusion of a round bar

Table 2.2 shows that the error in exit velocity is about $-1.7 \%$ when the triple node construction is applied, while it is accurate when the conditional normal is specified at 
a sharp corner. This means that the material conservation condition is not satisfied with the application of a triple node construction. The reason lies in connecting the degrees of freedom in the Cartesian coordinate system of the nodes located at the bearing corner representing a circular shape. For instance, a new example representing the extrusion of a square bar with an extrusion ratio 7 and ram speed of $1 \mathrm{~mm} / \mathrm{sec}$ is considered. Simulations for this example are performed similarly to the previous example and the results including the exit velocity and the extrusion force are presented in table 2.3. The table shows that the material conservation condition is satisfied with the application of the triple node construction. The extrusion force is underestimated due to the absence of shear deformation in the boundaries of the elements connected to the three nodes.

\begin{tabular}{ccc}
\hline $\begin{array}{c}\text { Construction } \\
\text { bearing } \\
\text { corner }\end{array}$ & $\begin{array}{c}\text { Extrusion } \\
\text { force } \\
{[\mathrm{N}]}\end{array}$ & $\begin{array}{c}\text { Exit } \\
\text { velocity } \\
{[\mathrm{mm} / \mathrm{sec}]}\end{array}$ \\
\hline Triple node & $8.5 \mathrm{E} 04$ & 7.06 \\
Conditional normal & $9.3 \mathrm{E} 04$ & 7.06 \\
\hline
\end{tabular}

Table 2.3: Exit velocity and extrusion force for the extrusion of a square bar

\subsection{Summary and conclusion}

In this chapter different constructions of the sharp corner are discussed. Specifying the normal with $\varphi=45^{\circ}$ at a sharp corner is tested for different element types. It shows that the normal with $\varphi=45^{\circ}$ works properly with two-dimensional models discretized uniformly with (4-node) plane strain element. Although the extrusion force can be acceptable with other two or three-dimensional elements, the material conservation condition is not satisfied.

As far as the triple construction goes, the following applies. In the first place, it consumes time in the preprocessing stage. The extrusion force is underestimated because of the absence of shear deformation in the boundaries of elements connected to the three nodes. Furthermore, the material flow conservation condition is not always satisfied, particularly when analyzing the extrusion of profiles with curved surfaces.

Specifying the conditional normal at the bearing corner can overcome the problems such as the large number of degrees of freedom and flow conservation. In addition, it can be implemented easily with 2D and 3D elements and it doesn't consume additional time to the preprocessing and solving. Changing the location of the bearing corner node seems to be inapplicable due to nonlinear terms in the constraint equation. 



\section{Measuring the deflection of a flat die}

\subsection{Introduction}

Finite element simulations give results on material flow and die deflection. An experiment is required to validate the results on die deflection. This chapter describes the experimental setup and presents the results such as deflection, extrusion force and ram speed. They are plotted during the extrusion cycle for more than one billet. This experiment has been conducted by Boal Group.

\subsection{Literature review}

Measuring the die deflection or the pressure on the die face is a challenging task especially in an industrial extrusion environment. In the literature different approaches were applied for measuring the pressure on the die face and deformation of the die.

In [47] the pressure distribution on the die face and the deformation of the die in the extrusion of a 1050 aluminum rod were measured by the use of a semi conductor strain gauge pressure sensor and a laser displacement meter respectively. The measurements were performed on a 400-ton vertical laboratory press. The pressure sensor was inserted in a hole drilled through the die and its holder so the sensor and the metal touch each other. The measurement of the die deformation was performed by measuring the deflection of a bar attached to the die at a specified position by a laser displacement meter.

In [4] the pressure on the die face is determined from a deformation measurement. A cylindrical flat steel capsule which deforms linearly was inserted in the die face. The 
capsule was connected to the deformation measurement system with a bar inserted in a hole drilled through the tool stack.

In [32] a technique was designed for measuring the pressure on the die face with the application of capacitive probes. These types of sensors were chosen due to their small size and functionality at temperatures above $400 \mathrm{C}^{\circ}$. In [32] and [27] the technique was applied successfully in measuring the pressure on the die face during the extrusion of a rod and a thin strip with an experimental vertical extrusion press. But it was not a complete success in measuring the pressure on the die face in an industrial U-shaped profile extrusion due to failure in the sensors [28].

In $[8,23,31]$ the deflection of the tongues of a die used in the extrusion of $2 \mathrm{U}$ shaped profiles is monitored by two laser displacement sensors functioning with laser triangulation technique.

Three different ideas were utilized in the above-mentioned experiments. First, the deflection of the die is measured by measuring the deflection of a bar connected to the die face. Second, the deflection of the tongue is measured by a laser displacement sensor. This idea is similar to the previous one where the bar is replaced by a laser beam. Third, the deformation of the die is measured by sensors integrated in the die. Moreover, a special die is required to be designed and manufactured for mounting the sensors and their connectors to the measurement system. In all those ideas, the absolute translational deflection of the die in the extrusion direction at a specified point is measured rather than the relative displacement at the bearing. The measured value is composed of the translational deflection of the die and the translational deflection of the other tool parts such as backer, bolster and pressure ring. This value doesn't give the real deflection of the die or information about misalignment in the bearing which influences the specifications of the profile. Therefore, more measurements at other points must be performed to find the real deflection of the die and misalignment of the bearing.

\subsection{Experimental setup}

Since the experiment has been carried out in an industrial environment, opportunities for modification to the tool stack are limited. A new setup has been built which works by applying a laser beam on a reflecting surface which is mounted on the reverse side of the die. The basic idea is to measure the angular deflection of the die tongue which implicitly measures the relative displacement at the bearing. By this experiment, the relative displacement is measured directly by applying a laser beam on a single point. 


\subsubsection{Extrusion of the profile}

The U-shaped profile shown in figure 3.1 is selected to be extruded in the experiment. The die employed in the extrusion of this profile is subjected to shear and bending stresses. The profile is formed with a 500 -ton press, $95 \mathrm{~mm}$ container diameter and an extrusion ratio of 11.658 . AA6060 billets with chemical composition of $0.40 \% \mathrm{Si}$ and $0.45 \% \mathrm{Mg}$ are utilized. The tool used in this process is exhibited in figure 3.2. In addition the die and the backer are shown in figures 3.3 and 3.4 respectively.

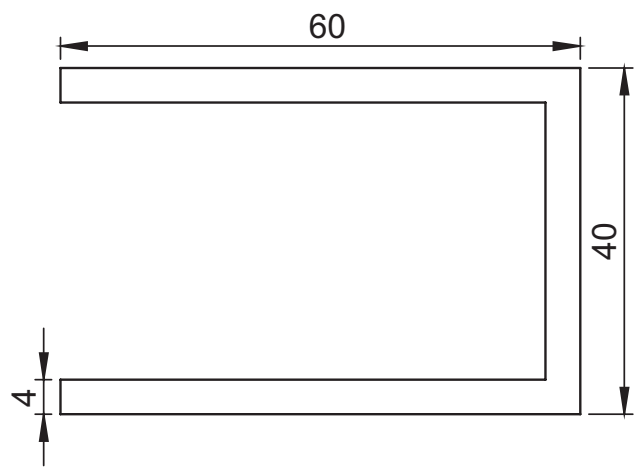

Figure 3.1: Profile (dimensions in $\mathrm{mm}$ )

The aim of the experiment is to measure the angular deflection of the tongue of a flat die. Figure 3.5 displays the sketch of the experimental setup. It shows a laser source placed outside the run-out table and far away from the press because it works at room temperature. It emits a laser beam toward a reflecting surface which reflects the beam on a white screen. A camera is placed in front of the screen. The camera records the movement of the reflected spot which is caused by the die deflection. The process parameters such as the cylinder pressure, seal pressure, ram speed and exit temperature are registered. The experiment is conducted in two rounds for checking its results and reproducibility. Table 3.1 shows the setting parameters in the two rounds.

\begin{tabular}{ccccc}
\hline Round & $\begin{array}{c}\text { Billet length } \\
{[\mathrm{mm}]}\end{array}$ & $\begin{array}{c}\text { Billet diameter } \\
{[\mathrm{mm}]}\end{array}$ & $\begin{array}{c}\text { Ram speed } \\
{[\mathrm{mm} / \mathrm{sec}]}\end{array}$ & $\begin{array}{c}\text { Puller force } \\
{[\mathrm{N}]}\end{array}$ \\
\hline 1 & 360 & 92 & 5.3 & 0 \\
2 & 410 & 92 & 4.0 & 135 \\
\hline
\end{tabular}

Table 3.1: Parameter settings in the two rounds 

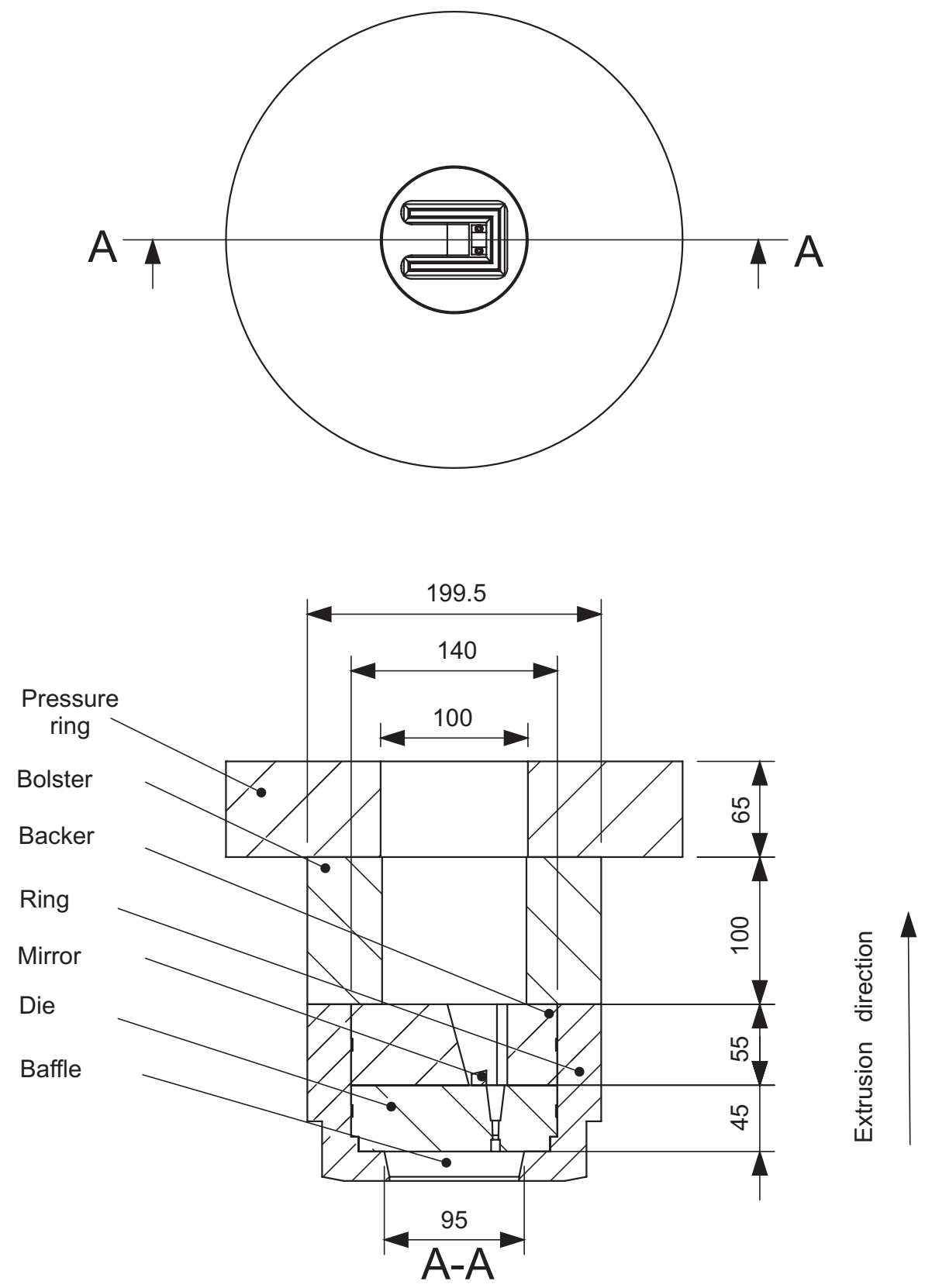

Figure 3.2: Tool stack with mirror (dimensions in $\mathrm{mm}$ ) 


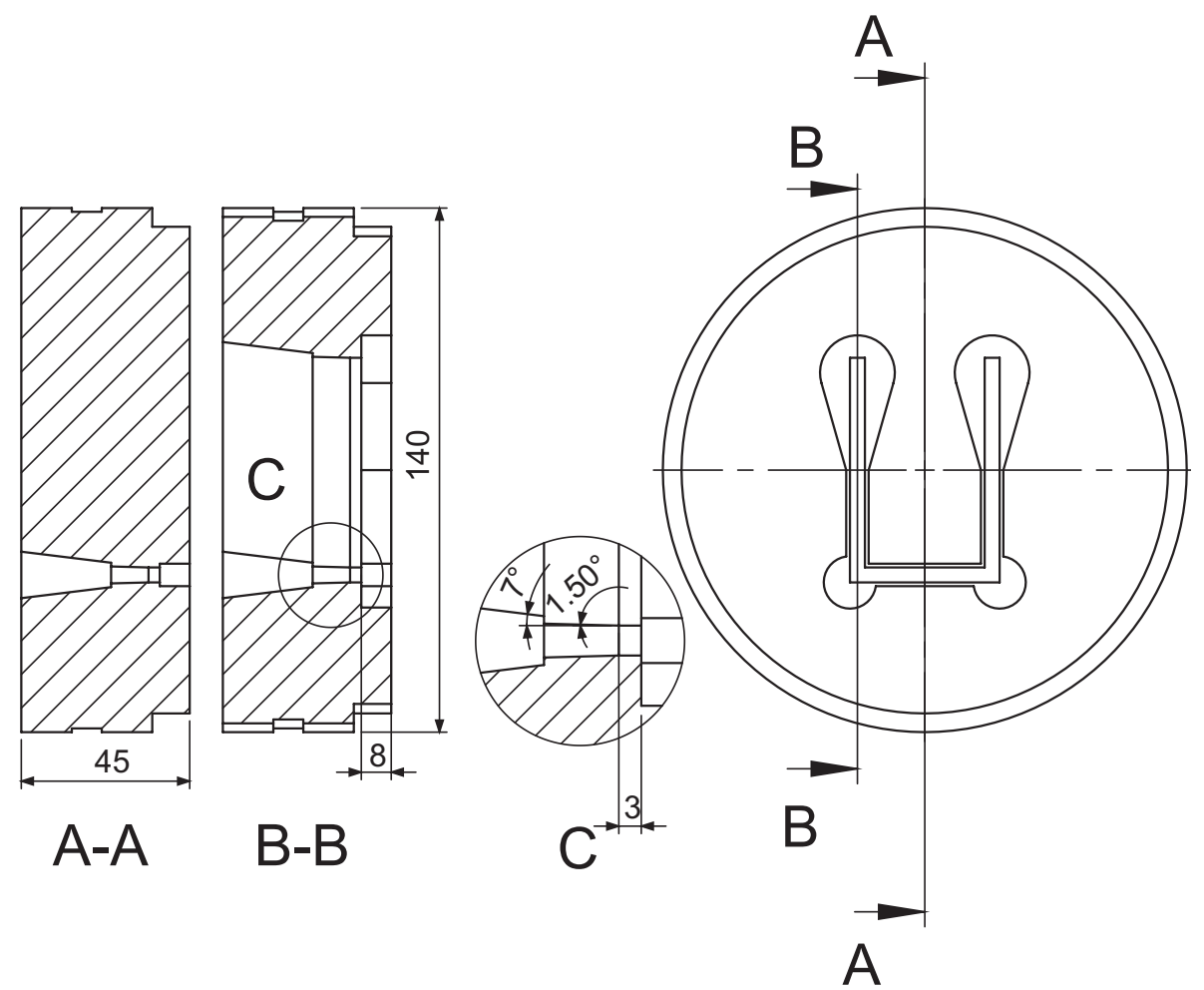

Figure 3.3: Die and its section view (dimensions in $\mathrm{mm}$ )

\subsubsection{Determination of the angular deflection}

The reflected beam is projected on a screen. The screen has a white background with four reference points. The reference points are used to calculate the movement of the reflected spot through a bilinear transformation.

The angular deflection of the tongue is determined from figure 3.6.

$$
\begin{gathered}
\tan \varphi=\frac{d * L}{\left(L^{2}+D_{1}^{2}\right) \cos \alpha+\left(D_{1} * d\right)} \\
\theta_{M}=\frac{\varphi}{2}
\end{gathered}
$$

Where $\varphi$ is angular deflection of the reflected beam, $\theta_{M}$ is angular deflection of the tongue, $d=$ total displacement of the spot in $\mathrm{mm}, L=3376 \mathrm{~mm}, D_{1}=810 \mathrm{~mm}, \alpha=12^{\circ}$. 


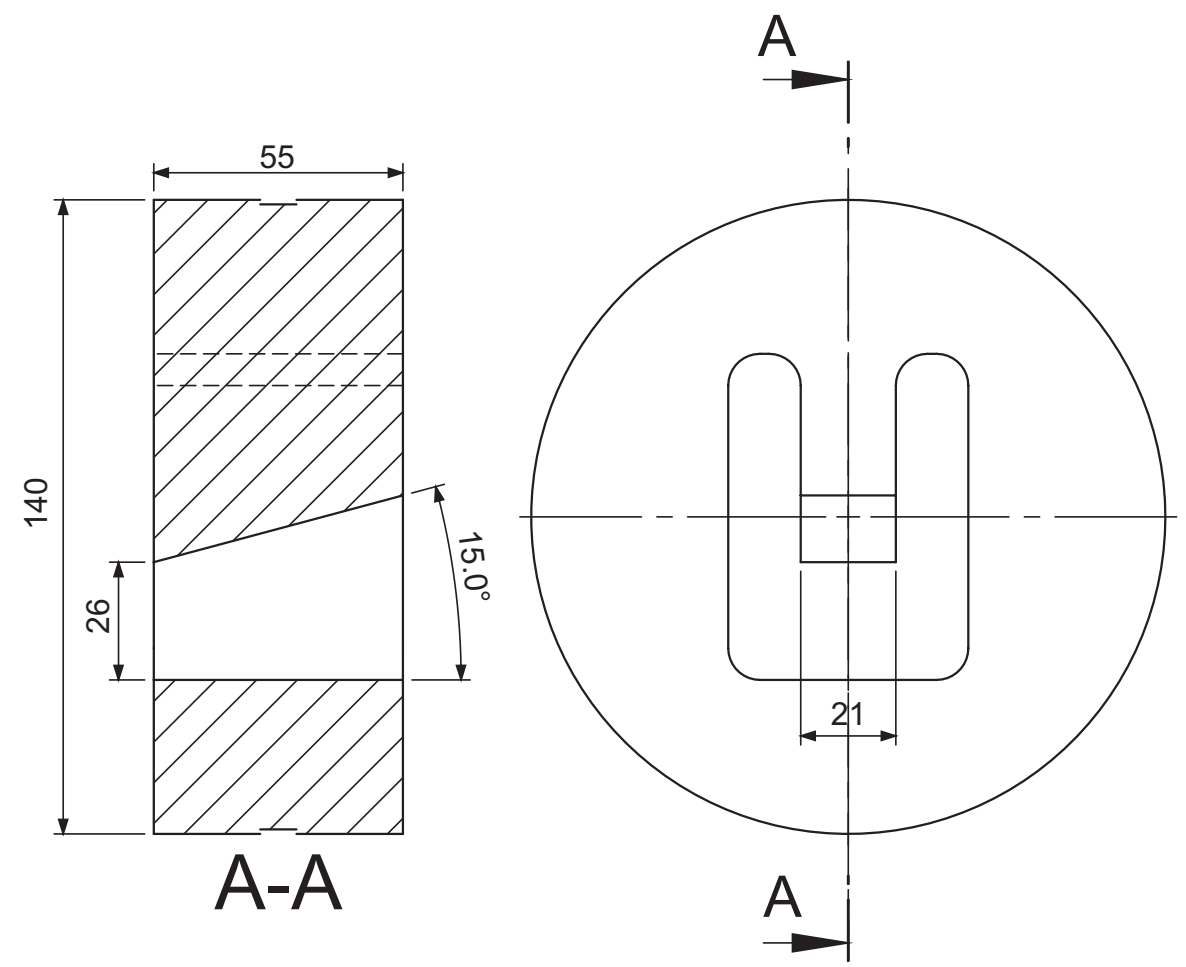

Figure 3.4: Front and section view of the backer (dimensions in $\mathrm{mm}$ )

The screen remains fixed in its position. An error in the measurement of the dimensions $L, D_{1}$, and $\alpha$ is small, so it can be neglected. An error in the calculation of the displacement of the spot leads to an error in the angular deflection of the tongue. An estimated value of the error in the calculation of the spot displacement is equal to the radius of the spot on the screen $(2.0 \mathrm{~mm})$. The error in the angular deflection of the tongue is calculated and it is about $\pm 0.3 \mathrm{mrad}$.

\subsubsection{Reflecting surface}

A stainless steel is chosen for producing the reflecting surface, because it withstands high temperature and preserves its reflectivity during the experiment. An inclined reflecting surface shown in figure 3.7 is designed because the laser source must be placed outside the run-out table. Its inclination angle is determined such that the incident and the reflected beams belong to the visible angle. The visible angle is determined by the opening in the pressure ring and the tip of the tongue where the mirror will be fixed. 


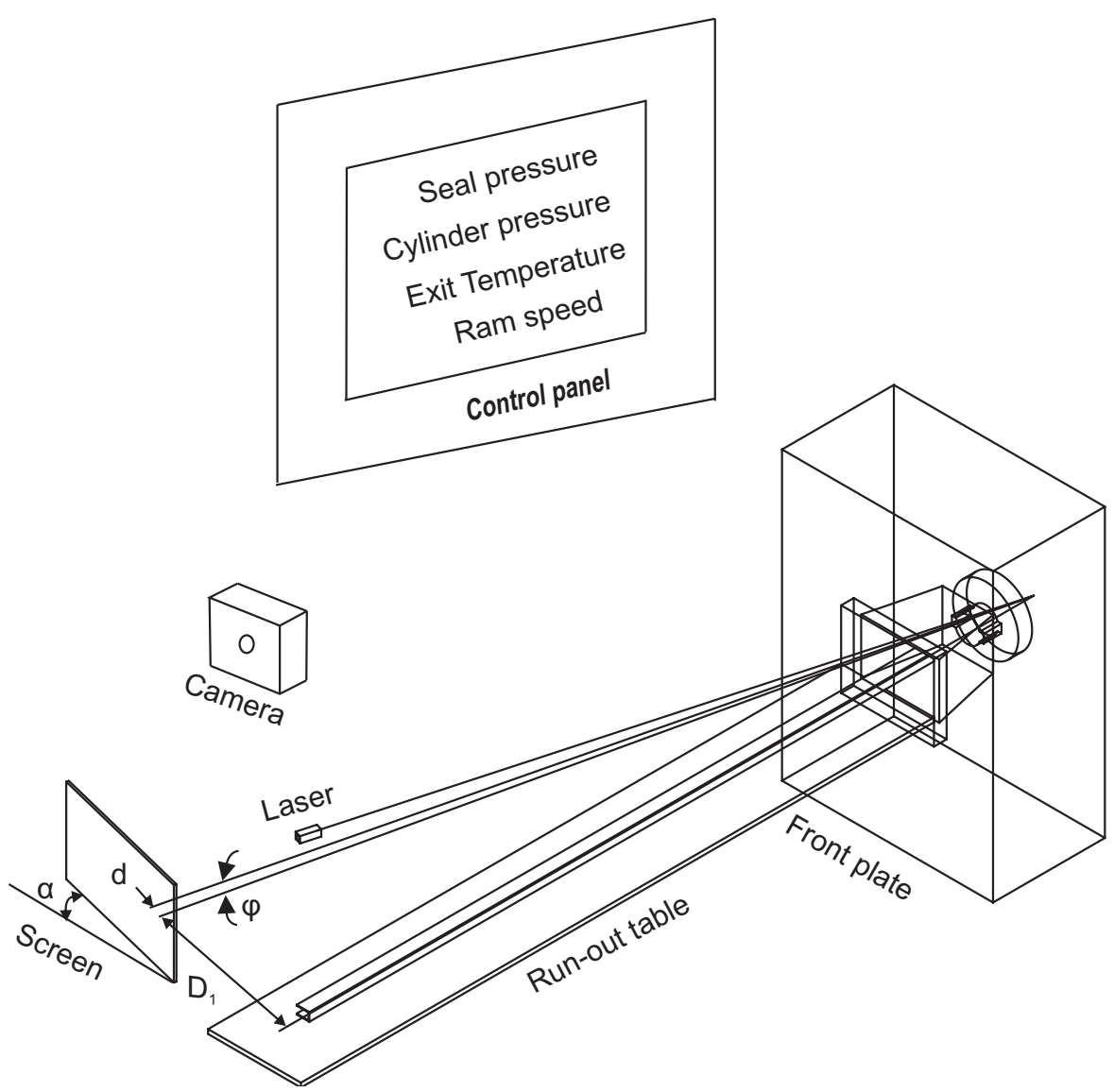

Figure 3.5: Experimental setup

Attempts to polish the small surface while maintaining its flatness did not succeed. The mirror was produced by embedding the stainless steel workpiece in Bakelite and polishing a flat surface. Finally the mirror is extracted by eroding. The production of the mirror is summarized in figure 3.8. The reflecting surface is fastened to the die with two M3 bolts as exhibited in figure 3.9.

\subsubsection{Laser source}

The laser source is chosen such that the diameter of the spot is less than the length of the side of the reflecting surface. A laser source is selected with the following specifications:

Green dot laser with $532 \mathrm{~nm}$ wavelength

Output power: $20 \mathrm{~mW}$. 


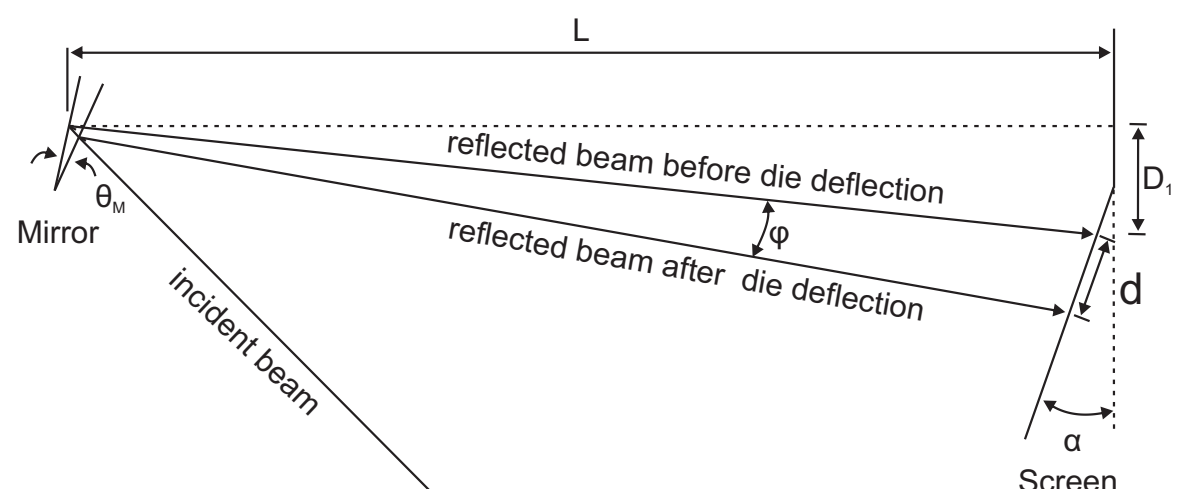

Figure 3.6: Sketch for calculating the angular deflection of the tongue
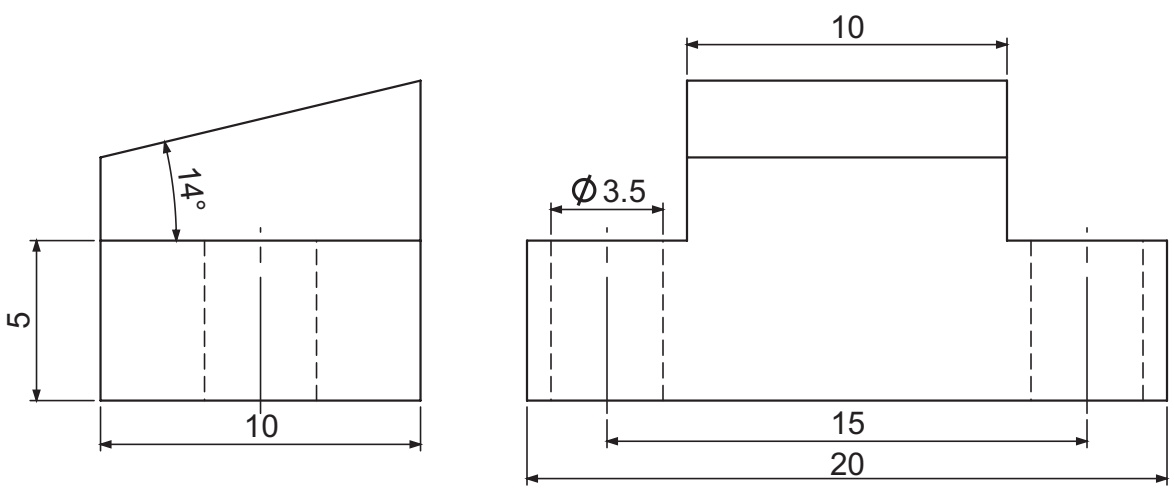

Figure 3.7: Front and side views of the reflecting surface (dimensions in $\mathrm{mm}$ )

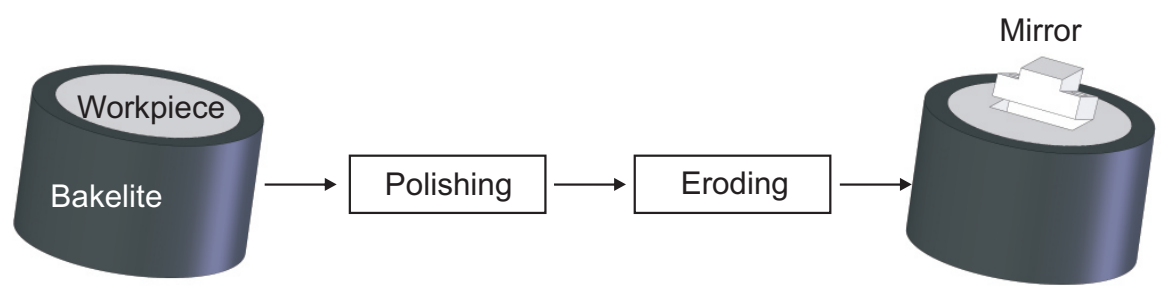

Figure 3.8: Production of the reflecting surface

Divergence: $0.1 \mathrm{mrad}$.

Outgoing diameter adjustable between $0.4 \mathrm{~mm}$ and $3.0 \mathrm{~mm}$. 


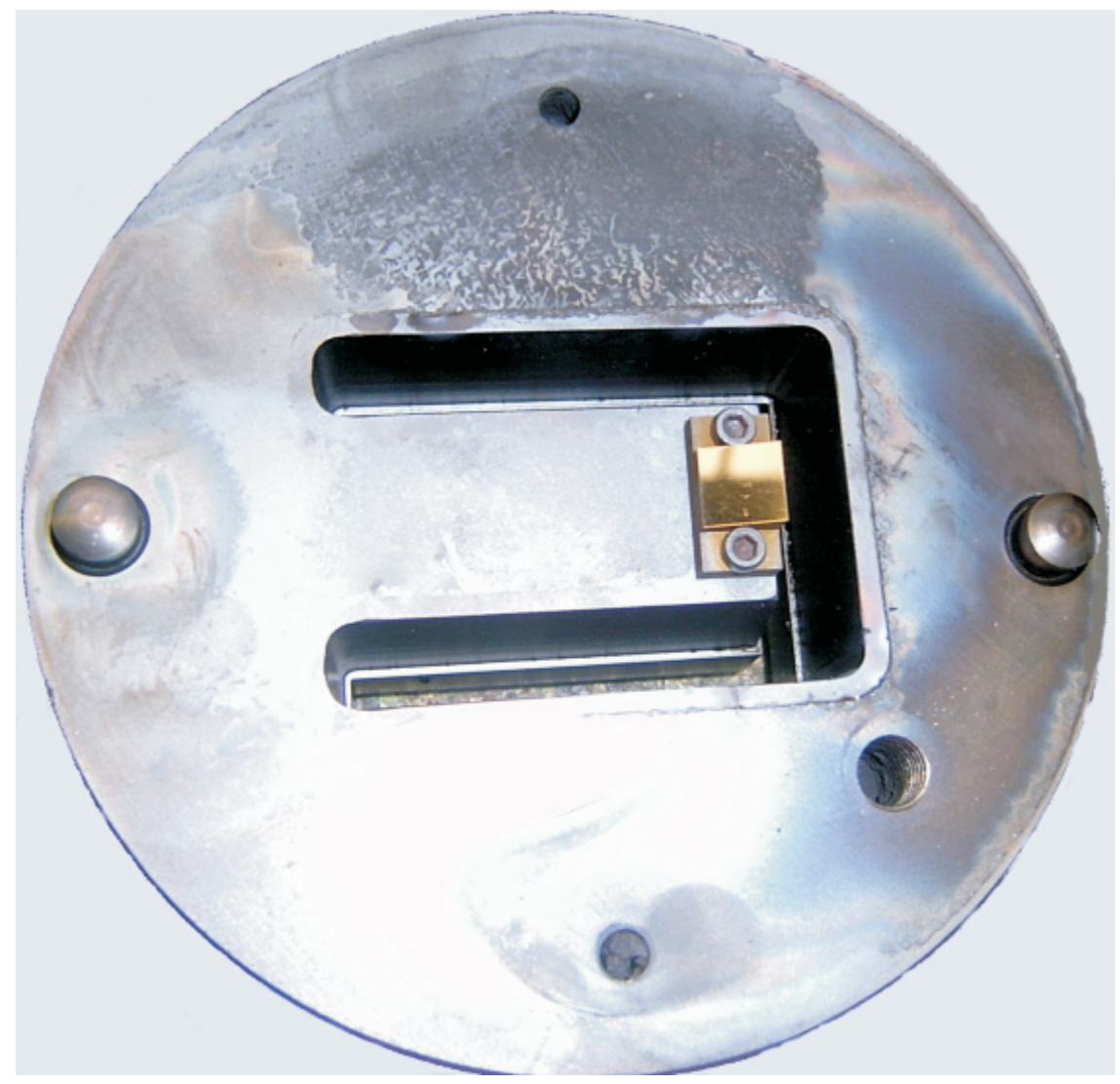

Figure 3.9: Fixation of the mirror to the die tongue

\subsubsection{Procedure}

The following points summarize the procedure of the experiment:

1. Mount the mirror to the die.

2. Assemble the tool parts such as die, backer, and ring.

3. Put the tool in the oven and heat it up to $460 \mathrm{C}^{\circ}$.

4. Place the laser source and screen in the visible region.

5. The video camera is placed in its position.

6. As soon as the temperature of the tool reaches the desired value, the die is removed from the oven and placed in the press. 
7. Turn on the laser source, aim it at the mirror and adjust the position of the screen until the reflected spot can be captured. This task must be done as fast as possible in order to prevent the tool from cooling down.

8. Turn on the video camera and start pressing.

9. Mark the actual positions of the laser source and screen.

\subsubsection{Extrusion cycle}

Figure 3.10 shows the change in the cylinder and seal pressure during the extrusion cycle. The cylinder pressure is the pressure applied on the ram to extrude the billet. The seal pressure gives the information about locking up the container to the tool. According to the change in pressure with respect to time, the extrusion cycle can be divided into four different stages:

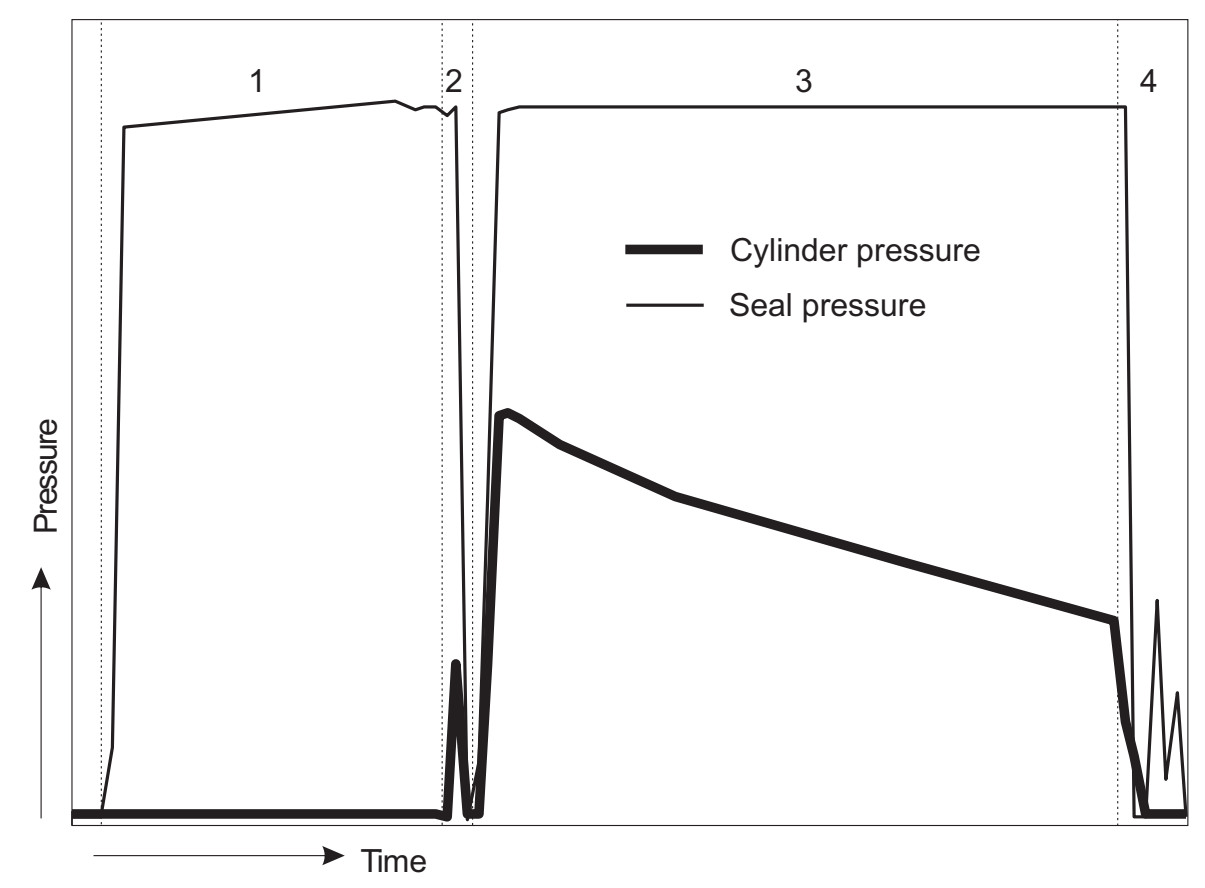

Figure 3.10: Stages in extrusion cycle

1. Loading the heated billet into the container;

2. Upsetting the billet and expelling the hot gas from the container "burp";

3. Extrusion of the billet; 


\section{Shearing of the butt end.}

The goal of the burp phase is to evacuate the hot gas from the container in order to avoid blisters. If the trapped air remains in the container during the extrusion process, it will be incorporated in the billet skin and follow its flow path and it has the potential to produce blisters. The profiles with blisters are discarded. The burp pressure is determined such that its optimum is equal to the difference between the break-through pressure and the pressure at the end of the stroke. It depends on the billet length, ram speed and temperature [7].

The burp cycle consumes about $10 \%$ of the dead cycle. The dead cycle include decompression of the main cylinder, stem return, opening container, shearing of the butt end, closing container and stem forward to start extrusion [24].

\subsection{Results}

The two rounds were conducted on different days with different setups to avoid systematic errors.

\subsubsection{Experimental results of the $1^{\text {st }}$ round}

The movie and the process parameters during the extrusion of the first four billets are read. The cylinder pressure and the seal pressure are plotted in figure 3.11. After loading the billet in the container, the seal pressure is increased to 210 bars in order to lock up the container to the tool. Then the cylinder pressure is increased to 50 bars in order to upset the billet in a $95 \mathrm{~mm}$ diameter container. This pressure is denoted as the burp pressure. For burping, the cylinder pressure is decreased to zero and the container is moved backward to allow the hot air to escape through the gap between the container end and the tool face.

The container is closed again and the cylinder pressure is increased to 120 bars and extrusion of the current billet is started. During extrusion the cylinder pressure decreases exponentially due to decrease of friction surface between the billet and the container [40]. The cylinder pressure is decreased by 50 bar.

After extruding the current billet, the container is moved backwards and part of the oil from the hydraulic circuit is passed to shear of the butt end.

As shown in figure 3.11, the profile of the cylinder pressure during the extrusion of the first billet is different from that of the successive billets because part of the first billet fills the die and the baffle. The baffle is the volume between the die and the 


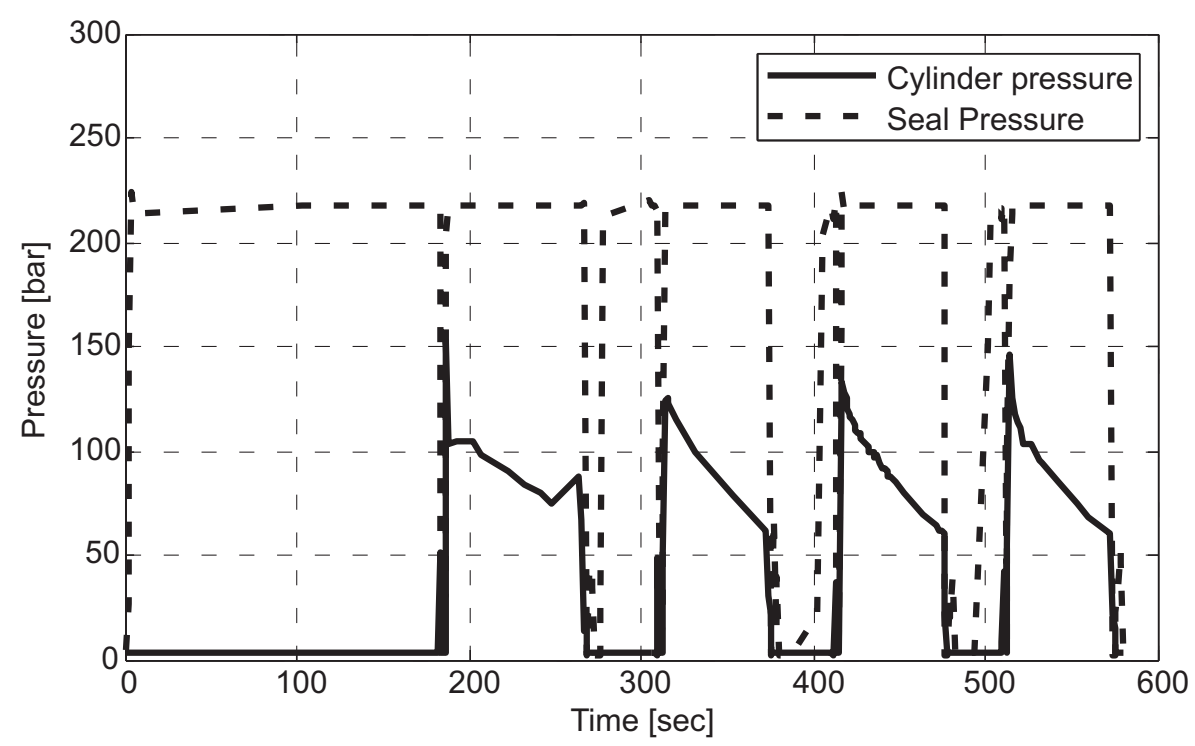

Figure 3.11: Pressure versus time ( $1^{\text {st }}$ round)

ring as shown in figure 3.2.

The extrusion force is calculated from the cylinder pressure and the diameter of the cylinder and is displayed in figure 3.12. The peaks in the extrusion force profiles for the third and fourth billets are higher than that of the second billet because of cooling down and variations of ram speed.

The ram speed during the extrusion for the four billets is plotted in figure 3.13. It has a nominal value of $5.3 \mathrm{~mm} / \mathrm{sec}$. The extruded billet length is calculated by integrating the ram speed in time. Table 3.2 shows that about $20 \%$ of the first billet is lost in filling the die and the baffle.

\begin{tabular}{ccccc}
\hline Billet & 1 & 2 & 3 & 4 \\
\hline Extruded length $[\mathrm{mm}]$ & 250 & 310 & 310 & 310 \\
\hline
\end{tabular}

Table 3.2: Extruded billet length

The movement of the reflected spot is determined from the movie. Figure 3.14 shows the distance traveled by the reflected spot during extrusion. A program is implemented using an image processing toolbox to read the movie and to calculate the position of the spot during the extrusion process. 


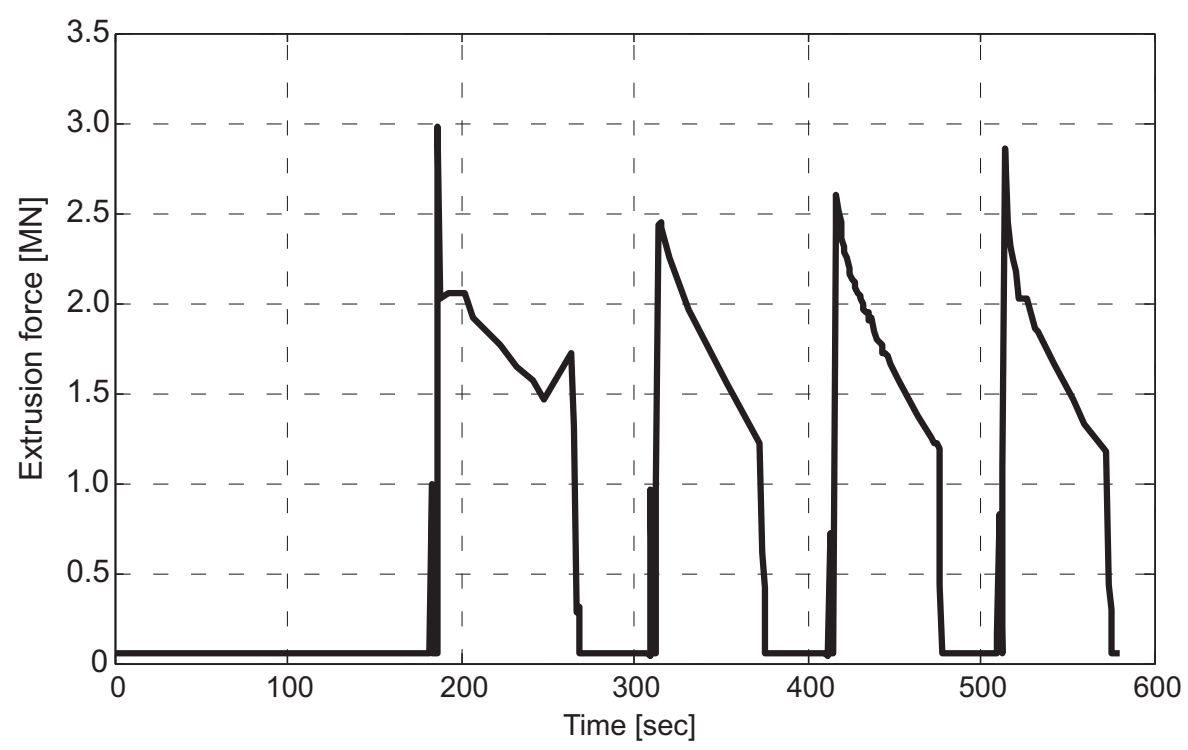

Figure 3.12: Extrusion force versus time ( $1^{\text {sd }}$ round)

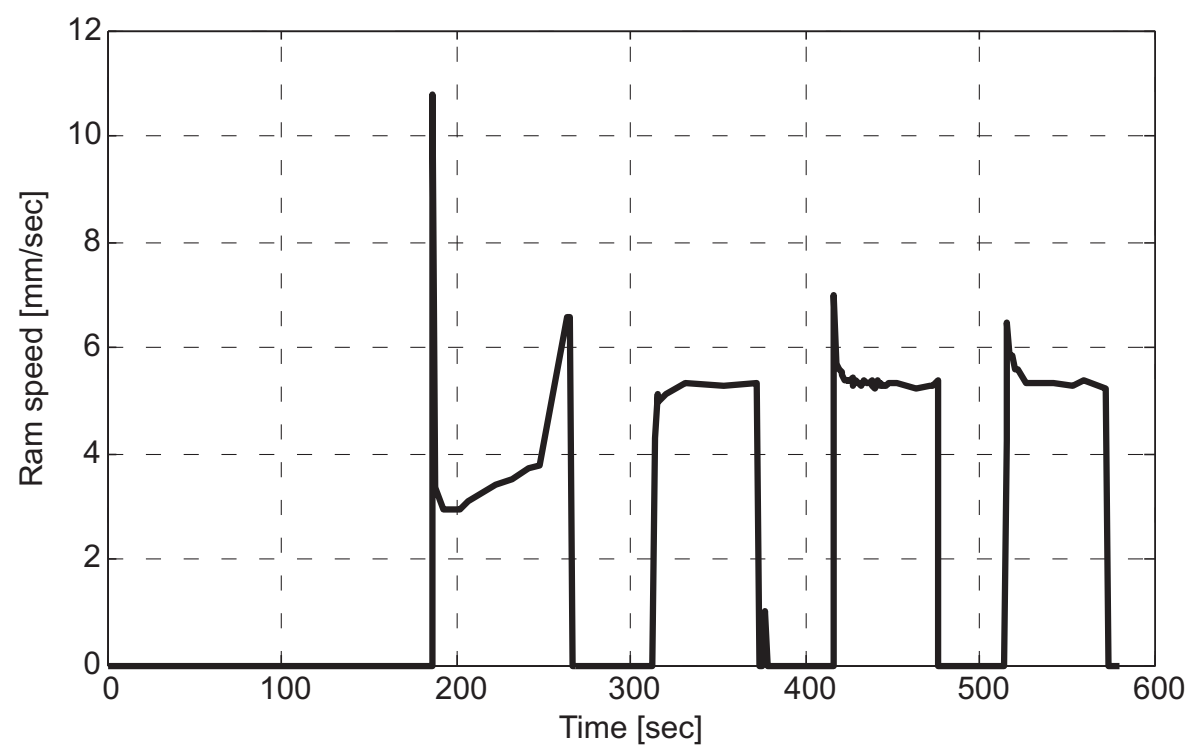

Figure 3.13: Ram speed versus time ( $1^{\text {st }}$ round)

The angular deflection of the tongue is displayed in figure 3.15. The angular deflection of the tongue reaches a value of $8 \mathrm{mrad}$ and $7 \mathrm{mrad}$ at the end of the extrusion of the 


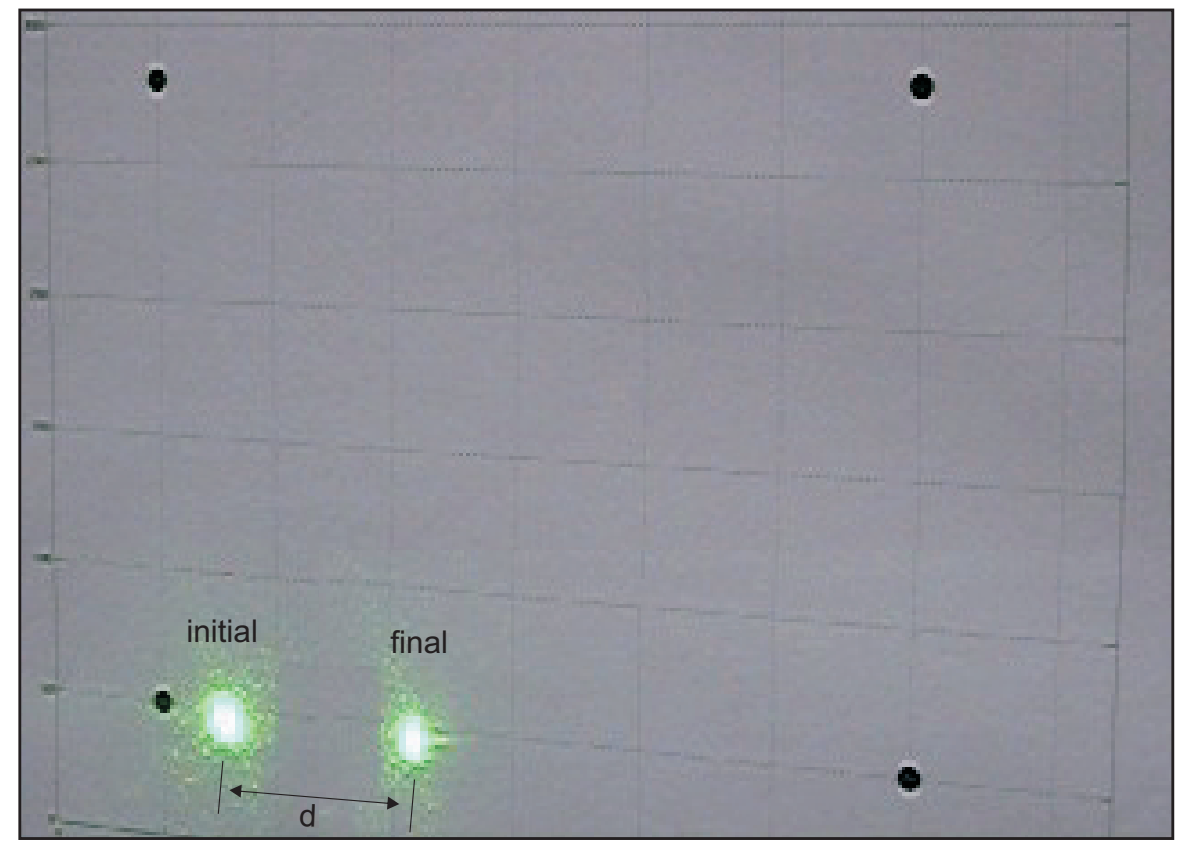

Figure 3.14: The initial and final reflected spots during extrusion $\left(1^{\text {st }}\right.$ round)

first and its successive billets respectively. The error is estimated to be $\pm 0.3 \mathrm{mrad}$. The flexibility of the die during the extrusion of the first billet leads to higher angular deflection of the tongue.

The angular deflection is composed of a recoverable and a non-recoverable parts as shown in figure 3.15. The non-recoverable part is the difference between the total angular deflection and the recoverable part. The non-recoverable part is about $0.7 \mathrm{mrad}$.

It is observed that angular deflection increases slightly during the extrusion of a billet. This increase reaches a value of $0.2 \mathrm{mrad}$. It is stated in [47] that the binding force $F_{b}$ shown in figure 3.16 between the container and the tool is responsible for the increase in the angular deflection. In [48], it is shown that this binding force is equal in magnitude to the friction force between the billet and the container. This force decreases during the extrusion process. The influence of this force on the angular deflection of the die tongue will be verified in section 4.3.3.

Afterward, the die is checked and $0.03 \mathrm{~mm}$ permanent deflection in the bearing is detected. This amount is equivalent to $0.6 \mathrm{mrad}$ angular deflection of the tongue. 


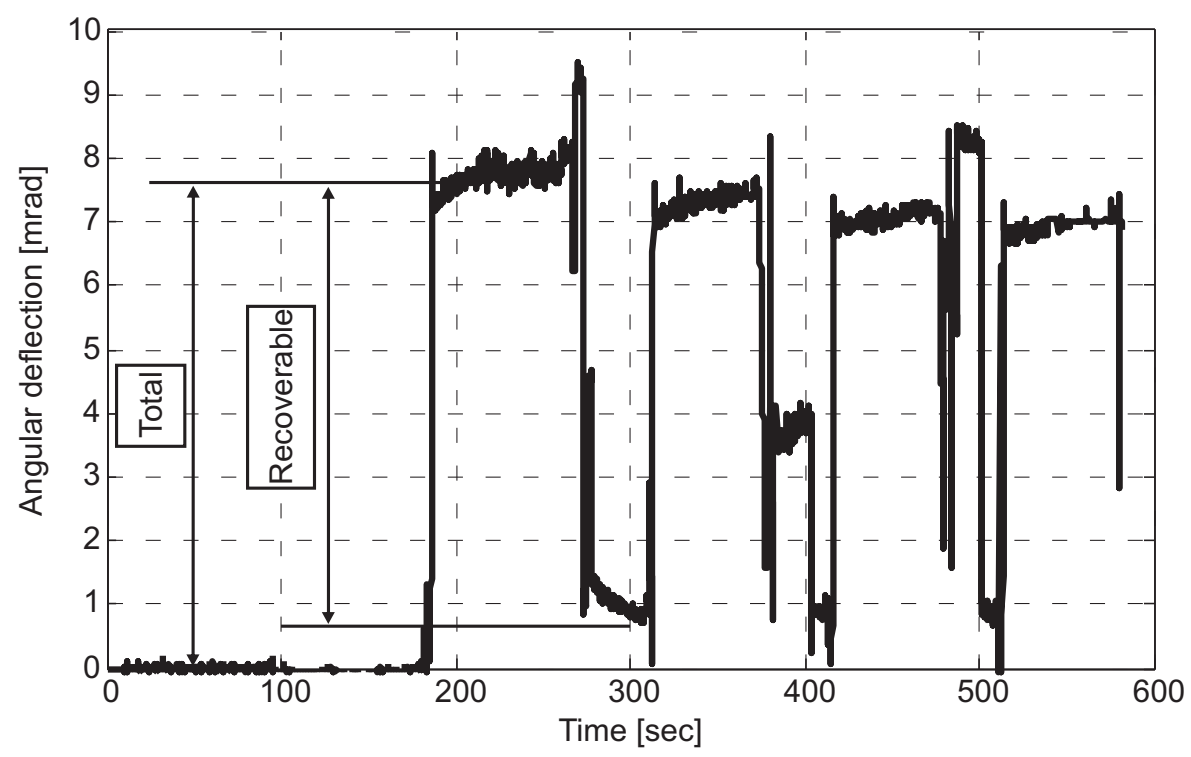

Figure 3.15: Tongue angular deflection versus time $\left(1^{\text {st }}\right.$ round)

Finally, a rigid body motion of the tool is detected when the butt end is sheared of, because the tool is then free. 

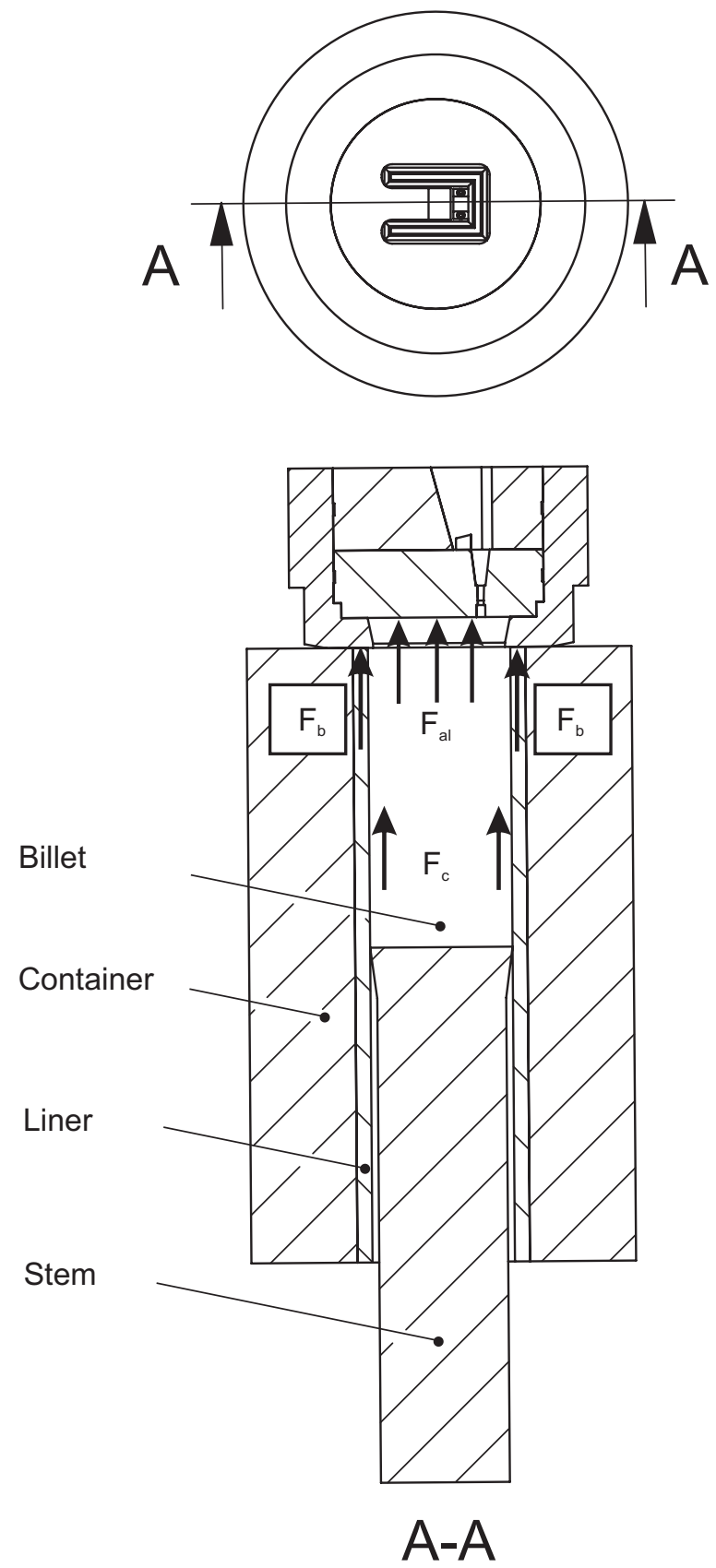

Figure 3.16: Loads on the tool 


\subsubsection{Experimental results of the $2^{\text {nd }}$ round}

Similarly as in the first round, data are extracted and plotted in figures $3.17,3.18$, 3.19 and 3.20 for two consecutive billets.

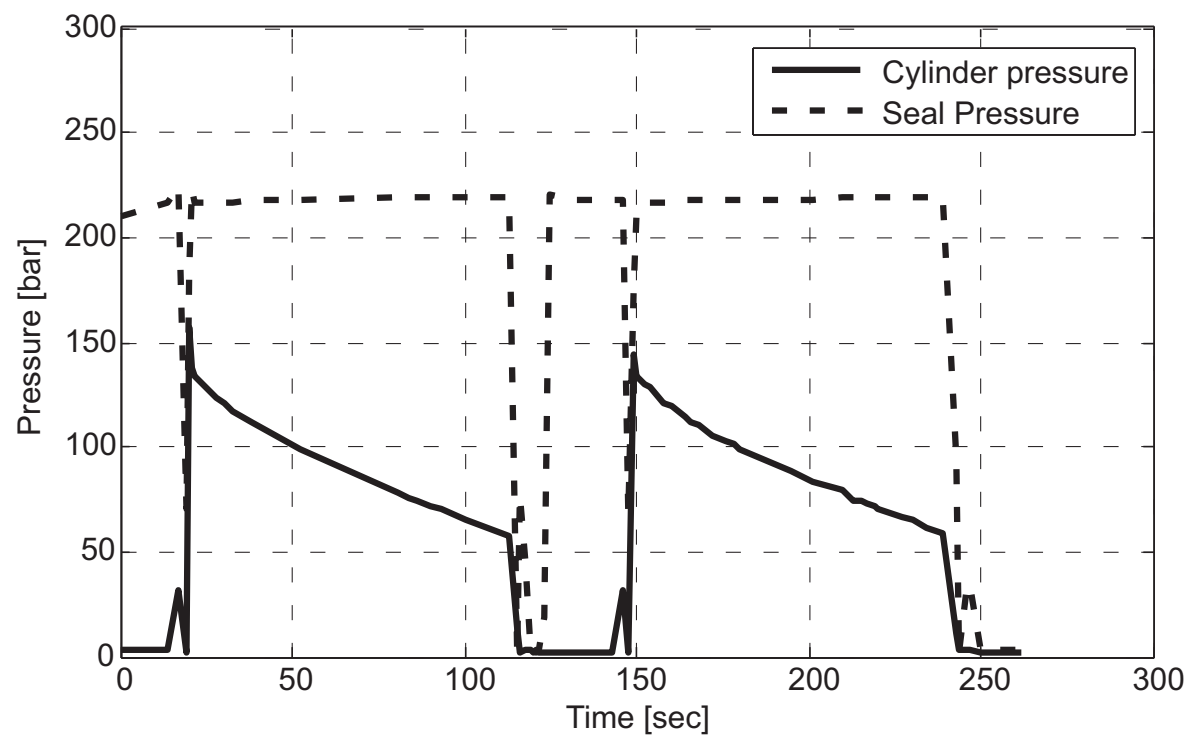

Figure 3.17: Pressure versus time ( $2^{\text {nd }}$ round)

In figure 3.17 the break-through pressure is about 150 bar. It is greater than that in the first round because the billets used in the second round are longer. The pressure is decreased by 100 bar due to the decrease in the friction surface between the billet and the container. Figure 3.19 shows that the nominal speed is about $4 \mathrm{~mm} / \mathrm{sec}$ which is lower than that in the first round. Figure 3.20 shows that angular deflection of the tongue reaches a value of $5.8 \mathrm{mrad}$ with an error of $\pm 0.6 \mathrm{mrad}$. The error in the second round is more than that in the first round because the reflectivity of the mirror decreased after cleaning the die. After the second round of the experiment, the die was checked and the permanent deflection didn't change.

\subsection{Summary and conclusion}

An experiment has been conducted to measure the angular deflection of the die tongue. The die is used to extrude a U-shaped profile. The angular deflection is measured by applying a laser beam on a reflecting surface. The experiment is performed in two rounds with different settings. 


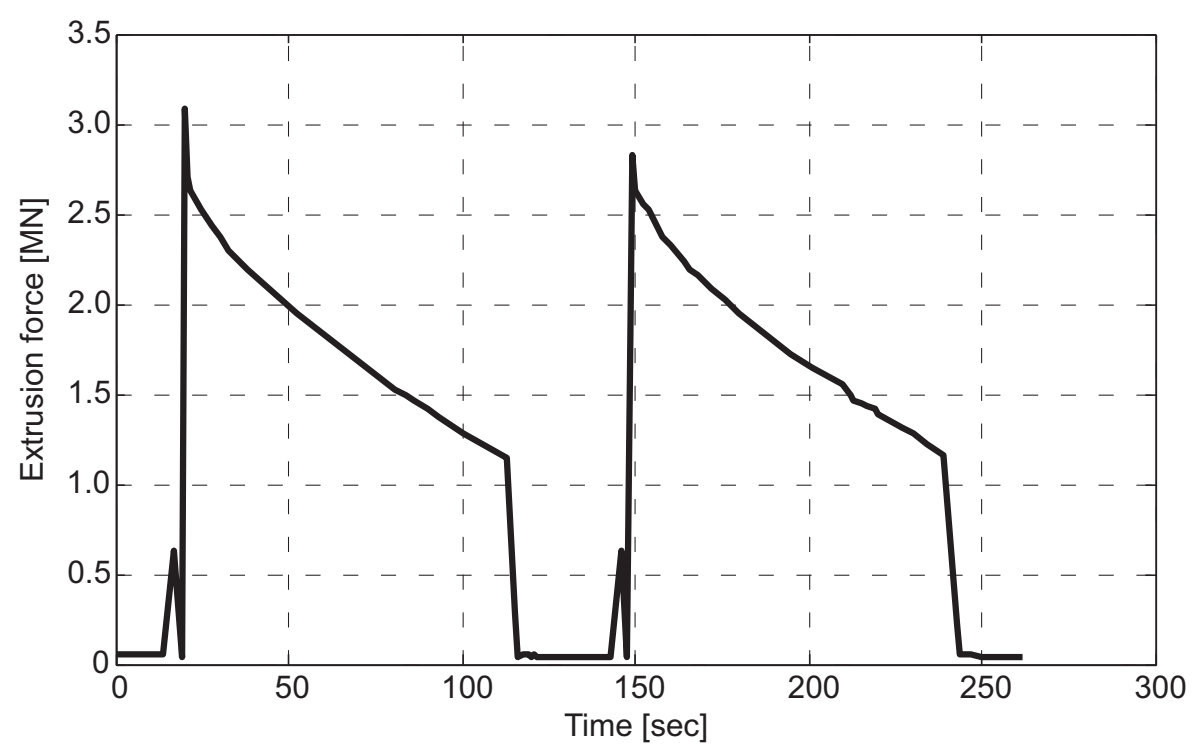

Figure 3.18: Extrusion force versus time $\left(2^{\text {nd }}\right.$ round $)$

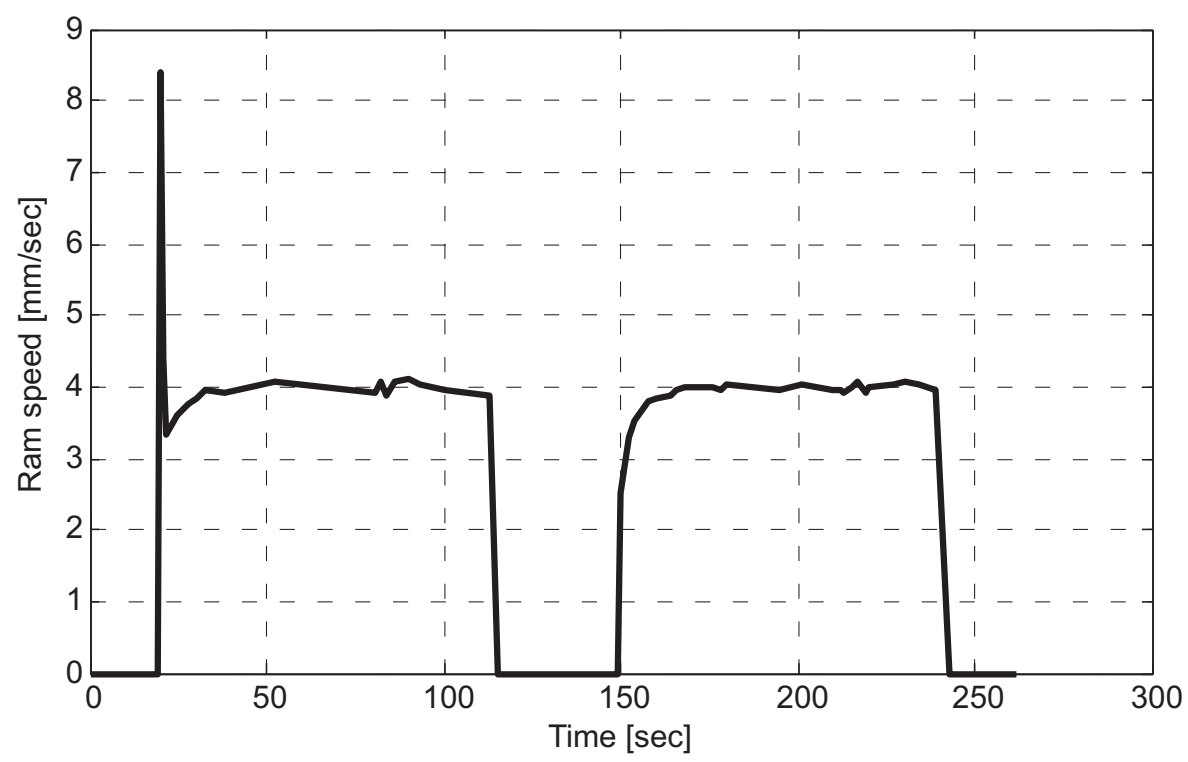

Figure 3.19: Ram speed versus time $\left(2^{\text {nd }}\right.$ round $)$

The experiment succeeded in measuring the angular deflection of the tongue of a flat die in an industrial environment. The modification in the tool is limited to 


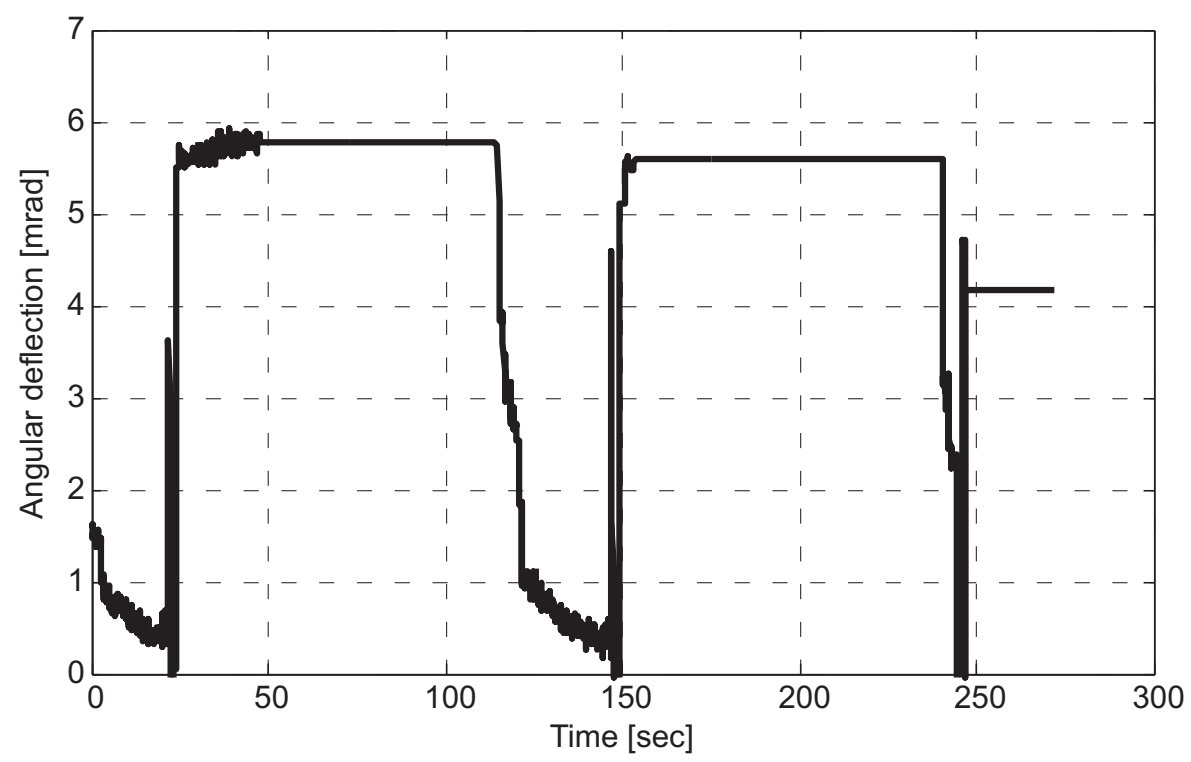

Figure 3.20: Tongue angular deflection versus time ( $2^{\text {nd }}$ round)

the cut in the backer and to the fixation of the mirror. This makes the cost of the experiment reasonable and its setup relatively simple. The angular deflection of the tongue measures implicitly the relative displacement of the bearing rather than measuring the absolute displacement. By this, the misalignment in the bearing can be monitored.

The experiment shows realistic results and it is reproducible. It emphasizes that during the extrusion of every billet there is a recoverable deflection in the tongue. Since the alignment of the tongue with the die surface is not checked before extrusion, the permanent deflection cannot be assured to originate from the extrusion of the first billet. 



\section{Calculation of the die deflection by the decoupled method}

\subsection{Introduction}

A decoupled analysis is applied for calculating the deformation of the flat die described in chapter 3. Different studies are performed on the model including a number of elements per profile thickness, model reduction, accelerating the calculation, employing different solvers and boundary conditions at the tool parts interfaces. An assessment of these studies is performed in terms of the extrusion force, exit velocity and angular deflection of the die tongue. Another important aspect, the calculation time, is checked.

\subsection{Decoupled method}

The simulation of an aluminum extrusion process has two main goals: prediction of the aluminum flow and prediction of the die deformation under aluminum loads. It requires solving the equations related to aluminum volume (billet) and the tool simultaneously. It usually involves a large number of degrees of freedom. Furthermore, if contact is taken into account, this will make solving the simulation more difficult. In order to decrease the number of equations to be solved at once, the simulation is split into two: simulation of the material flow and simulation of the tool deformation [9]. This can be accomplished by the decoupled method as illustrated in figure 4.1. First, a three-dimensional isothermal numerical simulation for the material flow is performed by applying a Eulerian formulation. In this analysis, the tool is assumed to be rigid and the die is filled with aluminum. As soon as the analysis reaches its 
steady state, the reaction forces of the nodes belonging to the interfaces between the tool and the billet are exported and applied on the die. Next, a three-dimensional isothermal numerical simulation for the tool is performed by applying an Updated Lagrangian formulation.

\subsection{Case study}

\subsubsection{Material flow simulation}

\section{Billet model}

The aluminum extrusion process is not a stationary process because the pressure on the billet is decreasing with respect to the ram displacement. Computing the pressure as a function of the ram displacement requires transient calculations that lead to unacceptable calculation times. To avoid these long calculation times, a stationary solution is calculated for a certain ram position $[18,26]$.

The surface layer of a casted billet includes iron-rich intermetallics and $\mathrm{Mg}_{2} S_{i}$ precipitations. In an unlubricated aluminum extrusion process, a high friction occurs at the interfaces between the billet, container and die. As a result, a nonuniform material flow occurs in the billet during the process. At the last third of this process, the material from the billet surface layer starts to flow into the extrudate. A discontinuity appears in the extrudate material. Accordingly, the quality of the extrudate becomes unacceptable and the extrudate must be discarded. This defect is known as the back-end defect $[10,45]$.

In order to avoid the back-end defect, the ram stops at a certain position where the part of the aluminum remaining in the container is called the butt end. According to industry practice, standard butt thickness for direct extrusion is kept to 10 to $15 \%$ of the billet length [38]. Before the next billet is loaded, the butt end is sheared off.

Since the simulation of the aluminum flow is performed with a filled die, the shape of the aluminum in the die can be determined by subtracting the geometry of the die from a solid cylindrical object. The geometry of the billet at the end of the ram stroke is formed from the cylindrical object such that its diameter is equal to the container diameter and its length $\left(L_{b i l}\right)$ is equal to the butt end length.

\section{Boundary conditions}

Since the numerical model has a large number of degrees of freedom, the usage of contact boundary conditions increases its complexity. Therefore, the contact boundary conditions must be simplified to fully slip and stick. Moreover, special attention must be given to applying the right boundary conditions on the right surface; 


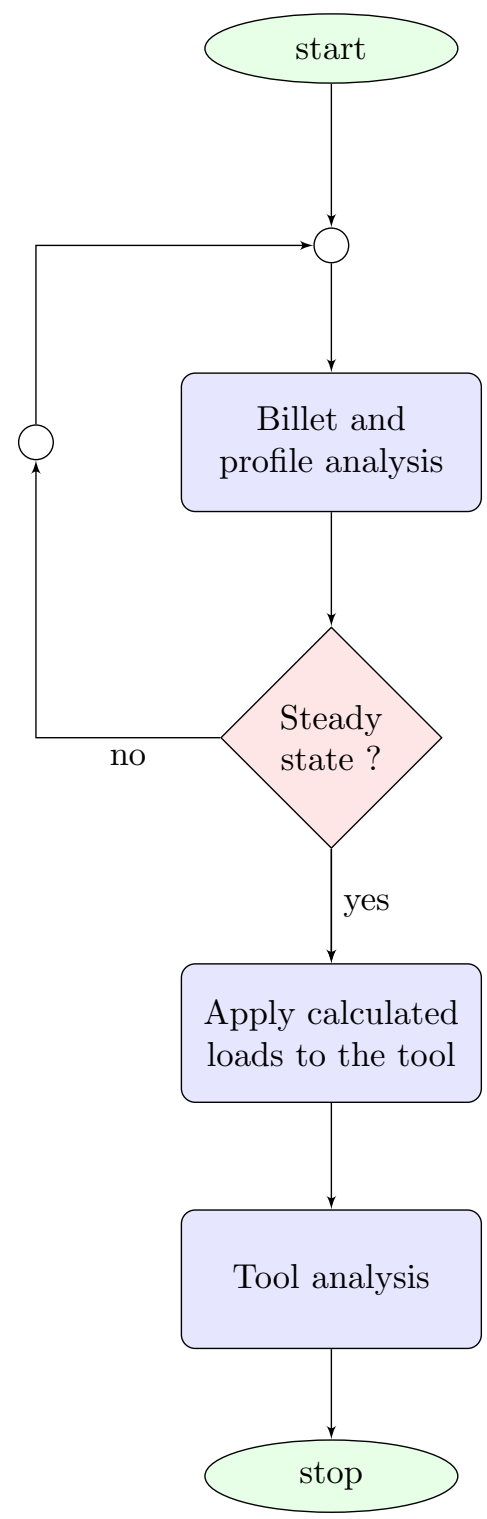

Figure 4.1: Flow chart of the decoupled analysis 
otherwise the model will be too stiff or too flexible. The following boundary conditions are applied on the billet as shown in figure 4.2 :

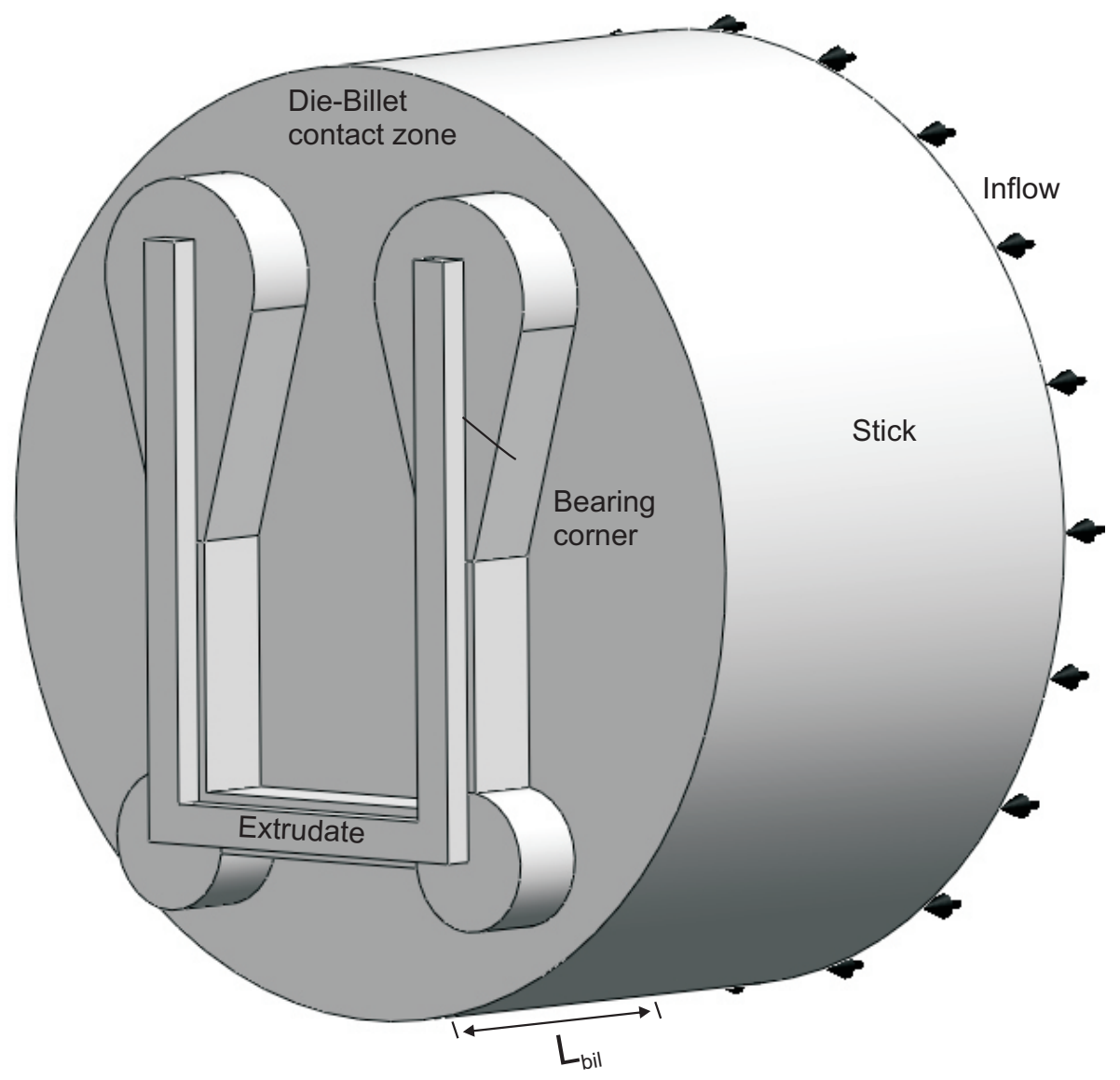

Figure 4.2: Billet's boundaries

1. Stick at cylinder-billet contact zone and die-billet contact zone;

2. Prescribed velocity equal to the ram speed at the inflow;

3. A constraint equation is determined at each bearing corner node between its incremental displacement components (construction of conditional normal) according to section 2.3 ;

4. Fully slip boundary conditions are applied at the interface between the extrudate and the bearing channel;

5. Concerning the crosssection of the extrudate, there are three different cases: 
(a) It is free in the extrusion direction. This case is equivalent to the extrusion of the nose piece;

(b) The nodes are connected to a single node in the extrusion direction. This case is similar to steady extrusion without using a puller;

(c) The nodes are connected to a single node in the extrusion direction and a force is applied to that node in the extrusion direction. This case is similar to the extrusion with a puller.

\section{Finite element model}

The billet is discretized by 10-node tetrahedron elements. Each node has three translational degrees of freedom. The important point is the choice of how many elements per profile thickness are necessary to give acceptable results. Three cases are studied with either 2,3 or 4 elements over the profile thickness.

In order to import and apply the loads on the tool more easily and accurately, the billet and the tool are discretized simultaneously to produce node-to-node contact.

In the tool, there are entities smaller than the length of the bearing channel. If the mesher meshes these entities, the total number of elements will increase tremendously. Therefore, a case named as "reduced" is studied where the small entities are disregarded.

\section{Solving the material flow simulation}

A Eulerian formulation is applied in the material flow simulation. The material flows through the mesh. When the material displacement increments are large relative to the element size, the stress and strain prediction shows oscillations. These oscillations increase with the number of increments until the convergence conditions are not satisfied and the simulation fails [13]. The use of large step size leads to convergence problems, whereas simulations with very small step size require an unacceptable computational time until it reaches the steady state. An appropriate step size must be determined to avoid these problems. The smallest elements are found at the entrance of the bearing channel, and the material incremental displacements reach maximum values there. Therefore, the step size in the material flow simulation is determined such that the incremental displacement of a node at the bearing entrance will not exceed a fraction of the smallest element length.

$$
\Delta u \leq \frac{C_{r} L}{E R}
$$

Where $\Delta u$ is the material incremental displacement of the inflow, $C r$ is the maximum allowable Courant number, $L$ is the element length and $E R$ is the extrusion ratio. $L$ is equal to the cubic root of the minimum volume of a tetrahedron element in the 
aluminum volume [20].

In order to accelerate solving the simulation, a proportional increment is used and the simulation is terminated when it reaches the steady state. When the proportional increment is employed, the material displacement increment of the converged solution of the previous step is used as the first iteration of the next step [54]. Concerning the termination of the simulation at the steady state, after each converged step the unbalance ratio and the displacement ratio are checked and if they become less than a certain threshold, the simulation stops. After several trial simulations, it is found that the threshold is equal to one hundredth of the reference unbalance and displacement ratios that are given the value of $10^{-} 2$.

The selection of the solver has a great influence on the total computational time of three-dimensional extrusion simulations due to the involvement of large number of degrees of freedom in these simulations. Three different solvers are checked where two of them are direct sparse solvers: Sun Performance and MUMPS, and one iterative which is Bi-CGSTAB. The performance of each solver is evaluated with different numbers of degrees of freedom.

\section{Results}

Table 4.1 gives the extrusion force, exit velocity and cpu time of material analysis of the three cases with 2, 3 and 4 elements over profile thickness. This table shows that three elements per profile thickness are sufficient for accurate simulation.

\begin{tabular}{cccrr}
\hline $\begin{array}{c}\text { Elements per profile } \\
\text { cross section }\end{array}$ & $\begin{array}{c}\text { Extrusion force } \\
{[\mathrm{MN}]}\end{array}$ & $\begin{array}{c}\text { Exit velocity } \\
{[\mathrm{mm} / \mathrm{sec}]}\end{array}$ & DOF & $\begin{array}{r}\text { CPU } \\
{[\mathrm{sec}]}\end{array}$ \\
\hline 2 & 1.20 & 61.52 & 40131 & 492 \\
3 & 1.12 & 61.63 & 104031 & 2070 \\
4 & 1.12 & 61.71 & 175914 & 5480 \\
\hline
\end{tabular}

Table 4.1: Results of the material flow simulation in the three cases

The billet and the tool are meshed simultaneously. Disregarding the tiny entities in the tool geometrical model allows choosing a bigger global element size. Subsequently, the number of degrees of freedom involved in the simulation of the material flow is reduced by $46 \%$. The reduction in the number of degrees of freedom leads to a significant decrease in the computational time without influencing the results as shown in table 4.2 .

After specifying the sufficient number of elements per profile thickness and decreasing the number of degrees of freedom by suppressing the tiny entities that don't influence the results, actions are taken to speed up the simulation of the material flow. The actions include using the proportional increment and terminating the simulation at the steady state. The model with 56319 degrees of freedom is solved with the same 


\begin{tabular}{cccrr}
\hline Model & $\begin{array}{c}\text { Extrusion force } \\
{[\mathrm{MN}]}\end{array}$ & $\begin{array}{c}\text { Exit velocity } \\
{[\mathrm{mm} / \mathrm{sec}]}\end{array}$ & DOF & $\begin{array}{r}\text { CPU } \\
{[\mathrm{sec}]}\end{array}$ \\
\hline Original & 1.12 & 61.63 & 104031 & 2070 \\
Reduced & 1.15 & 61.58 & 56319 & 284 \\
\hline
\end{tabular}

Table 4.2: Results of the material flow simulation of the original and reduced models

solver and on the same machine three times. First, the simulation is solved and the speeding up actions are not considered. This simulation is given the number 0 . Second, the simulation is solved with the proportional increment. This simulation is given the number 1 . Third, the simulation is solved with the proportional increment and it is stopped when it reaches the steady state. This simulation is given the number 2. Figure 4.3 shows the number of steps avoided during the third simulation. Figure 4.4 shows the reduction in cpu time with the simulation number 2 .
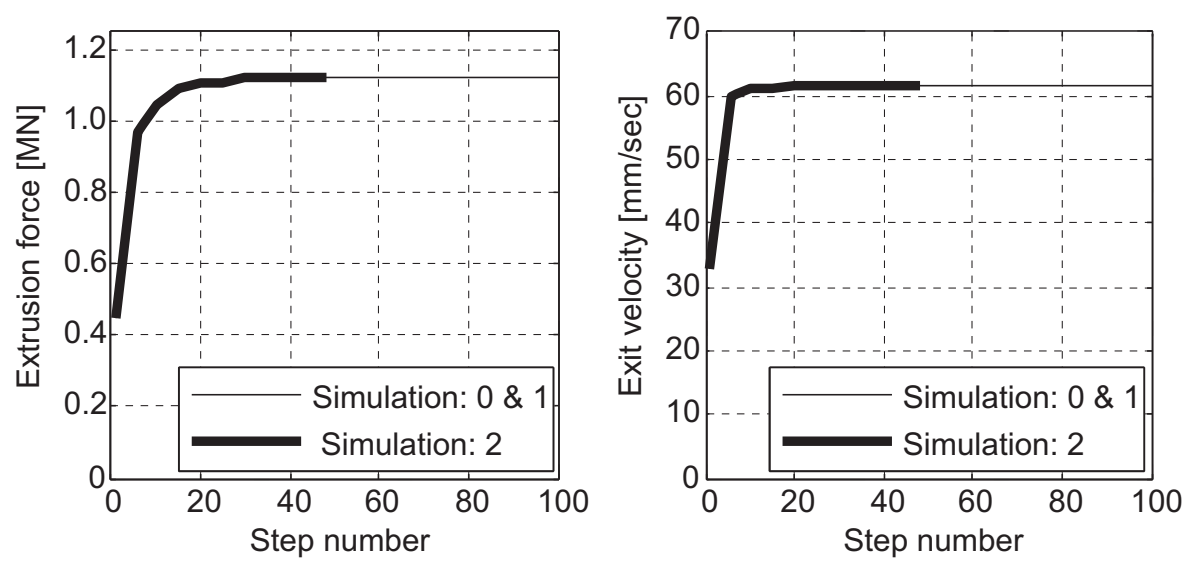

Figure 4.3: Extrusion force versus step number (left), Exit velocity (right)

Usually the number of degrees of freedom is relatively high in three-dimensional simulations of an aluminum extrusion problem. The selection of a suitable solver is essential, whether it is direct or iterative for solving the simulation with a certain number of degrees of freedom in an acceptable time. Therefore, the simulation of extruding the U-shaped profile with different numbers of degrees of freedom is solved by different solvers such as MUMPS, Sun Performance and Bi-CGSTAB and the cpu times are plotted in figure 4.5. It shows that MUMPS is a suitable solver for simulations with a number of degrees of freedom below 180000, while Bi-CGSTAB becomes suitable when the number of degrees of freedom exceeds 180000 in the simulations. In addition, the direct solvers will crash above this number of degrees of freedom. 


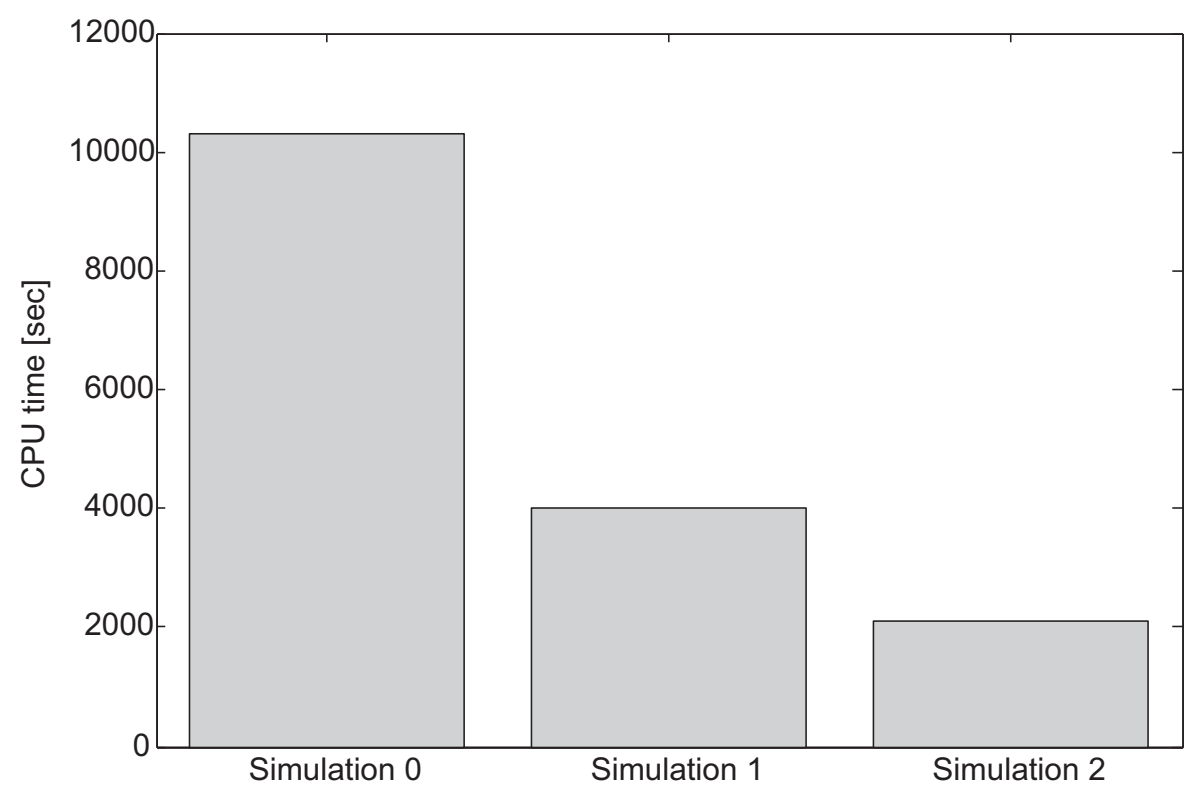

Figure 4.4: Reduction in cpu time with 104031 degrees of freedom
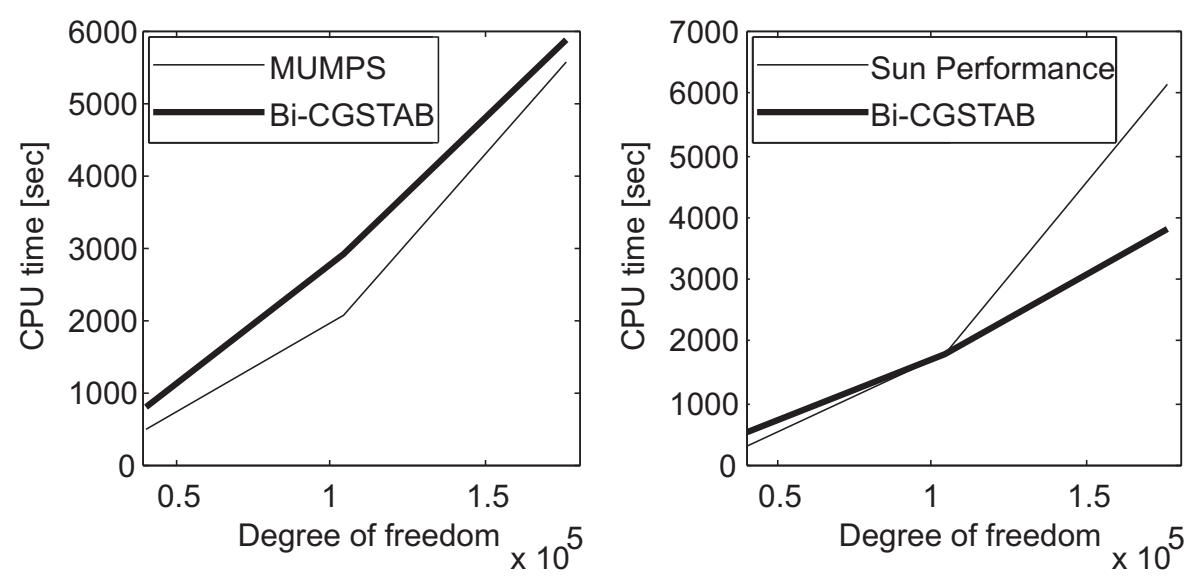

Figure 4.5: CPU times for different solvers on HPDL145 machine (left) and on Sun Fire X4450 machine (right) 


\subsubsection{Tool simulation}

\section{Modeling the tool parts}

Regarding the tool, in comparison to figure 3.2 only the die, backer and bolster are modeled. The presence of the pressure ring and ring is neglected. The deformation of the pressure ring doesn't influence the relative displacement in the die bearing. The ring doesn't provide any support in the direction of the load.

\section{Boundary conditions}

The following boundary conditions are applied as shown in figure 4.6:

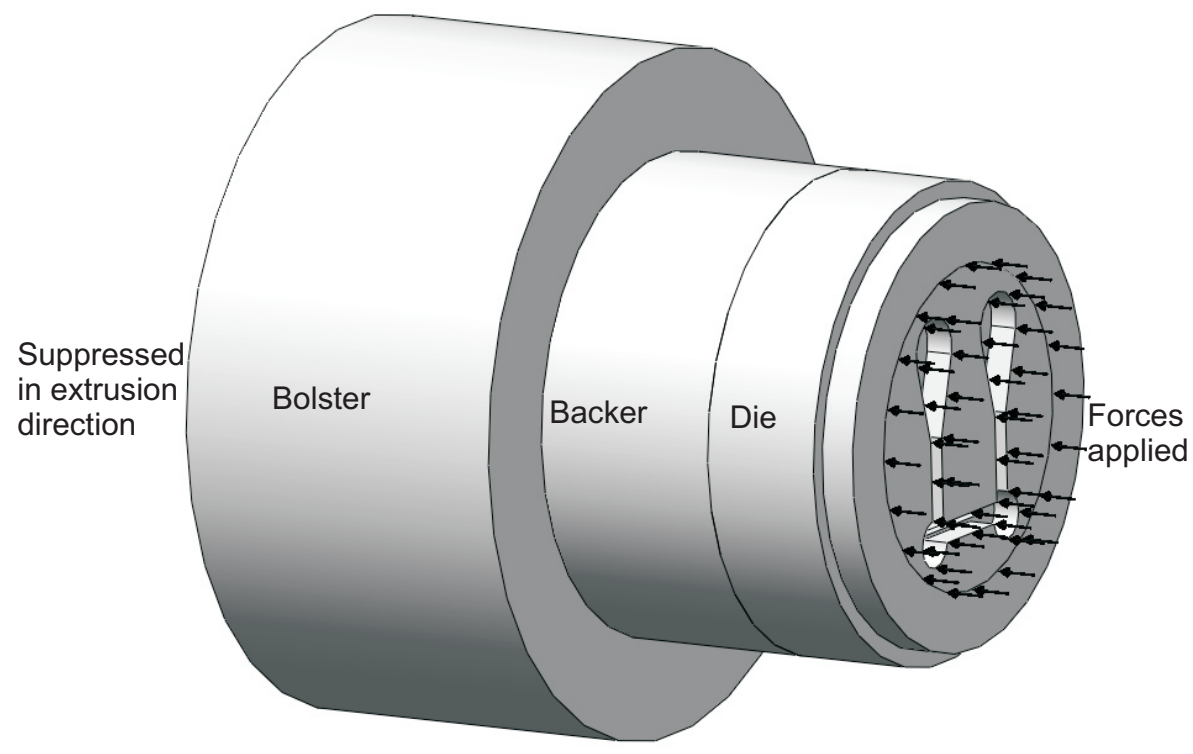

Figure 4.6: Tool's boundaries

1. Suppress the displacement in the extrusion direction at the downstream end of the bolster;

2. Forces are applied at the nodes belonging to die-billet contact zone;

3. In the tool there are two contact zones. One is between the backer and die and the other is between the bolster and backer. The contact zone between backer and die is divided into two regions $\Omega_{1}$ and $\Omega_{2}$ as shown in figure 4.7. There are two pins and one bolt connecting the backer to the die in the region $\Omega_{2}$ as shown in figure 3.9. Slipping is allowed in region $\Omega_{1}$ while it is prevented in region $\Omega_{2}$. Therefore, the equivalent boundary conditions must be such that the nodes in 
$\Omega_{1}$ are connected in the extrusion direction only and those in $\Omega_{2}$ are connected in all directions. In addition, the two other boundary conditions between the backer and the die are studied in order to check their influence on the die tongue deflection. In these boundary conditions, the nodes at the interface are either connected in all directions or in extrusion direction only.

In the contact zone between the bolster and the backer named as $\Omega_{3}$, the nodes are connected in the extrusion direction only. Slipping between the parts is allowed.

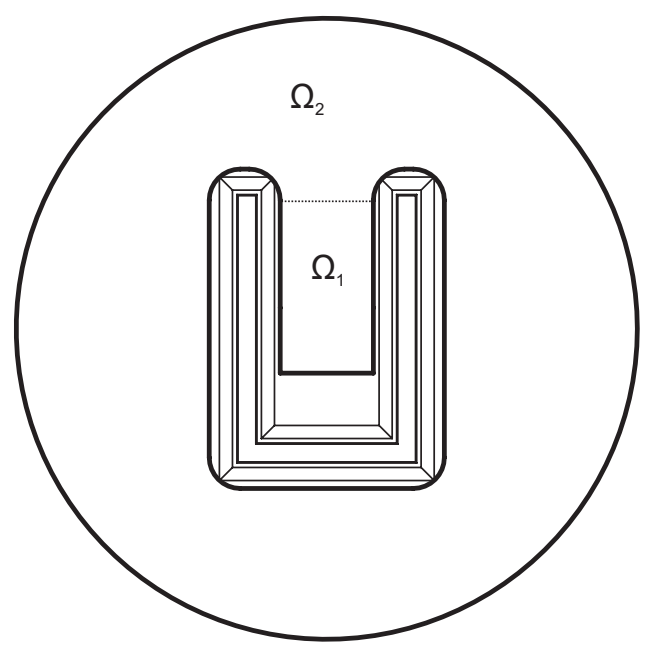

Figure 4.7: Different boundaries on the reverse side of the die

\section{Finite element models}

As described before the billet and the tool are meshed simultaneously with the same element type. The tool is also discretized with 10-node tetrahedron elements with translational degrees of freedom.

\section{Results}

Table 4.3 gives the angular deflection of the tongue and the cpu time of the tool analysis of the three cases with 2, 3 and 4 elements over the profile thickness. It confirms that the three elements per profile thickness are sufficient to give accurate results. 


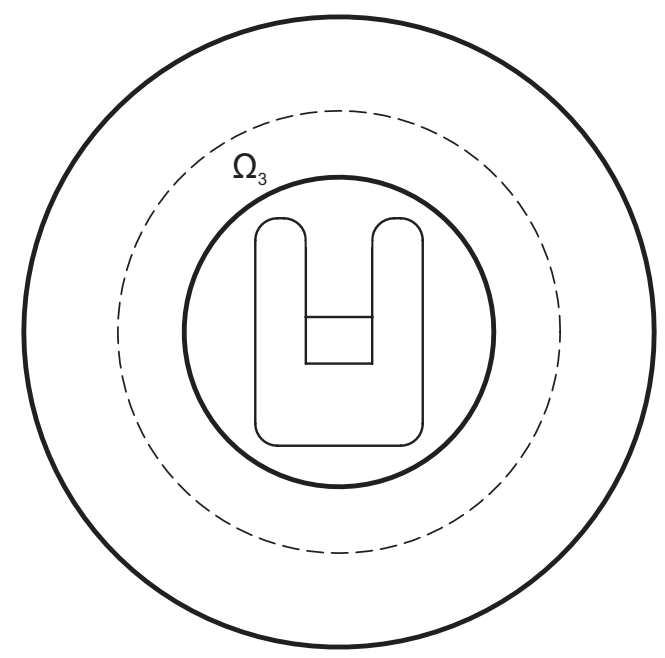

Figure 4.8: The contact zone between bolster and backer

\begin{tabular}{cccc}
\hline $\begin{array}{c}\text { Elements per profile } \\
\text { cross section }\end{array}$ & $\begin{array}{c}\text { Angular deflection } \\
{[\mathrm{mrad}]}\end{array}$ & DOF & $\begin{array}{c}\text { CPU } \\
{[\mathrm{sec}]}\end{array}$ \\
\hline 2 & 7.5 & 360915 & 589 \\
3 & 7.0 & 399108 & 520 \\
4 & 7.0 & 412728 & 751 \\
\hline
\end{tabular}

Table 4.3: Results of the tool deformation simulation in the three cases

Since tiny entities are disregarded from the tool geometrical model, the number of degrees of freedom is reduced by $83 \%$ in the simulation of the tool deformation. The reductions lead to a significant decrease in computational time without influencing the results as shown in table 4.4 .

\begin{tabular}{cccc}
\hline Model & DOF & $\begin{array}{c}\text { Angular deflection } \\
{[\mathrm{mrad}]}\end{array}$ & $\begin{array}{c}\text { CPU } \\
{[\mathrm{sec}]}\end{array}$ \\
\hline Original & 399108 & 7.0 & 520 \\
Reduced & 68052 & 7.0 & 44 \\
\hline
\end{tabular}

Table 4.4: Results of tool simulation of the original and reduced models

Simulations of the reduced model are performed with three different boundary conditions applied at the interface between the die and the backer. The angular deflection of the die tongue is calculated for each simulation and the results are listed in table 4.5. Table 4.5 shows that the boundary condition at the interface between the die and the backer has a significant influence on the angular deflection of the die tongue. The boundary condition at this interface must be applied carefully otherwise 
an error will appear in the angular deflection of the die tongue. If the degrees of freedom are connected in all directions, the angular deflection of the die tongue is underestimated by $24 \%$ because the tool becomes too stiff. If they are connected in extrusion direction only, the angular deflection of the die tongue is overestimated by $43 \%$ because the tool becomes too flexible.

\begin{tabular}{cc}
\hline $\begin{array}{c}\text { Connecting DoF of } \\
\text { nodes at }\end{array}$ & $\begin{array}{c}\text { Angular deflection } \\
{[\mathrm{mrad}]}\end{array}$ \\
\hline$\Omega_{1}$ and $\Omega_{2}$ in all directions & 5.3 \\
$\Omega_{1}$ and $\Omega_{2}$ in extrusion direction only & 10.0 \\
$\Omega_{2}$ in all directions and & 7.0 \\
$\Omega_{1}$ in extrusion direction only & \\
\hline
\end{tabular}

Table 4.5: Angular deflection of the tongue at different boundary conditions of the die-backer interface

The displacement distribution in the extrusion direction and the von Mises stress of the tool are plotted in figures 4.9 and 4.10 for the simulations corresponding to the first and second rounds respectively. Both figures show that the stress reaches the value of $1300 \mathrm{~N} / \mathrm{mm}^{2}$. This stress value is found at local regions especially at the joints connecting the tongue to the rest of the die. The experimental results concerning the first round show that the permanent deflection remains the same after the deflection caused by extrusion of the first billet. During the extrusion of the successors of the first billet, the material of the die behaves in a linearly elastic manner. This means that the von Mises stress exceeds the original yield stress during the extrusion of the first billet. Then the yield stress has a new value which is higher than the value of $1300 \mathrm{~N} / \mathrm{mm}^{2}$ [17]. Errors may appear in the stress calculations due to inaccuracy in material model and material constants.
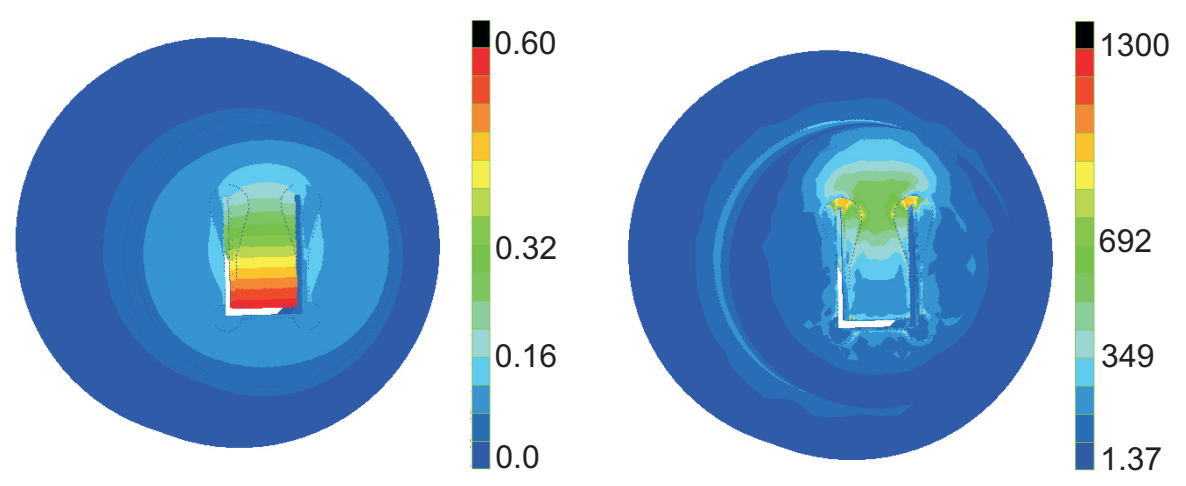

Figure 4.9: Deflection of the tool in the extrusion direction [mm] (left), Von Mises stress $\left[\mathrm{N} / \mathrm{mm}^{2}\right]$ (right) (first round) 

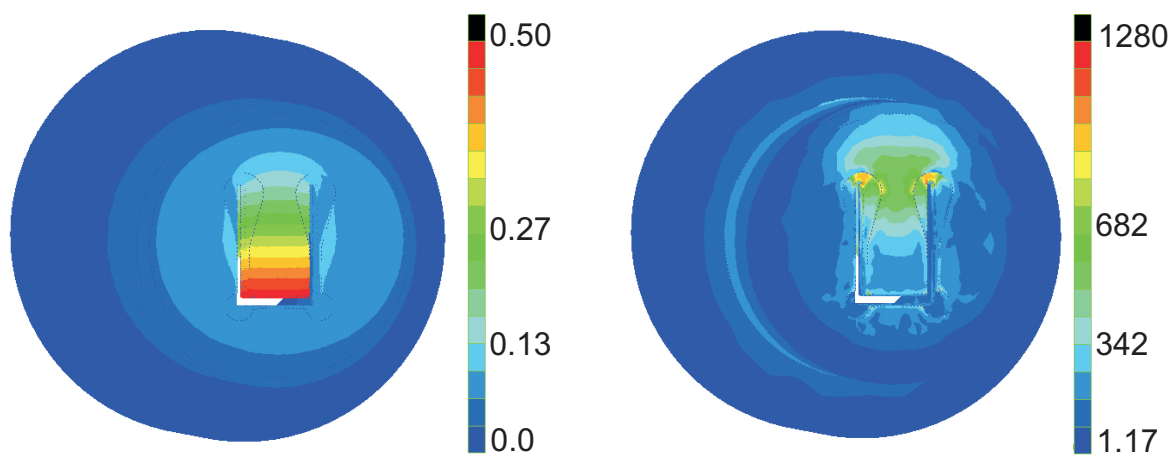

Figure 4.10: Deflection of the tool in the extrusion direction [mm] (left), Von Mises stress $\left[\mathrm{N} / \mathrm{mm}^{2}\right]$ (right) (second round)

\subsubsection{Comparison between experimental and numerical results}

As stated in 4.3.1 the material flow simulation is calculated. The numerical results are compared to those of the experiments in terms of velocity distribution, extrusion force and angular deflection of the tongue. In addition, the extrusion force and angular deflection are calculated at different boundary conditions applied at the crosssection of the extrudate.

The distribution of the velocity vectors of the profile crosssection is exhibited in figure 4.11. It shows a good match between the snapshot of the nosepiece and the plot of velocity vectors. In both figures the profile is faster at the top than at the bottom. In addition, an average exit velocity of $61.7 \mathrm{~mm} / \mathrm{sec}$ is calculated and this value matches the product of extrusion ratio (11.658) and the ram speed (5.3). Accordingly, it is confirmed that when the conditional normal is applied, the material flow is conserved.

As mentioned in the previous chapter, the puller was deactivated during the first round of the experiment while it was activated during the second round. The extrusion force and angular deflection of the tongue corresponding to the first round are calculated with two boundary conditions applied at the crosssection of the extrudate: its nodes are free or its nodes are connected in the extrusion direction. The results are summarized in table 4.6. Those corresponding to the second round are calculated with one more boundary condition, which is applying the puller force to the connected nodes. The results are summarized in table 4.7 .

Tables 4.6 and 4.7 show that these boundary conditions only have a small influence on the results. 

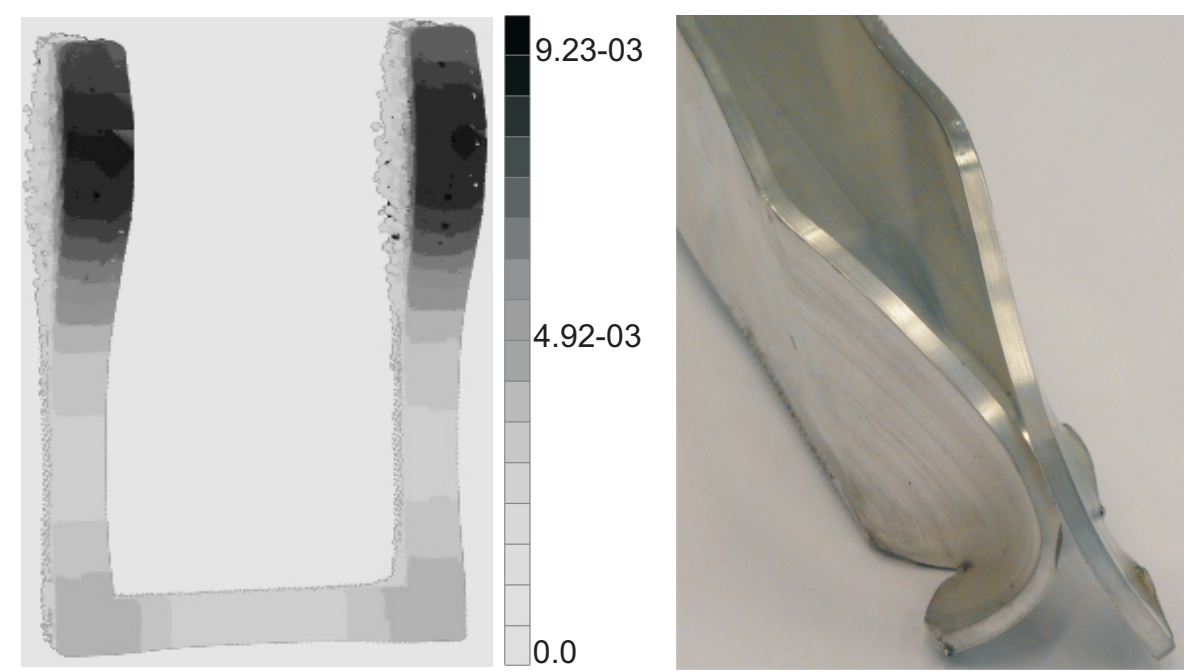

Figure 4.11: Velocity vector distribution $\mathrm{dt}=0.075[\mathrm{msec}]$ (left), nose piece (right)

\begin{tabular}{ccc}
\hline $\begin{array}{c}\text { Boundary } \\
\text { Condition }\end{array}$ & $\begin{array}{c}\text { Extrusion force } \\
{[\mathrm{MN}]}\end{array}$ & $\begin{array}{c}\text { Angular deflection } \\
{[\mathrm{mrad}]}\end{array}$ \\
\hline Free & 1.12 & 7.0 \\
Connected & 1.15 & 7.3 \\
Experiment & 1.20 & $7.0 \pm 0.3$ \\
\hline
\end{tabular}

Table 4.6: Results at different boundary conditions applied to the extrudate crosssection ( $1^{\text {st }}$ round)

\begin{tabular}{ccc}
\hline $\begin{array}{c}\text { Boundary } \\
\text { Condition }\end{array}$ & $\begin{array}{c}\text { Extrusion force } \\
{[\mathrm{MN}]}\end{array}$ & $\begin{array}{c}\text { Angular deflection } \\
{[\mathrm{mrad}]}\end{array}$ \\
\hline Free & 1.080 & 6.7 \\
Connected & 1.105 & 7.0 \\
Puller $(135 N)$ & 1.103 & 6.9 \\
Experiment & 1.130 & $5.8 \pm 0.6$ \\
\hline
\end{tabular}

Table 4.7: Results at different boundary conditions applied to the extrudate crosssection ( $2^{\text {nd }}$ round)

\section{Influence of binding force exerted by the container on the die}

As shown in figure 3.15, the angular deflection of the die tongue increases during the extrusion of a billet. The reason for this increase comes from the force exerted by the container on the die $\left(F_{b}\right)$ as shown in figure 3.16. This force is equal to the friction force at the interface between the billet and the container, but in the opposite sense. The friction force is directly proportional to the contact area between the billet and 
the container. This contact area decreases during the extrusion of the billet. The force $\left(F_{b}\right)$ deforms the die tongue in the opposite of the extrusion direction [47].

A numerical simulation is performed of the tool with an applied distributed load on the interface between the container and the die face as illustrated in figure 4.12. The total load is equal to the friction force between container and the billet which is equal to $1.2 \mathrm{MN}$. Figure 4.13 shows that the tongue deflects by a value of $0.2 \mathrm{mrad}$ opposite to the extrusion direction. This value agrees with that measured during the extrusion trials.

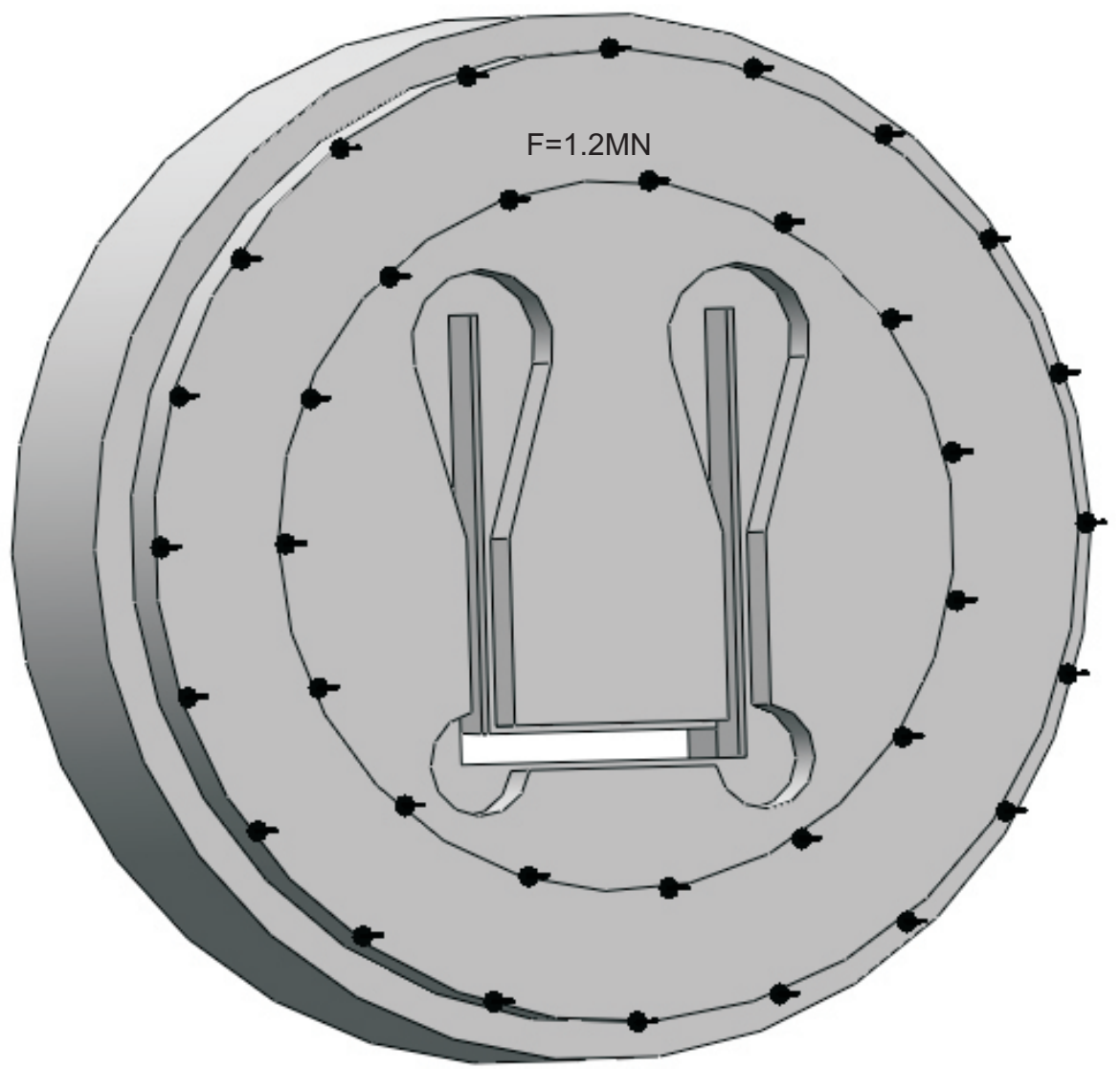

Figure 4.12: Uniform distributed load applied on the interface between the container and die face 


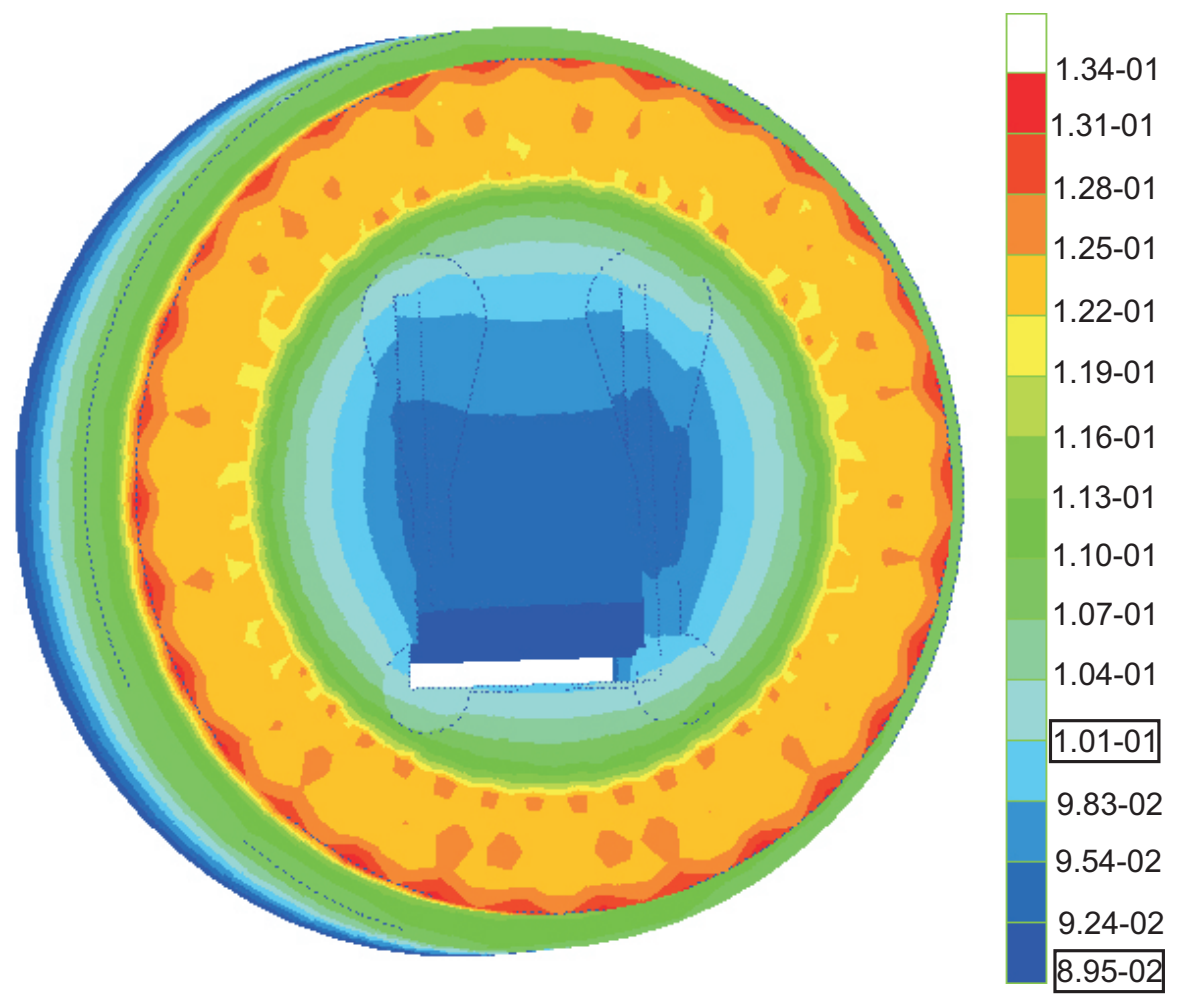

Figure 4.13: Deflection of the die under the friction force [mm]

\section{Permanent deflection of the die}

Figures 3.12 and 3.13 show higher values in the extrusion force and ram speed respectively during the extrusion of the first billet than during the extrusion of its successors. As a result, the angular die tongue deflection during the extrusion of the first billet is higher than that during its successors. It is not fully recoverable after the extrusion of the first billet while it is after the extrusion of its successors. A permanent deflection remains in the tongue after the extrusion of the first billet as described in figure 3.15 .

In order to check the source of the permanent deflection in the tongue, a new simulation for loading and unloading the tool is performed with an estimated load. This load is 1.25 times bigger than that in the previous simulation. It is deduced from the ratio between the angular deflection of the tongue during the extrusion of the first billet and second billet.

It is found that $0.015 \mathrm{~mm}$ of permanent deflection in the tongue remains. As 
mentioned in the previous chapter, $0.03 \mathrm{~mm}$ of permanent deflection in the tongue is measured after every round of the experiment. This highlights the fact that a permanent deflection appears during the extrusion of the first billet where a higher force is applied on the die as shown in figure 3.12.

\subsection{Summary and conclusion}

The procedure of the decoupled method is described. The extrusion of a U-shaped profile mentioned in the previous chapter is considered as a case study. In the case study, the boundary conditions applied in the simulations concerning the material flow and the tool deformation are represented.

It is determined that discretization by three elements over the profile thickness yields sufficiently accurate prediction of extrusion force and exit velocity. The total number of elements is reduced by $50 \%$ by suppressing the small entities without influencing the results.

Actions are taken for speeding up the simulation, including using the proportional increment and terminating the simulation when it reaches the steady state. They show about $80 \%$ reduction in cpu time. Different solvers are tested in solving the same problem with different numbers of degrees of freedom and it is clarified that the iterative solver, the Bi-CGSTAB, becomes more suitable for simulations with numbers of degrees of freedom exceeding 180000. The stress calculations of the tool shows that Von Mises stresses reach the value $1300 \mathrm{~N} / \mathrm{mm}^{2}$ at local regions. Since the experimental results show that no additional permanent deflection appears during the extrusion of the successors of the first billet, the die material has a new yield stress which is above the value $1300 \mathrm{~N} / \mathrm{mm}^{2}$. An advanced material model and material constants at extrusion temperatures are required in order to get more accurate stress predictions.

As a conclusion, the decoupled method can give a good prediction of the extrusion force, exit velocity distribution and the deflection of the die in a short time. Simulation time is not only made short by decreasing the number of equations to be solved simultaneously, but also by reaching the steady state quickly through the simulation of material flow. The decoupled method has a disadvantage in predicting the velocity distribution when simulating an extrusion through a less supported die because the influence of the die deflection is not considered in calculating the material flow. 



\section{Calculation of die deflection by the coupled method}

\subsection{Introduction}

In [8] an experimental investigation aimed at measuring the deflection of two tongues of a single flat die utilized in an aluminum extrusion process is presented. In this process two identical U-shaped profiles are extruded through identical openings in the die and its feeder. The alteration is in the support of the tongues where one is fully supported and the other is partially supported. The partially supported tongue deflects more than the fully supported one with a difference of $0.45 \mathrm{~mm}$ as presented in [31]. The profile at the partially supported tongue is slower than that at the fully supported tongue. The difference in speed between the two profiles is about $3 \%$. If the decoupled method described in the previous chapter is applied in calculating the exit velocity distribution, the profiles will have equal velocities. These experimental results highlight the weak point of the decoupled method, where the die deflection is not considered in calculating the velocity distribution of the aluminum.

In this chapter the coupled method where the aluminum and the tool are calculated simultaneously is presented with its three different procedures. They include a fullscale model, substructuring without condensation and a statically condensed tool. An assessment in terms of computational time, extrusion force, exit velocity and angular deflection of the tongue is executed for the procedures applied in analyzing the extrusion of the U-shaped profile described in chapters 3 and 4 . In addition, different solver types such as direct and iterative sparse solvers are utilized in the assessment.

Appendix A shows that the die has a $3 \mathrm{~mm}$ bearing length. The discretization of the tool and the aluminum volume at once will lead to smaller elements at the 
bearing area where the element size is smaller than the bearing length. From chapter 3, it can be deduced that the tip of the tongue will have a displacement around $0.4 \mathrm{~mm}$ in the extrusion direction. Since Updated Lagrangian and Eulerian formulations are assigned to the tool and aluminum respectively during the simulation, the elements at the boundaries will be distorted. Convergence problems will arise due to highly distorted elements in this area. Therefore, an Arbitrary Lagrangian Eulerian formulation is required in order to avoid problems at the interface and highly distorted elements at the bearing area. As a result, new mesh management options for the nodes at the interface between the aluminum volume and the die and inside the aluminum volume are implemented.

On the one hand, the results show good agreement between the three procedures with respect to extrusion force, exit velocity and angular deflection of the tongue. On the other hand, the statically condensed tool shows a very high computational time in comparison to the other two procedures.

\section{$5.2 \quad$ A coupled method}

In a coupled method, the aluminum volume (billet) and the tool are solved simultaneously. Unfortunately, the application of this method becomes more difficult as the complexity of the die increases. With complicated dies, the number of degrees of freedom of the finite element model which consists of the aluminum volume and the tool becomes high. For example, it reaches the value of 1,500,000 in the model analyzed in the Extrusion Benchmark 2007, Bologna, Italy. Subsequently, the simulation either consumes long computation time due to arithmetic operations or fails due to memory shortage.

As aforementioned in chapter 3, the tool deforms elastically. Therefore, the full-scale model consists of two main regions, one is linear, which is the tool and the other is nonlinear, which is the aluminum volume. The nonlinear analysis for the full model tends toward unwanted arithmetic operations which affects the cpu time. In recent years, substructuring or domain decomposition technique has been proposed to be applied in large-scale elastic-plastic finite element analysis.

Substructuring is the division of the original structure into regions, identified by the user at the beginning and usually adopted as a way to manage a large finite element analysis project or as a way to fit the analysis into limited computer resources [34]. Since each substructure has its own nodes and elements, the substructures may have different mesh density or element types. The global system of equations will be solved at once after the stiffness matrices and internal force vectors of all substructures are built separately and assembled. Unless a static condensation is applied in the substructures, the total number of degrees of freedom of the full structure doesn't change with substructuring. In case of applying the static condensation in substructures, the internal nodes of each substructure are condensed 
to its external nodes, which decreases the total number of nodes and degrees of freedom. Although the rank of the reduced stiffness matrix becomes smaller, the cpu time may be increased due to the non-sparsity of the global stiffness matrix. Finally, the displacements, strains and stresses of the local substructures will be calculated after the displacements at the interface are known $[3,35]$.

Substructuring or domain decomposition is employed in different fields in computational mechanics. For instance, in [19] an overlapped domain decomposition method with different mesh density for each domain is applied in 2D and 3D analysis of an extrusion process and it shows a significant increase in computational efficiency. In [46], the hierarchical domain decomposition method is applied to large-scale (millions of dofs) elastic-plastic finite element analysis of nuclear structures in a parallel environment and the subdomains are discretized with different element types. In [12], non-overlapped substructuring is applied to the analysis of an incremental sheet forming process where a small-sized forming tool travels all over the blank in order to introduce the global deformation. The finite element mesh is split into iteratively, incrementally and multi-incrementally updated domains. In the iteratively updated domain, the geometrical and material nonlinearity for the tangent stiffness matrix and the internal force vector are updated during each iteration. In the incrementally updated domain, the tangent stiffness matrix and the internal force vector are calculated at the beginning of each increment including the geometrical and material nonlinearity. This domain contains the elements that experience weak nonlinearity due to geometrical effects. In the multi-incrementally updated domain, a similar procedure applied to the incrementally updated domain is performed over a number of increments instead of one increment. The classification of the domains is determined automatically according to indicators developed for localized plastic deformation. It is shown that the application of this method speeds up the simulation by a factor of 2 . In addition, static condensation is applied to the incrementally and multi-incrementally updated domains but it doesn't show an improvement in speeding up the simulation.

In this chapter three different procedures of a coupled method are examined in simulating an extrusion process. The procedures include a full-scale model where a nonlinear analysis is performed. The next procedure concerns substructuring without condensation which shows the influence of decreasing the arithmetic operations on the computational time. Finally, a statically condensed tool is modeled which indicates the influence of decreasing the arithmetic operations and number of degrees of freedom on the computational time.

\subsection{Procedures of the coupled method}

The application of a coupled method in aluminum extrusion requires solving the equations of the aluminum and the tool simultaneously. The aluminum has a temperature which exceeds $400 C^{\circ}$ during the process. Hot aluminum has a rate 
dependent or visco-plastic behavior. It encounters large deformations especially near the extrusion opening. The tool which is made from tool steel has an elasto-plastic material behavior. It encounters small deflections $(<1 \mathrm{~mm})$.

There are two main finite element formulations, Lagrangian and Eulerian formulations. In Lagrangian formulations the frame is fixed to the initial geometry (Total Lagrangian) or the frame is fixed to the geometry at the beginning of the time step (Updated Lagrangian), thus the frame is moving with the material. In the Lagrangian formulations the free surfaces can be modeled and the history-dependent behavior can be taken into account. In the Eulerian formulation, the material flows through a fixed reference frame in space. In this formulation, the material boundaries are not equal to the grid boundaries. Special procedures must be applied to follow free surfaces [54]. History-dependent behavior is taken into account by calculating convection along stream lines.

In simulating an aluminum extrusion process with a coupled method, the application of Lagrangian formulations leads to high element distortions due to large deformations in the aluminum volume. At highly distorted elements the Jacobian determinant at integration points may be negative. As a result severe local inaccuracies will appear or the simulation will fail. The application of Eulerian formulations doesn't lead to element distortions but it fails in following the moving boundaries [13, 44]. Therefore an Arbitrary Lagrangian Eulerian formulation which combines the advantages of both the Lagrangian and Eulerian formulations becomes suitable in the simulation of an aluminum extrusion process with a coupled method.

In the coupled method, material and grid displacements of the nodes belonging to the tool are coupled together while the grid displacements of the nodes belonging to the aluminum volume (billet) are controlled by mesh management options. The mesh management options are described later in the current section.

After assembling the global stiffness matrix of the aluminum and the tool models, the following system of equations is solved by Newton-Raphson method:

$$
K \Delta U=\Delta F=F-R
$$

where $\mathrm{K}$ is the global stiffness matrix, $\Delta U$ is the incremental displacement, $\mathrm{F}$ is the external force vector and $\mathrm{R}$ is the internal force vector.

Initially the internal force vector $(\mathrm{R})$ is equal to zero. The material incremental displacement is calculated. The strains, stresses and internal forces are computed from the determined material incremental displacement.

Concerning the aluminum volume, the grid incremental displacement is determined by the material incremental displacement and the convective incremental displacement. 
The stresses at the new grid are updated by adding a convective part. The internal forces are calculated from the stresses at the new grid. When steady state is reached, the internal force vector $(\mathrm{R})$ tends to a constant vector which is different from the reaction force vector $(\mathrm{F})$. As a result, the calculated incremental material displacement will be constant.

Concerning the tool, the grid incremental displacement is equal to the material incremental displacement. The stresses at the new grid are calculated from the incremental material displacement. The internal force vector $(\mathrm{R})$ is calculated from the calculated stresses. When the steady state is reached, the internal force vector (R) tends to the external force vector $(\mathrm{F})$. As a result, the calculated incremental material displacement will be zero.

In the next paragraphs the three different procedures of the coupled method are described.

\subsubsection{Full-scale model}

The full-scale model is considered as a reference model for monitoring the accuracy and computation time of the other procedures. In the current procedure, a nonlinear finite element analysis with Arbitrary Lagrangian Eulerian formulation is performed for the aluminum volume (billet) and the tool including die, backer and bolster. In the following paragraphs, the boundary conditions and mesh management options are described.

\section{Boundary conditions and finite element model}

The interface between the aluminum and the tool is divided into three sets as shown in figure 5.1 and different boundary conditions are applied to each set.

The degrees of freedom of the nodes belonging to set $\mathrm{A}$ are connected in the plane perpendicular to the extrusion direction. The degrees of freedom of the nodes belonging to set $\mathrm{C}$ are connected in all directions. As a result, slipping between the nodes belonging to set $\mathrm{A}$ is allowed in the extrusion direction and the nodes belonging to set $\mathrm{C}$ are sticking together. However, the degrees of freedom of the nodes belonging to set $\mathrm{B}$ are connected in the direction of the conditional normal defined in chapter 2. Figure 5.2 shows how the degrees of freedom are connected. A linear constraint equation is formulated such that the projected velocity components on the normal direction of the node $B_{\text {billet }}$ are equal to that of node $B_{\text {die }}$. The constraint equation is as follows:

$$
v_{b}=u_{d} \cot \varphi+v_{d}-u_{b} \cot \varphi
$$




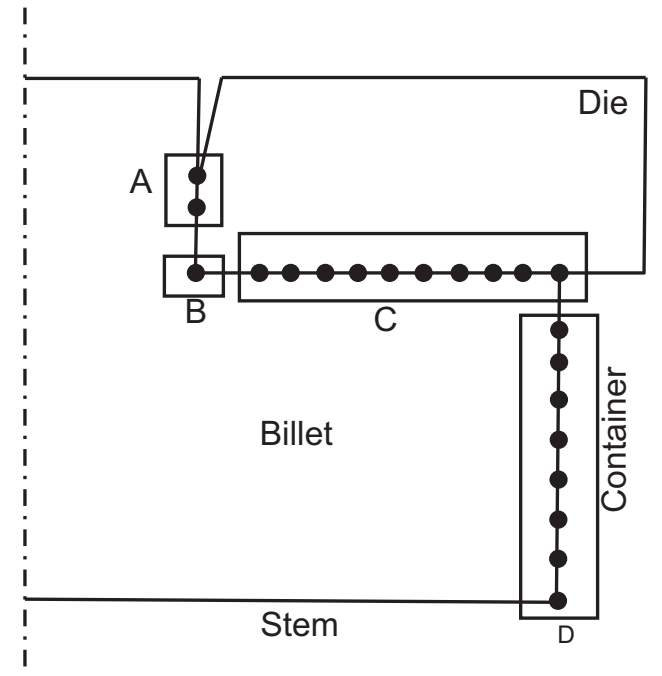

Figure 5.1: The sets at the interface between aluminum and the tool

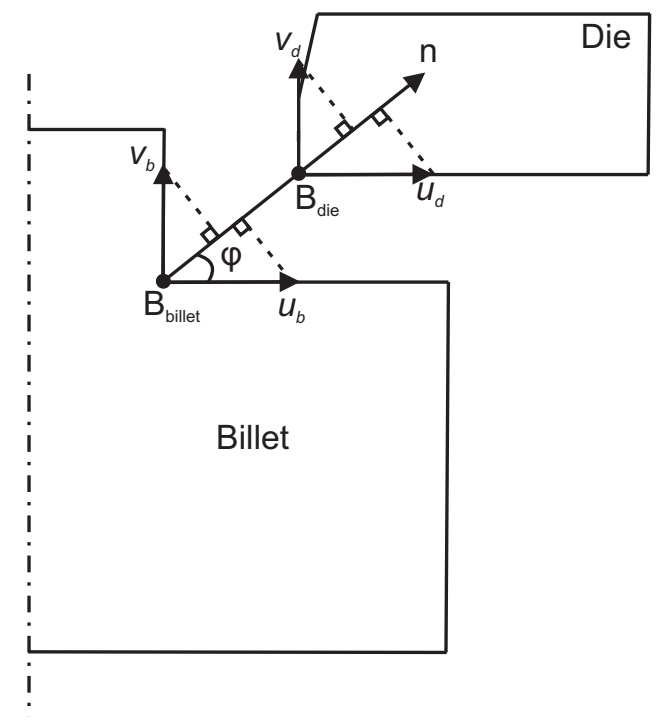

Figure 5.2: Connecting the degrees of freedom in the direction of the conditional normal

\section{Mesh management options}

In the ALE method the displacement of the mesh is decoupled from the material displacement. Different mesh displacement specifications are applied to the boundary 
and inner nodes of the billet volume.

\section{Outer nodes of the aluminum volume}

Figure 5.1 displays the three different boundaries of the billet with the extrusion tool. The nodes belonging to sets $\mathrm{A}$ and $\mathrm{B}$ are relocated to the location of their corresponding nodes on the die as shown in figure 5.3. The nodes belonging to set $\mathrm{C}$ are made to follow the deformation of the die. The nodes belonging to set $\mathrm{D}$ do not move since the material is assumed to stick to the container wall.

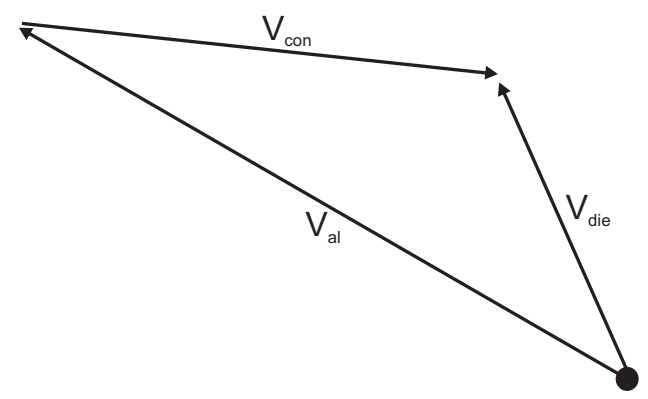

Figure 5.3: Convection of nodes belonging to sets A and B

\section{Internal nodes of the aluminum volume}

The centering method discussed in [41] is applied for the internal nodes of the aluminum volume. Here a distinction is made between element corner nodes and element midside nodes.

Corner nodes

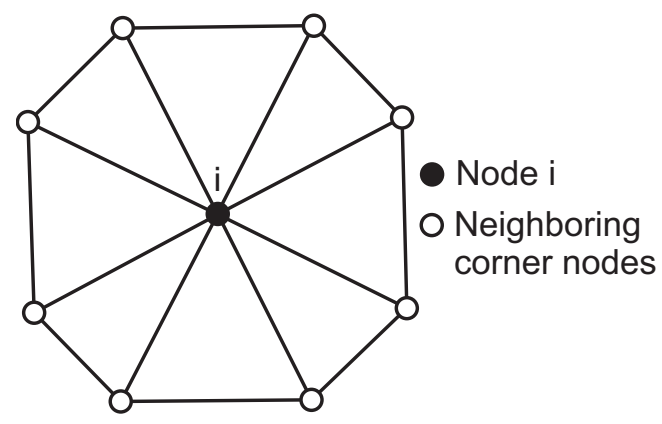

Figure 5.4: An inner node with its neighboring corner nodes

The mesh displacement of the nodes in the interior of the mesh is evaluated by averaging the mesh displacements of the neighboring nodes: 


$$
\overline{V_{g}^{i}}=\frac{1}{m} \sum_{j=1}^{m} V_{g}^{j}
$$

Note that the mesh displacement is averaged, not the mesh location. Initial mesh refinement is preserved.

Midside nodes

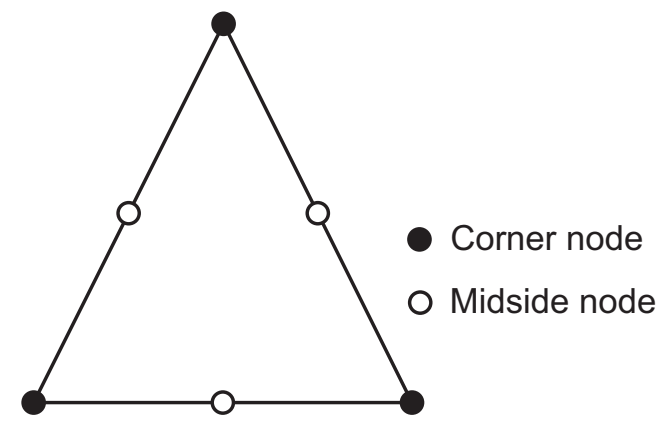

Figure 5.5: Corner and midside nodes

The mesh displacement of the midside node is calculated from the average of the corresponding corner nodes (i-1) and (i+1) of the same element:

$$
\overline{V_{g}^{i}}=\frac{1}{2}\left(V_{g}^{i-1}+V_{g}^{i+1}\right)
$$

\subsubsection{Substructuring without condensation}

The aluminum extrusion problem is divided into four substructures as shown in 5.6. One plastic substructure (1) undergoes nonlinear calculations and the other three $(2,3$ and 4) substructures are assumed to remain elastic throughout the analysis.

The tangent stiffness matrix for each substructure is built by assembling its element stiffness matrices

$$
K^{s}=\sum_{e=1}^{s e} k_{e}
$$

The global tangent stiffness matrix is assembled from the tangent stiffness matrices of the substructures as

$$
K^{g}=\sum_{s=1}^{n} K^{s}
$$




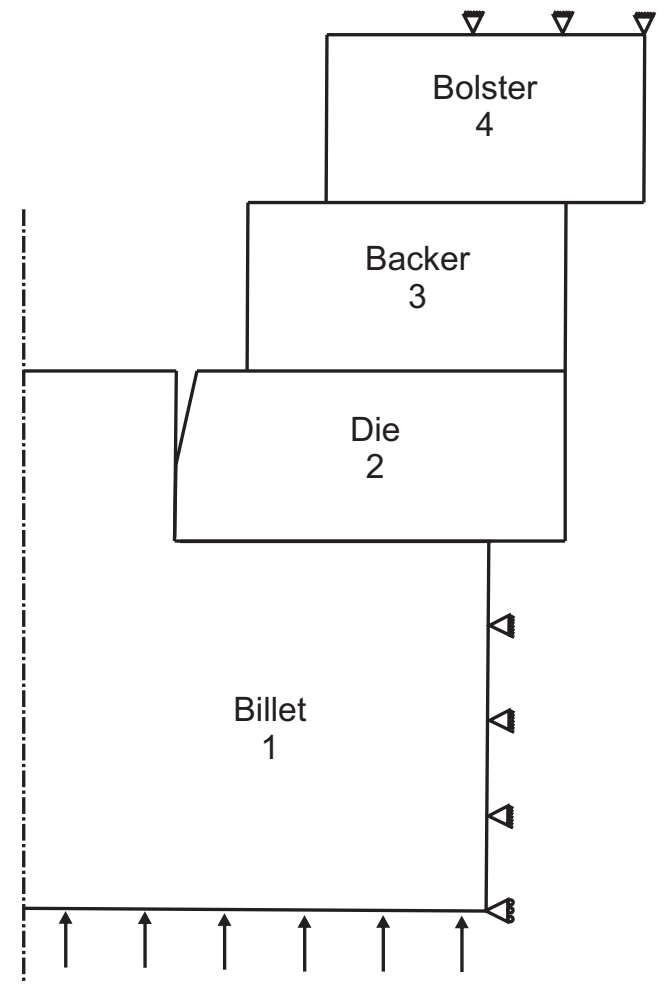

Figure 5.6: The components used in substructuring

The internal force vector of each substructure is assembled from the internal force vector of the elements in the current substructure as

$$
F_{i n t}^{s}=\sum_{e=1}^{s e} f_{i n t, e}
$$

The global internal force vector is assembled from the internal force vectors of the substructures as

$$
F_{i n t}^{g}=\sum_{s=1}^{n} f_{i n t, s}
$$

The tangent stiffness matrices of the elastic substructures can be updated every iteration or every increment or remain unchanged during the whole analysis. When the tangent stiffness matrices are updated every iteration then the simulation is similar to the full-scale model. 


\subsubsection{Statically condensed tool}

The stiffness matrix of the tool which consists of die, backer and bolster is built separately. The boundary conditions at the interface between the parts and downstream of the bolster are applied as described in the previous chapter. The displacement and force vectors of the tool's nodes are partitioned into two parts. The part indicated with subscript " o" corresponds to the nodes at the interface between the aluminum and the tool as described in figure 5.7. The part indicated with subscript "i" corresponds to the internal and remaining boundary nodes of the tool.

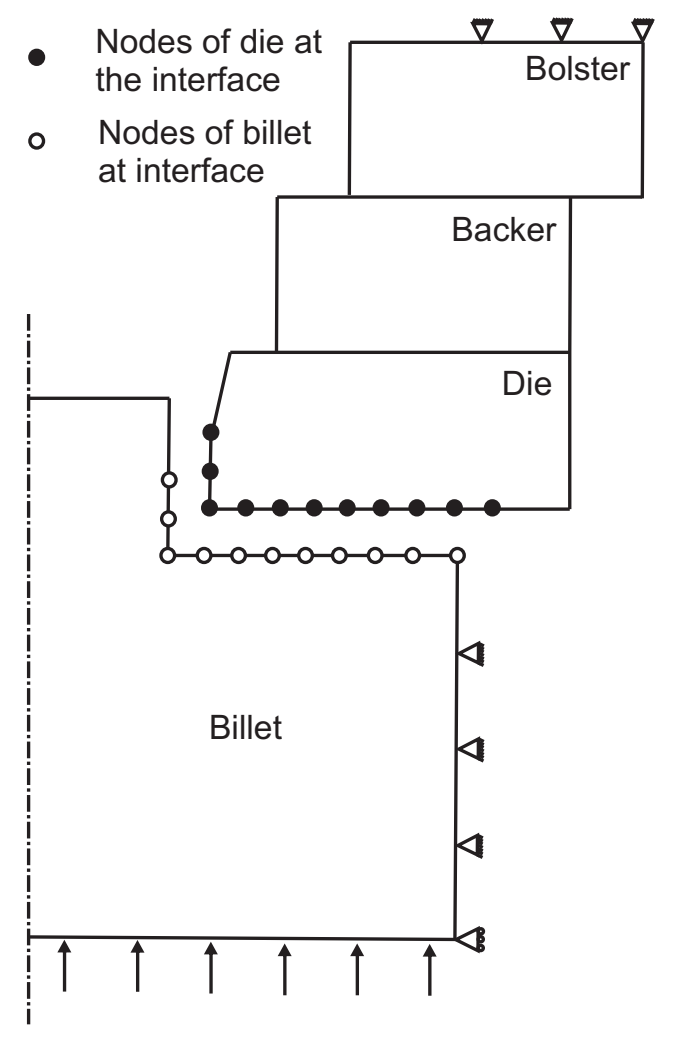

Figure 5.7: A schematic extrusion model showing the condensed tool

Partitioning of the tool stiffness matrix and its condensation is described in the following equations:

$$
\begin{gathered}
{\left[\begin{array}{cc}
K_{o o} & K_{o i} \\
K_{i o} & K_{i i}
\end{array}\right] \cdot\left[\begin{array}{l}
u_{o} \\
u_{i}
\end{array}\right]=\left[\begin{array}{c}
F_{o} \\
F_{i}
\end{array}\right]=\left[\begin{array}{c}
F_{o} \\
0
\end{array}\right]} \\
\left(K_{o o}-K_{o i} K_{i i}^{-1} K_{i o}\right) u_{o}=F_{o}
\end{gathered}
$$




$$
\bar{K} u_{o}=F_{o}
$$

Since the original stiffness matrix of the tool is symmetric, only the matrices $K_{o o}, K_{i i}$ and $K_{i o}$ will be stored. The condensed stiffness matrix $\bar{K}$ is calculated.

Finally the upper half of $\bar{K}$ and the corresponding list of node numbers are imported into the FE package "DiekA". The condensed stiffness matrix $\bar{K}$ is added to the global stiffness matrix as an element stiffness matrix. The boundary conditions at the interface between the aluminum and the condensed tool are applied. During the simulation the right-hand side of the superelement is updated by multiplying the total displacement of its nodes with its stiffness matrix.

\subsection{Case study}

The reduced model for extruding a U-shaped profile discussed in the previous chapter is analyzed by the coupled method. The three procedures of the coupled method including full-scale model, substructuring without condensation and statically condensed tool are studied. Tables 5.1 and 5.2 show the number of nodes, elements and degrees of freedom in the analysis of these procedures. In addition different solvers such as direct or iterative sparse are examined in the evaluation of these procedures. Table 5.3 shows that MUMPS is the fastest for this number of degrees of freedom. The simulation with the coupled method (full-scale model) procedure consumes more time than the decoupled method. Not only the difference in the number of equations solved simultaneously but also the time needed to reach the steady state causes this large difference in computational time between the decoupled method and coupled method (full-scale model). Figure 5.8 displays the extrusion force and the outflow velocity calculated with the decoupled and coupled methods. It shows that about $50 \%$ of the simulation is spent in compressing the tool before the extrusion process will start.

\begin{tabular}{cccccr}
\hline Part & Billet & Die & Backer & Bolster & Total \\
\hline Nodes & 18773 & 17650 & 1658 & 3376 & 41457 \\
Elements & 11752 & 10597 & 897 & 1985 & 25231 \\
DoF & 56319 & 52950 & 4974 & 10128 & 124371 \\
\hline
\end{tabular}

Table 5.1: Number of nodes and elements in the full analysis

Concerning substructuring without condensation, two analyses are performed with the same solver and on the same machine. In one the substructure including the tool is treated incrementally while in the other it is treated multi-incrementally. In table 5.4 a comparison in the cpu time is shown between the two analyses and the full-scale model. 


\begin{tabular}{cccc}
\hline Part & Billet & Condensed tool & Total \\
\hline Nodes & 18773 & 4327 & 23100 \\
Elements & 11752 & 1 & 11753 \\
DoF & 56319 & 12981 & 69300 \\
\hline
\end{tabular}

Table 5.2: Number of nodes and elements in the analysis with static condensation

\begin{tabular}{ccccc}
\hline Machine & Dieka version & Solver & DoF & CPU [h] \\
\hline HPDL145 & 64 bit & MUMPS & 124371 & 3.0 \\
HPDL145 & 64 bit & Bi-CGSTAB & 124371 & 6.5 \\
Sun fire X4450 & $32 \mathrm{bit}$ & Sun Performance & 124371 & 6.0 \\
Sun fire X4450 & $32 \mathrm{bit}$ & Bi-CGSTAB & 124371 & 4.6 \\
\hline
\end{tabular}

Table 5.3: Comparison in CPU time between different solver for the full-scale model
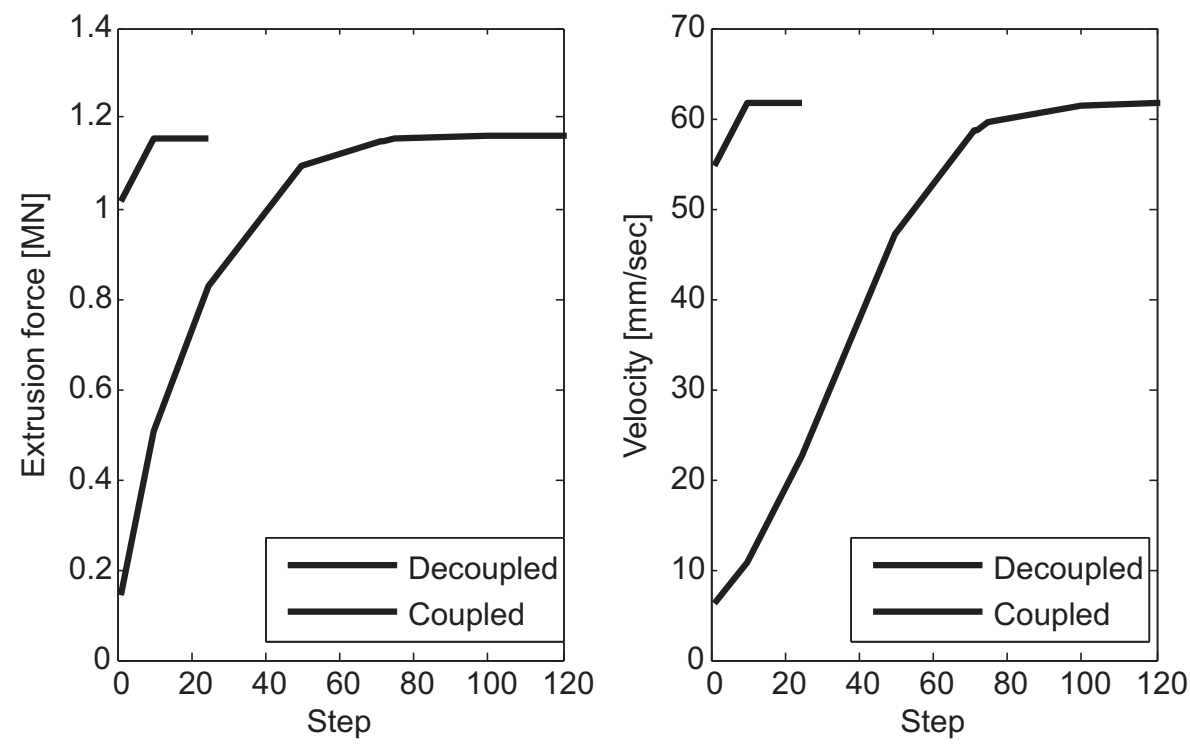

Figure 5.8: Comparison between simulations with the decoupled and coupled methods

Unfortunately, the two analyses don't show any improvement in the cpu time because the solver consumes $90 \%$ of the iteration time.

Concerning the statically condensed tool, the nodes of the tool are condensed to the nodes belonging to the contact surface with the billet. The number of nodes of the tool is decreased by $80 \%$ with respect to the full-scale model which automatically 


\begin{tabular}{cc}
\hline Analysis & CPU $[\mathrm{hr}]$ \\
\hline Full scale & 6.0 \\
Incrementally & 6.4 \\
Multi-increment & 6.0 \\
\hline
\end{tabular}

Table 5.4: Comparison in CPU time between different analyses of substructuring without condensation

decreases the amount of memory required for storing these nodes, their coordinates and their connectivity. The stiffness matrix becomes smaller in size and denser. This is confirmed by table 5.5 showing the number of non-zero numbers and number of degrees of freedom in the full-scale model and the statically condensed tool procedures. Since solving the analysis fails with direct sparse solver due to insufficient memory, it is solved with an iterative solver "Bi-CGSTAB". Table 5.5 shows that the calculation time spent in solving the analysis with static condensation is about 7 times bigger than the time spent in solving the full-scale model. Table 5.6 shows that the largest portion of the time is spent in solving the system. This time depends on the number of local iterations in the iterative solver which depends on the tolerance and convergence criteria.

\begin{tabular}{ccrc}
\hline Procedure & $\begin{array}{c}\text { Degrees of } \\
\text { freedom }\end{array}$ & $\begin{array}{c}\text { Non-zero } \\
\text { numbers }\end{array}$ & CPU [hr] \\
\hline Full-scale & 124371 & 4581982 & 6.5 \\
Statically condensed tool & 69300 & 86268436 & 69.0 \\
\hline
\end{tabular}

Table 5.5: Comparison in CPU time between static condensation and full-scale model

\begin{tabular}{crrc}
\hline $\begin{array}{c}\text { Iteration } \\
\text { number }\end{array}$ & $\begin{array}{c}\text { Stiffness } \\
\text { assembly } \\
\text { [sec] }\end{array}$ & $\begin{array}{rrc}\text { Solve } \\
\text { [sec] }\end{array}$ & $\begin{array}{c}\text { Number of } \\
\text { local } \\
\text { iterations }\end{array}$ \\
\hline 1 & 2522 & 242 & 44 \\
2 & 129 & 2630 & 500 \\
3 & 134 & 2564 & 500 \\
4 & 105 & 1800 & 358 \\
5 & 104 & 1119 & 222 \\
6 & 112 & 786 & 155 \\
\hline
\end{tabular}

Table 5.6: Time spent in solving the first step

Table 5.7 displays the extrusion force, exit velocity and angular deflection of the die tongue resulting from the decoupled and coupled methods. The results are in good agreement with the experimental results. The agreement in the results between the coupled and decoupled method indicates that the tongue is well supported by the backer. Therefore, two new simulations are performed where, in each one, the 
tongue of the die is supported differently as shown in figure 5.9. The thickness of the tongue's support is decreased to half and quarter of its original thickness in the first and second simulations respectively. In these simulations, the full-scale model is applied. Table 5.8 manifests a comparison between the results of these simulations and the original one. The angular deflection of the tongue increases by decreasing the thickness of its support. But the exit velocity and the extrusion force remain the same. Concerning the exit velocity, it is calculated from the incremental displacement of the nodes when the simulation reaches the steady state, which means that the history of the exit velocity is not involved. Therefore, the extrusion force and exit velocity of the simulations with different tongue's support thickness are plotted versus the step number in figure 5.10 in order to check their history. It shows that when the deflection of the tongue increases, the simulation takes longer to reach the steady state. In other words, the aluminum takes more time to come out through the die's opening. This agrees with experimental results of the extrusion benchmark conducted in Dortmund, Germany, in 2009 which shows that the profile at the partially supported tongue is slower than that at the fully supported one [31].

\begin{tabular}{cccc}
\hline Method & $\begin{array}{c}\text { Extrusion force } \\
{[\mathrm{MN}]}\end{array}$ & $\begin{array}{c}\text { Exit velocity } \\
{[\mathrm{mm} / \mathrm{sec}]}\end{array}$ & $\begin{array}{c}\text { Angular deflection } \\
{[\mathrm{mrad}]}\end{array}$ \\
\hline Full-scale & 1.16 & 61.73 & 7.2 \\
Substructure without & 1.16 & 61.86 & 7.2 \\
condensation & & 61.85 & 7.2 \\
Statically condensed & 1.15 & & \\
tool & & 61.58 & 7.0 \\
Decoupled & 1.15 & 61.78 & $7.0 \pm 0.3$ \\
Experiment & 1.20 & & \\
\hline
\end{tabular}

Table 5.7: Comparison between different methods

\begin{tabular}{ccccc}
\hline Support & $\begin{array}{c}\text { Thickness } \\
{[\mathrm{mm}]}\end{array}$ & $\begin{array}{c}\text { Extrusion force } \\
{[\mathrm{MN}]}\end{array}$ & $\begin{array}{c}\text { Exit velocity } \\
{[\mathrm{mm} / \mathrm{sec}]}\end{array}$ & $\begin{array}{c}\text { Angular deflection } \\
{[\mathrm{mrad}]}\end{array}$ \\
\hline Full & 55.00 & 1.159 & 61.73 & 7.2 \\
Half & 27.50 & 1.160 & 61.77 & 10.0 \\
Quarter & 13.75 & 1.161 & 61.84 & 13.3 \\
\hline
\end{tabular}

Table 5.8: Comparison between simulations with different tongue's support thickness

\subsection{A semi-coupled method}

As mentioned before, in the simulation with coupled method about $50 \%$ of the computational time is spent in compressing the tool. This delays reaching the steady state and this point is considered to be a drawback of the coupled method. A semicoupled method is a solution where the material flow and the tool are solved separately 

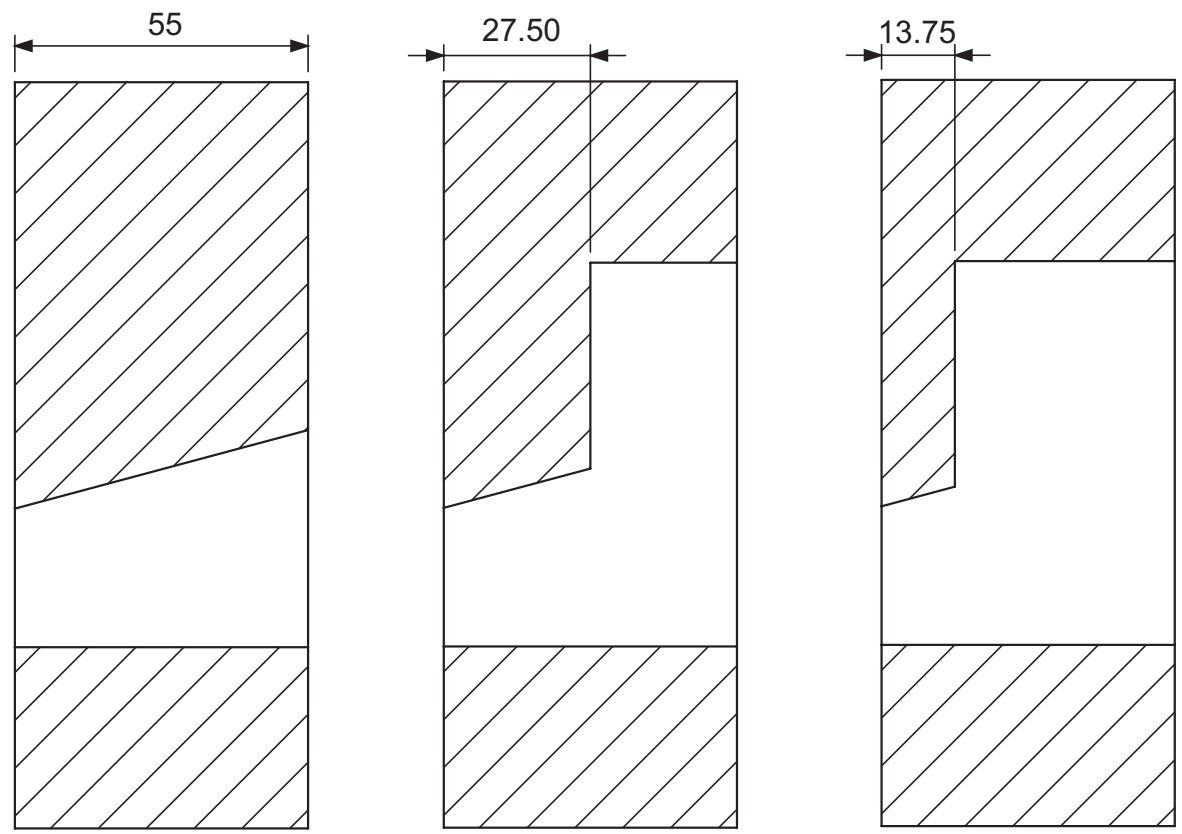

Figure 5.9: Backer with different tongue thickness
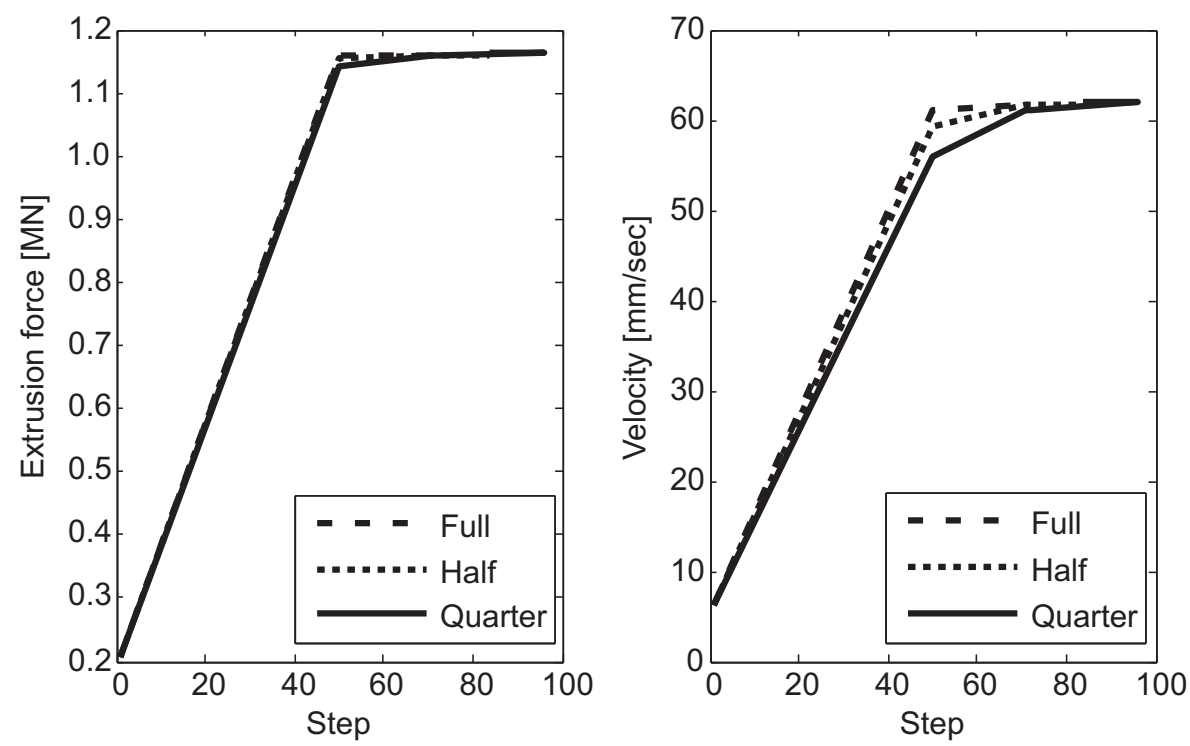

Figure 5.10: Extrusion force and outflow velocity at different tongue thickness 
as in the decoupled method. The semi-coupled method differs from the decoupled method by updating the coordinates of the billet's nodes at the interface between the billet and the die. The simulation of the material flow is repeated with a new tool shape. The procedure is stopped when the change in the extrusion force falls below a certain threshold. In the literature, it is applied in the simulation of stamping process of automotive panel [55] and in calculating the blank springback in deep drawing simulations with a deformable rigid tool [25]. The flow chart of the semi-coupled method is represented in figure 5.11.

The same model described in the case study is solved again with the semi-coupled method which is performed in four iterations. The extrusion force and the exit velocity are listed in table 5.9.

\begin{tabular}{ccc}
\hline Iteration & $\begin{array}{c}\text { Extrusion force } \\
{[\mathrm{MN}]}\end{array}$ & $\begin{array}{c}\text { Exit Velocity } \\
{[\mathrm{mm} / \mathrm{sec}]}\end{array}$ \\
\hline 1 & 1.16 & 61.58 \\
2 & 1.14 & 59.92 \\
3 & 1.14 & 59.97 \\
4 & 1.14 & 60.00 \\
\hline
\end{tabular}

Table 5.9: Extrusion force and exit velocity at four iterations for semi-coupled method

Table 5.9 shows that two iterations are sufficient to do the simulation with the semicoupled method. The two iterations consume about $700 \mathrm{sec}$ in computation without the user time which can be reduced by automation. But the drawback of this method is highlighted in loss of material because the direction of the conditional normal is not updated in the second iteration. It can be done though.

\subsection{Summary and conclusion}

The coupled method is presented with its different procedures such as full-scale model, statically condensed tool and substructure with condensation is presented. It is concluded that the full-scale analysis up to a certain limit of the total number of degrees of freedom is the most efficient in terms of computing time. The selection of the solver has the biggest influence on the efficiency of the simulation. Substructuring without condensation doesn't show a change in calculation time in comparison to the full-scale model. As far as static condensation is concerned, the calculation time is large when compared with the full-scale model and, furthermore, it also consumes a fair amount of time during condensation. In addition, the semi-coupled method is presented and shows that the simulation of an extrusion process can be solved in an acceptable time. But it has drawbacks such as the time spent by the user between 


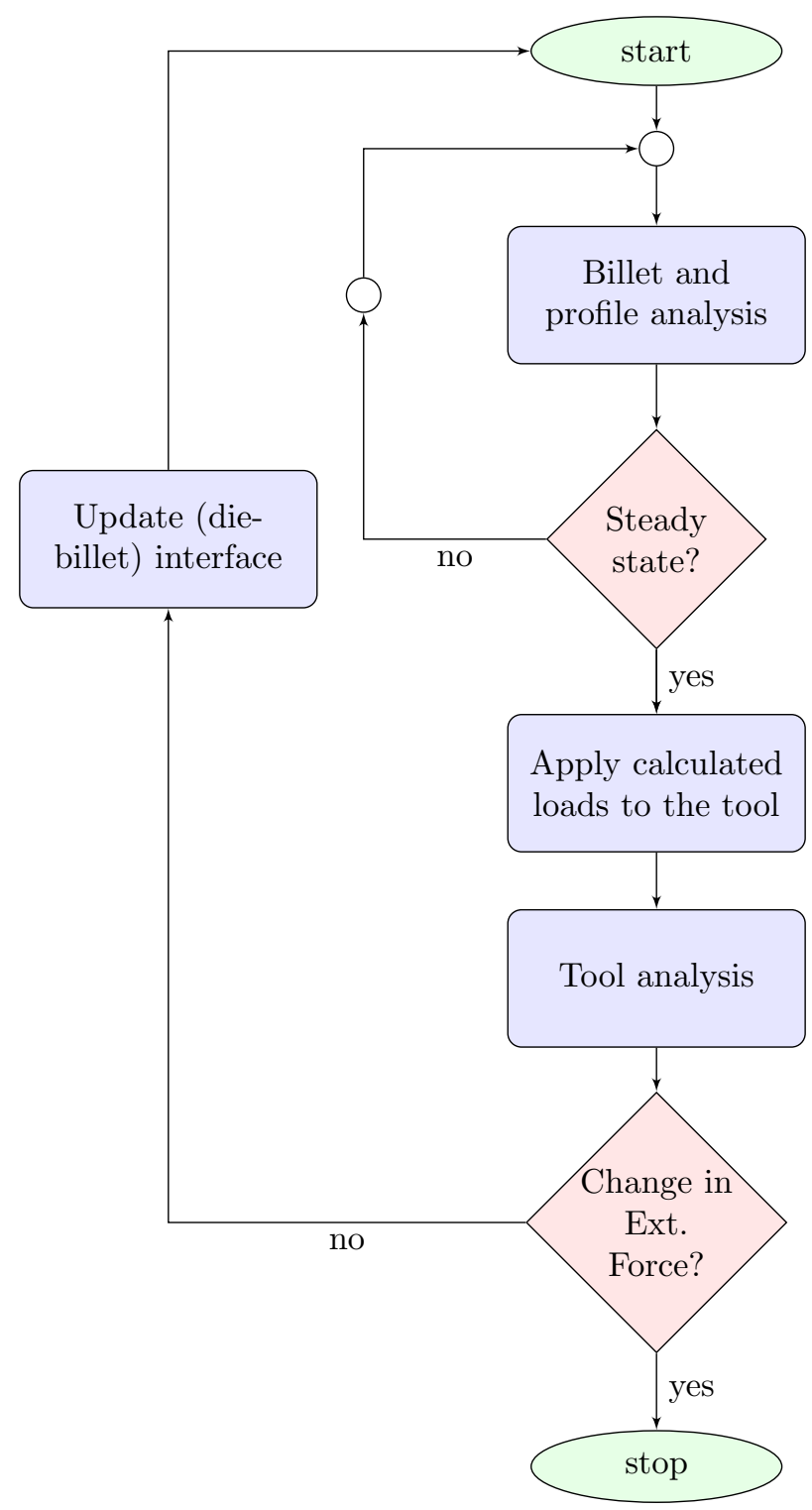

Figure 5.11: Flow chart of a semi-coupled method 
the material flow simulation and the tool simulation and the loss in material. These drawbacks can be resolved. 


\section{Applications}

\subsection{Introduction}

The methods discussed in the previous chapters are applied to two extrusion benchmarks. The first extrusion benchmark was organized on the occasion of an extrusion conference in Bologna, Italy in 2007 [21]. The other one was organized on the occasion of an extrusion conference in Dortmund, Germany in 2009 [31].

In the 2007 benchmark, four L-shaped profiles are extruded through different designs of die pockets. The main goal is to test the performance of the die pockets and whether finite element simulations can be exploited in predicting their performance. The parameters that can be used in the judgment on the performance of the die pockets are the extrusion force and the exit velocities. A material flow simulation through a rigid die is sufficient for calculating those parameters. Simulations are performed with the conditional normal described in section 2.3. In addition, the proportional increment and terminating the simulation when it reaches the steady state are applied in the material flow simulation.

In the 2009 benchmark, two C-shaped profiles are extruded through a die with tongues that are supported differently. The main goal is to check the influence of the die deflection on the exit velocity and whether finite element simulation can be utilized in predicting this influence. The parameters that can be checked are the extrusion force, exit velocities and die deflection. Here, the decoupled and coupled methods are applied in the calculation of those parameters. 


\subsection{Extrusion benchmark 2007}

In this benchmark, the extrusion of four L-shaped profiles selected from standard industrial applications is analyzed. The profiles have two different thicknesses and they are extruded through die openings equipped with different pockets in order to check the effect of the die pocket on the extrusion of a profile with a certain thickness. Figures 6.1 and 6.2 show the profiles and the die pockets respectively. Two profiles with $3 \mathrm{~mm}$ thickness are extruded through stepped and conical pockets. The remaining profiles with $2 \mathrm{~mm}$ thickness are extruded through straight pockets, but one of them comes out of a die opening which is placed asymmetrically in the pocket in order to check the drag effect.

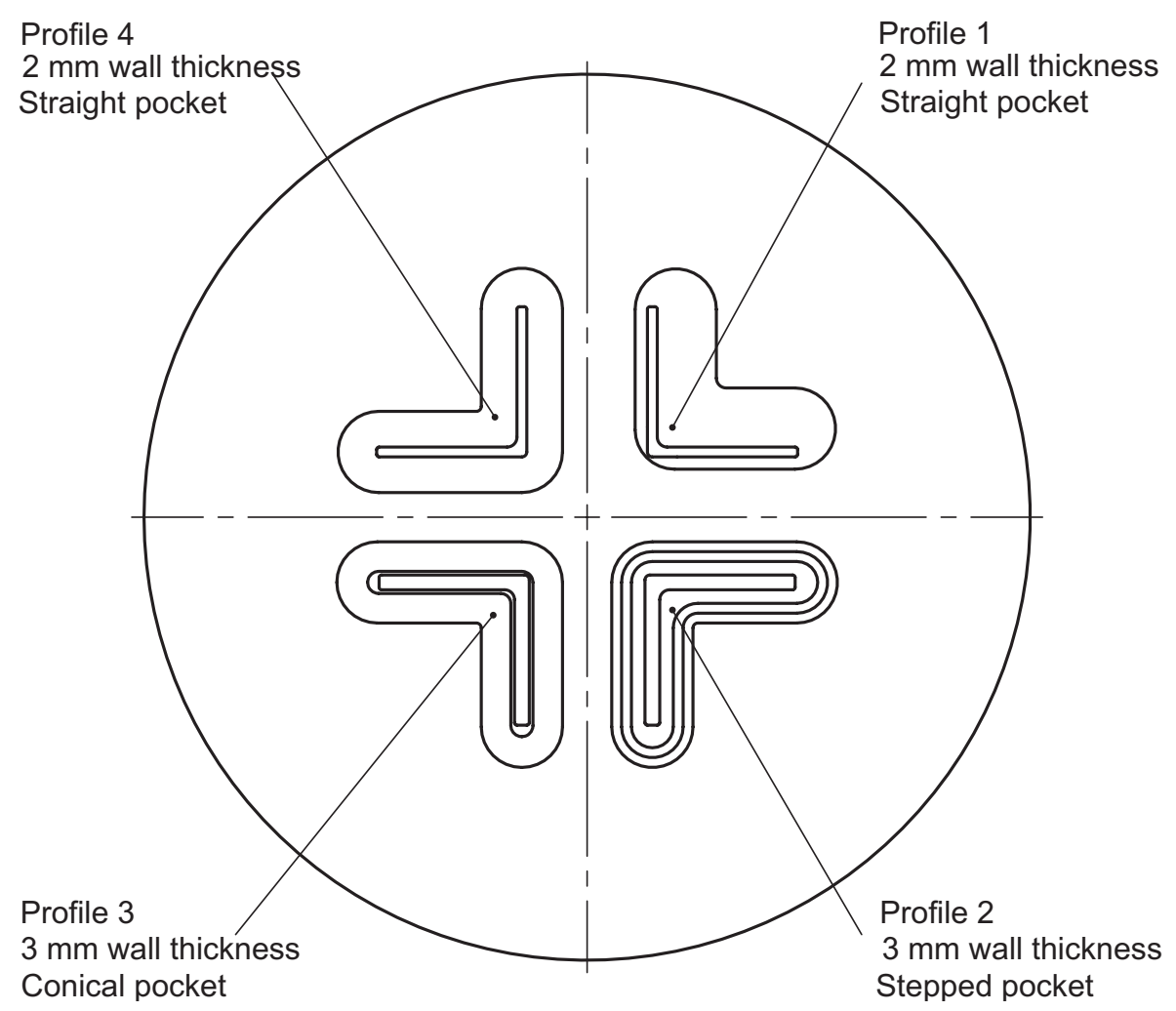

Figure 6.1: Die appearance

\subsubsection{Finite element simulation}

Since the extrusion force decreases slightly exponentially (linearly) with the ram stroke, two models of the billet are created. One represents its shape after filling the die and the other represents its shape at the end of the ram stroke. For each model 


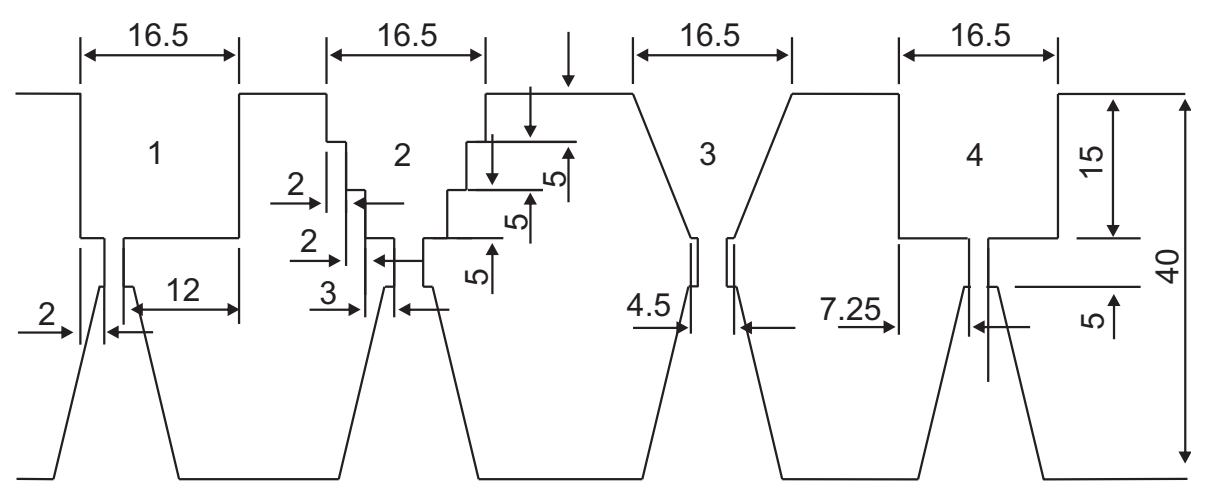

Figure 6.2: Pocket geometries for the four orifices

an isothermal simulation with a Eulerian formulation is performed. The settings of the benchmark are listed in table 6.1.

\begin{tabular}{cc}
\hline Billet & $\varnothing=140 \mathrm{~mm}$ and $\mathrm{L}=302 \mathrm{~mm}$ \\
Billet temperature & $460 \mathrm{C}^{\circ}$ \\
Container & $\varnothing_{\text {in }}=146 \mathrm{~mm}$ and $\mathrm{L}=360 \mathrm{~mm}$ \\
Ram speed & $0.5 \mathrm{~mm} / \mathrm{sec}$ \\
Ram stroke & $250 \mathrm{~mm}$ \\
\hline
\end{tabular}

Table 6.1: Settings of the benchmark 2007

The degrees of freedom of the nodes at the interface between the billet and the container and between the billet and the die face are suppressed in all directions. The degrees of freedom of the nodes at the interface between the extrudate and the die bearing channel are suppressed in the directions perpendicular to the extrusion direction. At the sharp corner, a conditional normal is specified at the bearing corner node.

The model is discretized with a 10-node tetrahedron element with translational degrees of freedom. The total number of degrees of freedom is about 600,000. Since the number of degrees of freedom exceeds 180,000, the iterative solver Bi-CGSTAB is used.

\subsubsection{Results}

In figures 6.3 and 6.4 the velocities of the profiles and the extrusion forces are plotted. The figures show the values determined numerically and experimentally. 


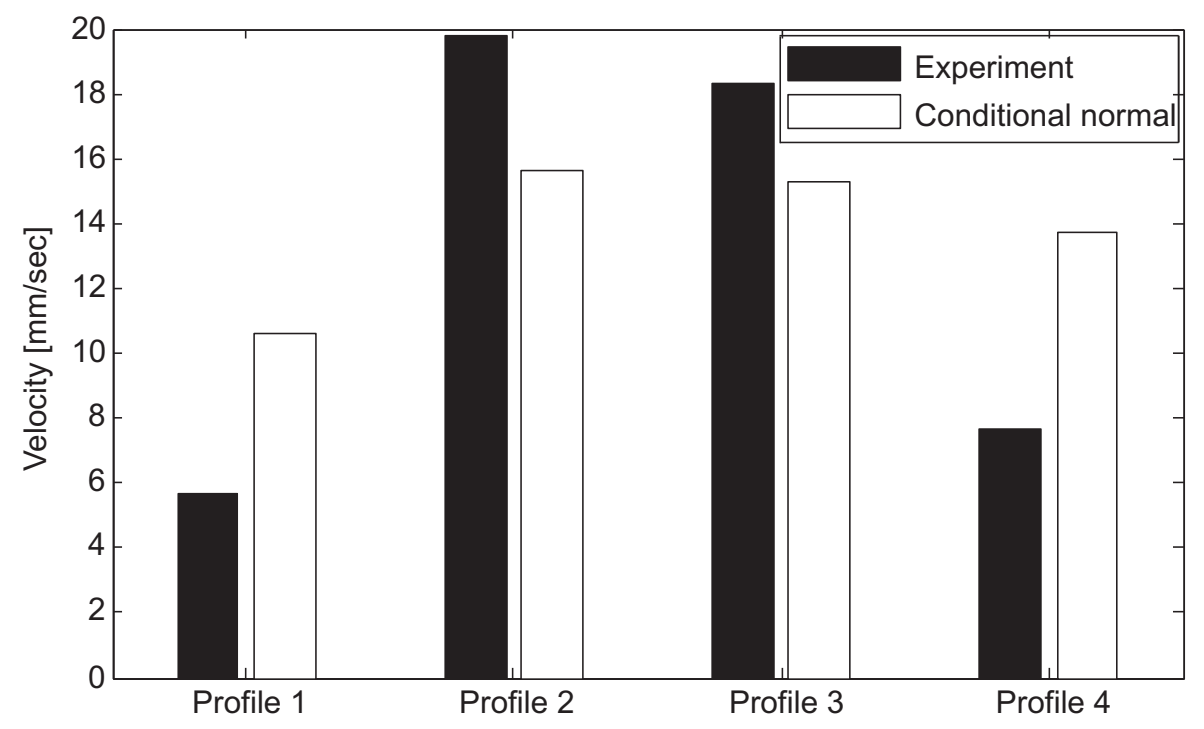

Figure 6.3: Profile velocities

In figure 6.3 the conditional normal construction gives a correct prediction about sorting the profiles from fastest to slowest. The velocities of the profiles determined by this construction don't agree with the experimental values. There are three elements per thickness of the $2 \mathrm{~mm}$ L-shaped profiles and four elements per thickness of the $3 \mathrm{~mm}$ L-shaped profiles. The wrong velocity values of the profiles can be related to the boundary conditions applied in the conical and stepped pockets.

Figure 6.4 displays the extrusion force calculated with the conditional normal construction. The extrusion force is overestimated because the temperature in the simulation is set equal to the initial temperature of the billet. The increase in the temperature due to deformation is not considered.

\subsubsection{Achievements since 2007}

In [21] the results of the simulations performed by the FE code DiekA show the following observations: wrong prediction about sorting the profiles from fastest to slowest, non-conserved material flow and long computational time. There was a $13 \%$ loss in material flow as regards material conservation. Concerning the computational time, each simulation with 600,000 degrees of freedom consumed 167 hours. In this benchmark, the simulations were performed with the average normal construction at the sharp corner. The results confirm what is stated in chapter 2 , that the average 


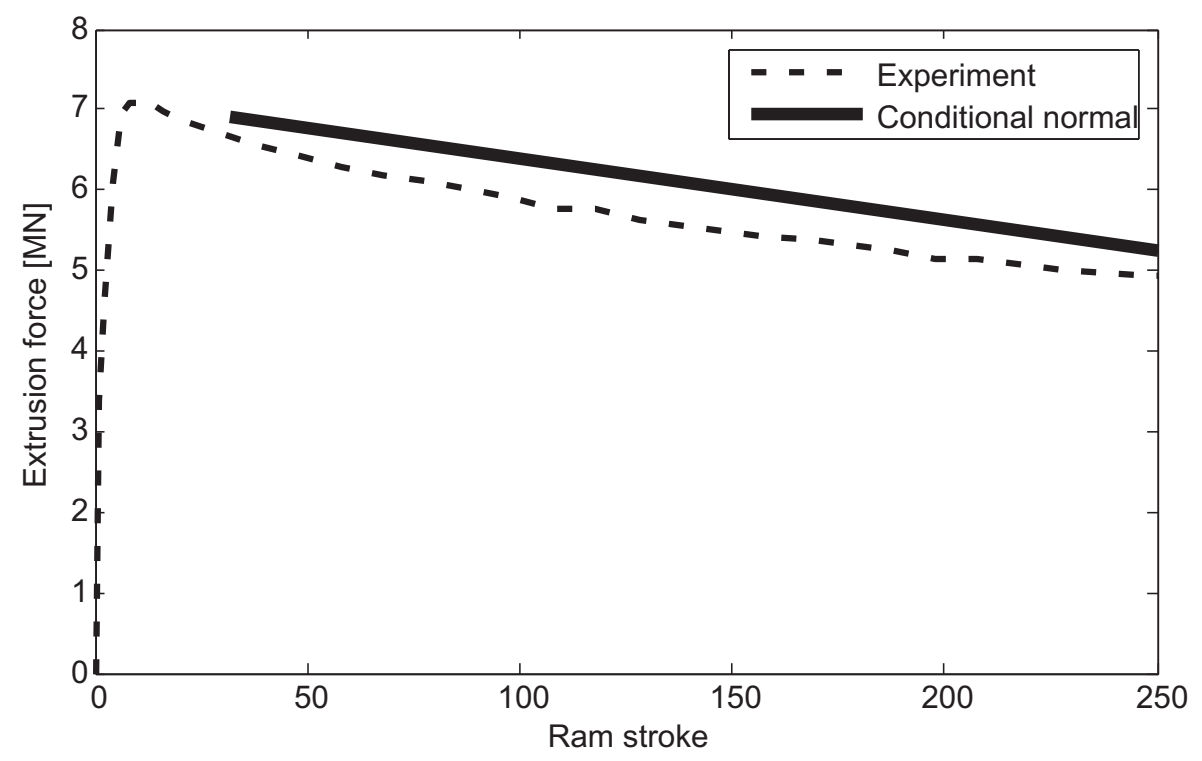

Figure 6.4: Extrusion force versus ram stroke

normal construction causes a non-conserved material flow.

The simulations are repeated with the conditional normal construction at the sharp corner. They are solved with the employment of the proportional increment. And the simulations are terminated when they reach the steady state. The results of these simulations show that the material flow is conserved and the computational time is short. For example, each simulation with about 600,000 degrees of freedom consumes about 47 hours. A reduction of $70 \%$ in computational time is observed.

\subsection{Extrusion benchmark 2009}

In this benchmark, the extrusion of two identical C-shaped profiles shown in figure 6.5 is analyzed. The tongues in the flat die are supported differently: one is fully supported and the other is partially supported. The goal of this benchmark is to calculate the deformation of the tongues that are supported differently and the velocities of the profiles in order to evidence the relationship between the material flow and the die deflection. The settings of the benchmark are listed in table 6.2. 


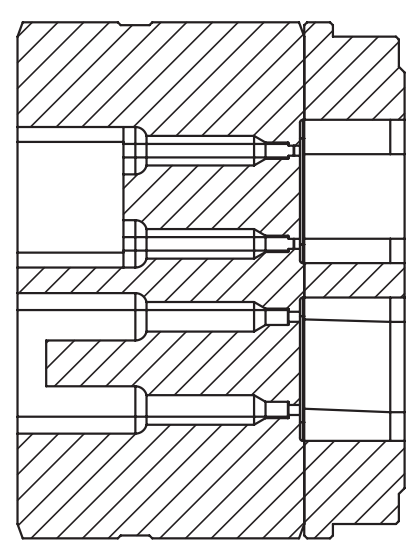

A-A

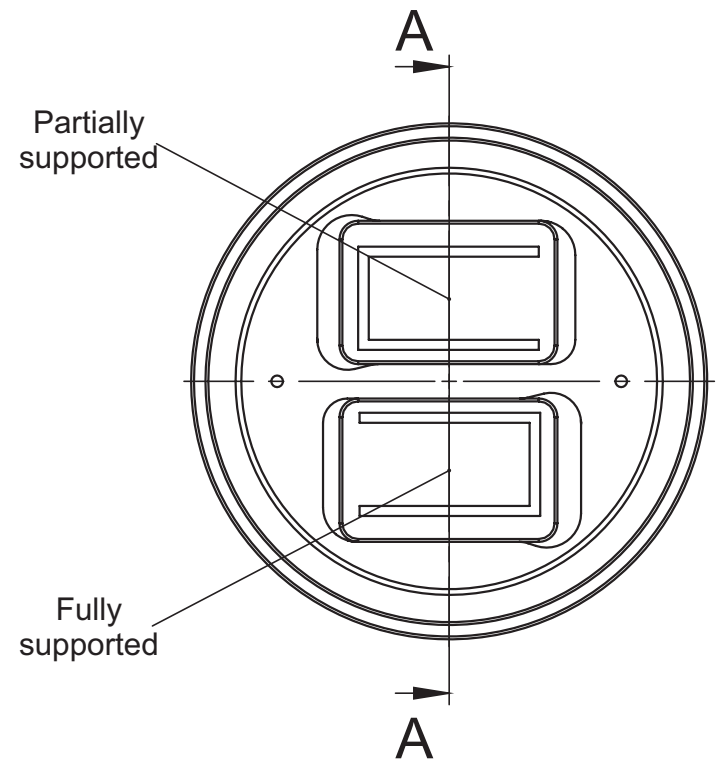

Figure 6.5: Die sketch for extrusion benchmark 2009

\begin{tabular}{cc}
\hline Billet material & AA $6082-\mathrm{O}$ \\
Billet & $\varnothing=140 \mathrm{~mm}$ and $\mathrm{L}=300 \mathrm{~mm}$ \\
Billet temperature & $432 \mathrm{C}^{\circ}$ \\
Die material & AISI H-13 steel, tempered $45 \mathrm{HRC}$ \\
Container & $\varnothing_{\text {in }}=146 \mathrm{~mm}$ and $\mathrm{L}=360 \mathrm{~mm}$ \\
Ram speed & $10.3 \mathrm{~mm} / \mathrm{sec}$ \\
Ram stroke & $250 \mathrm{~mm}$ \\
\hline
\end{tabular}

Table 6.2: Settings of the benchmark 2009

\subsubsection{Finite element simulation}

As mentioned in the previous chapters, the deformation of the die can be calculated by the decoupled, coupled or semi-coupled methods. In the current benchmark, the tool deformation is calculated by the decoupled and coupled methods only. In the coupled method, only the full-scale model procedure is applied. Two geometrical models of the billet and the tool are created. One corresponds to its shape after filling the die and the other corresponds to its shape at the end of the ram stroke. Both geometrical models are discretized simultaneously with 10-node tetrahedron elements with translational degrees of freedom to produce node-to-node contact. Node-to-node contact allows exporting the aluminum loads from the material simulation and applying them to the tool more accurately and easily in the case of the decoupled method. The simulations are performed with a constant temperature which is assumed to be $482 \mathrm{C}^{\circ}$ taking into 
account the increase in the billet temperature during deformation.

\subsubsection{Results}

Concerning the decoupled method, the extrusion force versus the ram stroke is plotted in figure 6.6. The extrusion force calculated numerically is underestimated. This is probably due to the assumed temperature in the simulation. The velocities of the profiles that are determined experimentally and numerically are plotted in figure 6.3. In the simulation no difference is noticed in the velocities of the profiles due to the tongue deformation. The material flow is conserved.

The loads exerted by the aluminum on the die cause a translational deflection of the tool in the extrusion direction and an angular deflection of the tongue.

The difference in the linear deflection in the extrusion direction of the tongues is measured in order to eliminate the influence of their support. In table 6.4 the difference in the deflection of the tongues calculated by the FE code DiekA is compared to the experimental values and the numerical values calculated by other FE codes: Deform 3D and STRUC. The experimental results and the results of the two FE codes are presented in [23]. The numerical results of the simulations performed by different FE codes with different material models of the tool and element types are comparable. A large difference is observed between the experimental and numerical values. As mentioned in the previous chapters, the deformation of the tool depends on the boundary conditions applied at the interfaces between its parts and the material model. In the current benchmark, the die and the backer are designed as one part. The influence of the boundary condition at the interfaces between the parts can be eliminated. Although the material model and the related constants for the tool are not accurate enough, the $100 \%$ error between numerical and experimental values is too big to be related to it. Therefore, the error can be related to the measurement of the deflection.

\begin{tabular}{ccc}
\hline Results & $\begin{array}{c}V_{\text {fully }} \\
{[\mathrm{mm} / \mathrm{sec}]}\end{array}$ & $\begin{array}{c}V_{\text {partially }} \\
{[\mathrm{mm} / \mathrm{sec}]}\end{array}$ \\
\hline Experiment & 160.19 & 155.56 \\
Numerical & 155.00 & 155.00 \\
\hline
\end{tabular}

Table 6.3: Profiles' velocities for the decoupled method

Regarding the computational time, each simulation with about 240,000 degrees of freedom consumes less than 2 hours instead of 75 hours as a cpu time after the employment of the proportional increment and terminating the simulation when it reaches the steady state. As a result, the reduction in cpu time reaches the value of 


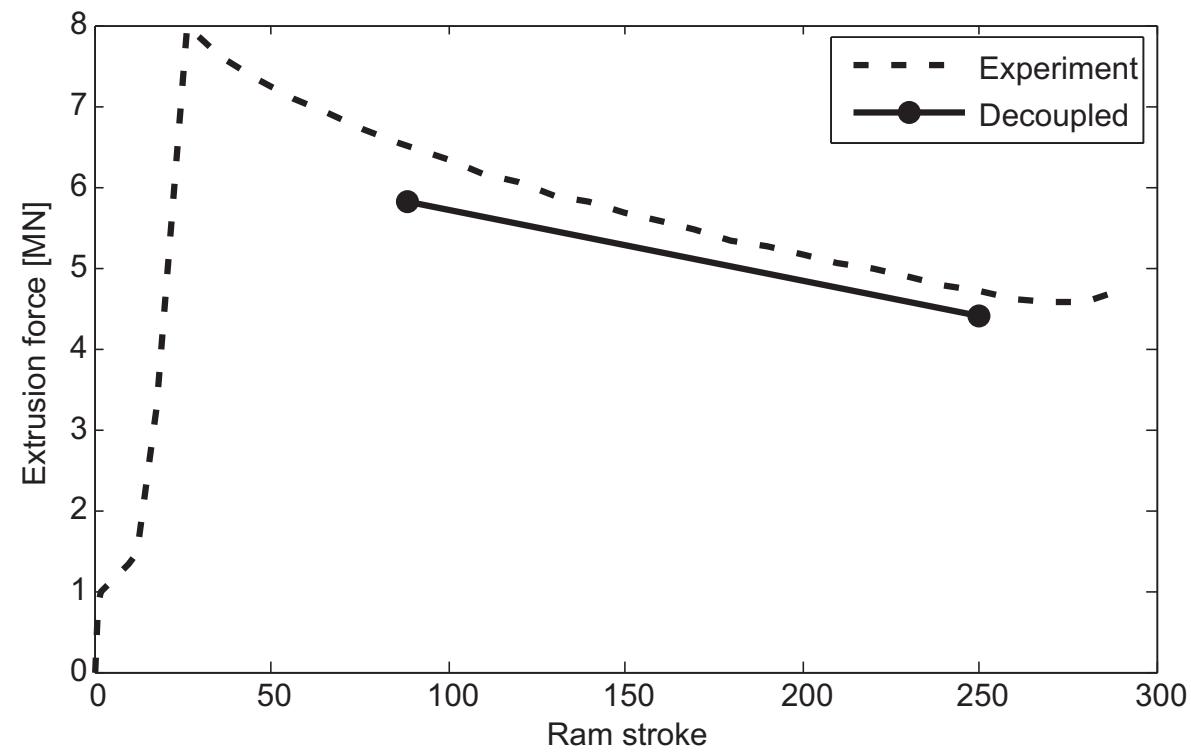

Figure 6.6: Extrusion force versus ram stroke for the decoupled method

\begin{tabular}{cccc}
\hline Experimental & & & $0.39 \mathrm{~mm}$ \\
DEFORM 3D & 4-node Tetrahedron & Elastic & $0.19 \mathrm{~mm}$ \\
STRUC. code & 10-node Tetrahedron & Elastic & $0.22 \mathrm{~mm}$ \\
STRUC. code & 10-node Tetrahedron & Elastic plastic & $0.23 \mathrm{~mm}$ \\
DiekA & 10-node Tetrahedron & Elastic plastic & $0.20 \mathrm{~mm}$ \\
\hline
\end{tabular}

Table 6.4: Deflection difference of die tongues

$97 \%$.

Concerning the coupled method, the extrusion force, velocities of the profiles and deflection of tongues are calculated for the geometrical model equivalent to the shape of the billet after filling the die, and are plotted with respect to the step number in figures $6.7,6.8$ and 6.9 respectively. Figure 6.7 shows that the extrusion force reaches the value of $5.79 \mathrm{MN}$ at the steady state. This value is identical to that determined by the simulation of the material flow through a rigid die.

Figure 6.8 illustrates that the velocities of the two profiles reach the same value at the steady state but the profile at the fully supported tongue gets to the steady state before that at the partially supported tongue. This means that the profile at the fully supported tongue is faster than the one at the partially supported tongue. 


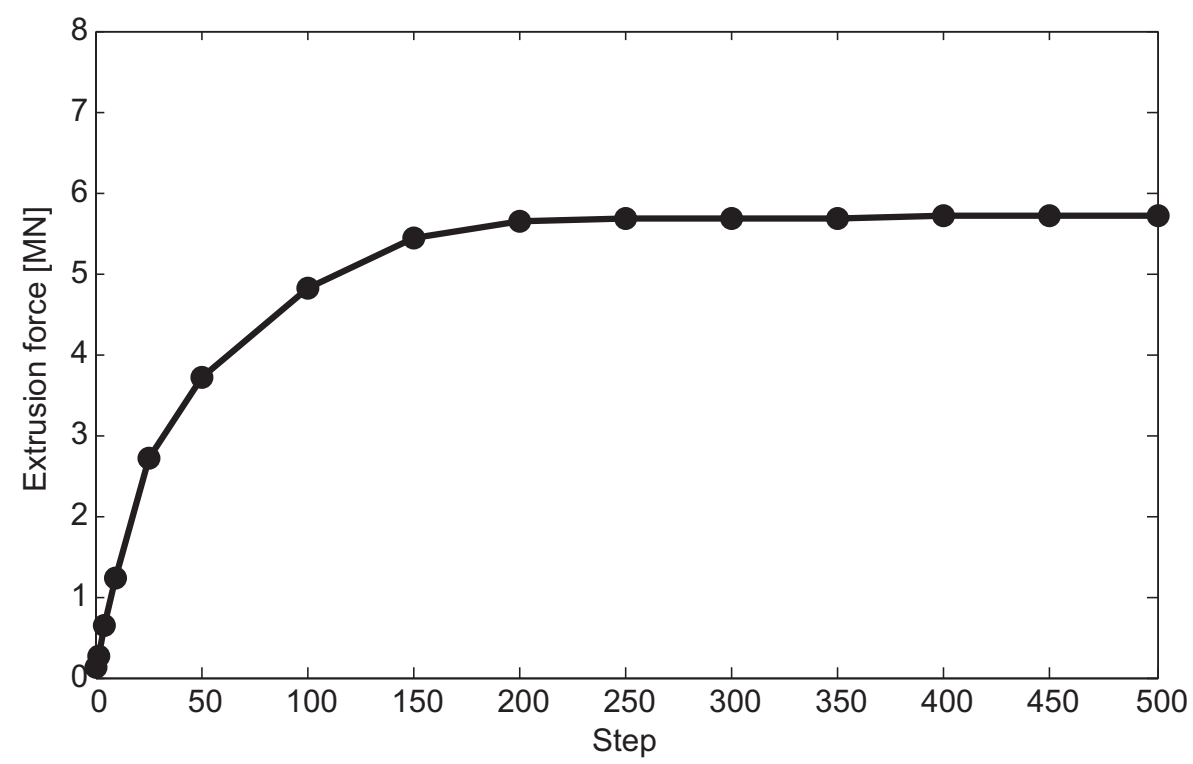

Figure 6.7: Extrusion force versus step number for the coupled method

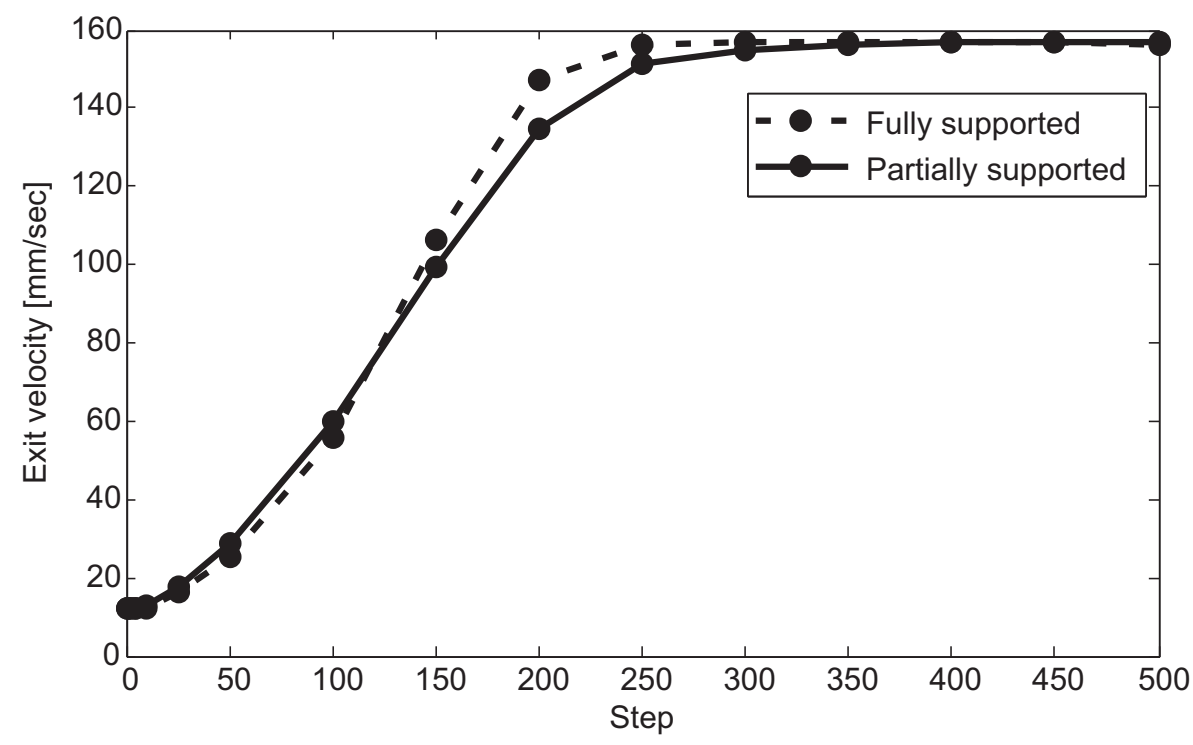

Figure 6.8: Profiles' velocities versus step number for the coupled method 
Figure 6.9 shows that the partially tongue deflects more than the fully supported one. It can be deduced from the plots concerning the deflections and the velocities that the extrusion starts after the tool has been deformed.

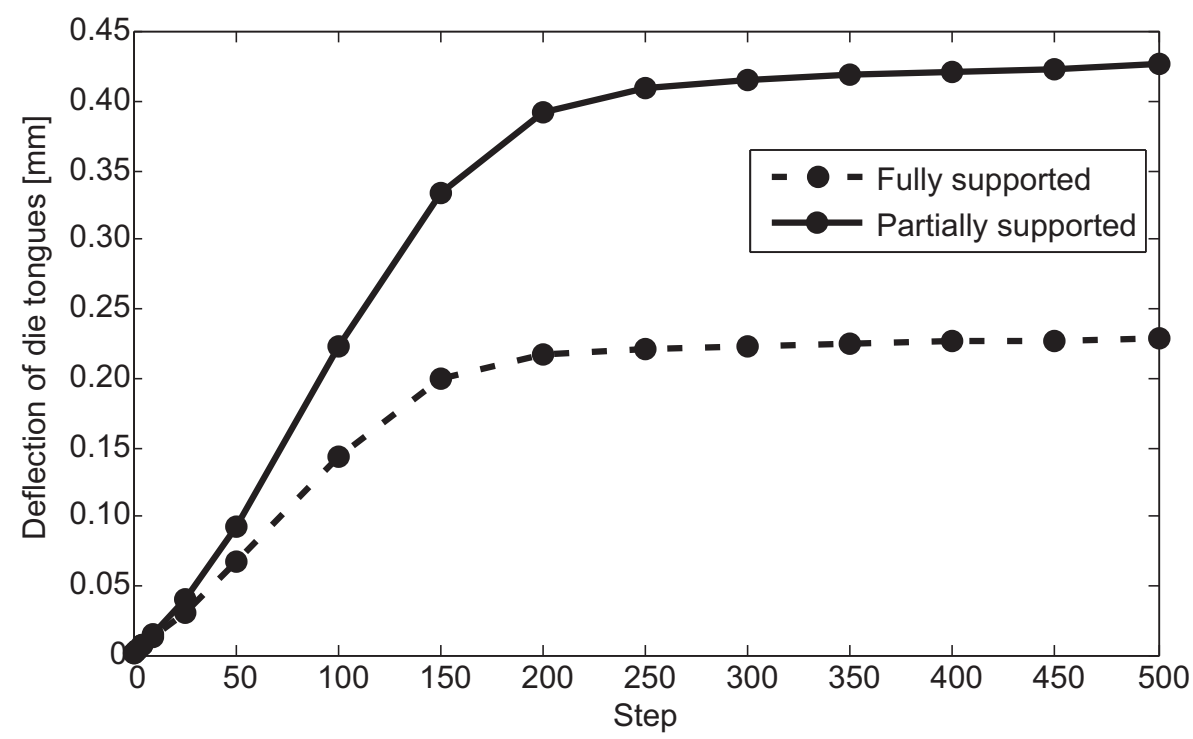

Figure 6.9: Tongue deflection versus step number for the coupled method

\begin{tabular}{ccccc}
\hline Results & $\begin{array}{c}\text { Extrusion force } \\
{[\mathrm{MN}]}\end{array}$ & $\begin{array}{c}\text { Relative displacement } \\
{[\mathrm{mm}]}\end{array}$ & $\begin{array}{c}V_{\text {fully }} \\
{[\mathrm{mm} / \mathrm{sec}]}\end{array}$ & $\begin{array}{c}V_{\text {partially }} \\
{[\mathrm{mm} / \mathrm{sec}]}\end{array}$ \\
\hline Experiment & 6.54 & 0.39 & 160.19 & 155.56 \\
Decoupled & 5.79 & 0.20 & 155.00 & 155.00 \\
Coupled & 5.79 & 0.20 & 156.00 & 157.00 \\
\hline
\end{tabular}

Table 6.5: Results of the simulations with decoupled method, coupled method and experiments

Table 6.5 summarizes the results of the simulation performed with the decoupled method, coupled method and those obtained from the experiment.

The simulation is solved in 500 steps and 30 hours as a cpu time. By this application, it is confirmed that the coupled analysis consumes more time than the decoupled method because a large portion of the cpu time is spent until the simulation reaches its steady state solution. Therefore, the semi-coupled will be the most appropriate method for predicting the influence of the die deformation on the velocity of the profiles. 


\section{Conclusion}

\subsection{Modeling a sharp corner in aluminum extrusion}

Different approximations for the modeling of a sharp corner in aluminum extrusion are studied. Drawbacks of those approximations are lack of material flow conservation, time consuming in preprocessing, increase the cpu time, and difficulty in implementation.

A new approximation is implemented by specifying a conditional normal to a sharp corner. The direction of the conditional normal is determined such that the material flow is conserved. This construction is easy to implement with different types of elements and doesn't consume additional time in the preprocessing and solving.

\subsection{Measuring the deflection of a flat die}

Different procedures found in the literature for measuring the deflection of the die are assessed. All these procedures measure the total displacement of the die in the extrusion direction. This includes the translational displacement of the die and the translational displacement of the supporting structure. By this, the misalignment in the bearing is not known unless the displacement at the other side of the bearing is measured also.

A new experiment setup is built to measure the angular deflection of a die tongue by applying a laser beam on a reflecting surface which is mounted on the die tongue. A die for extruding a U-shaped profile is used. In this experiment an inclined reflecting surface is used.

The alterations in the tool are limited to the small cut in the backer and the fixation of the mirror. These alterations are relatively negligible with respect to labor work. 
Therefore, it can be considered as a simple and cheap experiment.

The angular deflection of the tongue of the flat die has been successfully measured. By measuring the angular deflection, the relative displacement is measured implicitly rather than the absolute displacement.

The results are realistic and reproducible. There appears to remain a permanent deflection in the die after the extrusion of the first billet.

\subsection{Calculating the deflection of the die}

The deflection of the die is calculated with decoupled and coupled methods. In the decoupled method, the material flow and the tool deflection are calculated separately. This method gives a good prediction of extrusion force, exit velocity and die deflection. It consumes an acceptable computational time. In this method the influence of the tool deflection on the material flow is not considered.

In coupled method, the material flow and tool deflection are solved simultaneously. Three procedures of the coupled method are studied such as full-scale model, substructuring and statically condensed tool. It gives a good prediction of the extrusion force, exit velocity distribution in the case of well supported tongue and the deflection of the die. Concerning the coupled method, the full-scale model shows a considerable analysis time while the statically condensed tool shows a large computation time due to the increase in bandwidth in the matrix. A drawback appears in the coupled method in predicting the accurate exit velocity of the profile because the exit velocity is calculated from the incremental displacement at the steady state. Furthermore it takes a long time to reach the steady state in comparison to the decoupled method due to the deformation of the tool.

Therefore, the semi-coupled method will be an optimum solution. In the first iteration, it is solved similarly to the decoupled method. After the deformation of the tool is calculated, the new locations of the aluminum nodes at the interface with the tool are updated. A new calculation of the aluminum with a rigid die is performed until it reaches the steady state. The deformation of the die is recalculated under the change in the loads. The procedure is repeated until the change in extrusion force becomes less than a certain threshold. The update of the conditional normal direction at the bearing corner according to the new shape of the die has not yet been implemented. This influences the flow conservation in the simulations. 


\section{Recommendations for further development}

A preprocessor was built to read the finite element models, to apply the required boundary conditions for 3D aluminum extrusion simulations and to save them in a format accepted by the FE code DiekA. Enhancements on the preprocessor are required to make it user friendly and to increase its efficiency.

The specification of a conditional normal at sharp corners shows good results in the simulations of material flow through dies with straight pockets. The prediction of the extrusion force is accurate and the material flow is conserved. It gives an unsatisfactory prediction of the exit velocities in the simulation of extrusion of the four L-shaped profiles shown in chapter 6 . This is probably due to the boundary conditions applied at the conical and stepped pockets. More study is required to assure the appropriate boundary conditions to be specified and the suitable direction of the conditional normal to be chosen.

The application of semi-coupled method shows a problem in the material conservation. This problem can be resolved by updating the direction of the conditional normal for the simulation of material flow through a deformed die. In addition, the performance of this method can be increased by making it automatic.

Aluminum extrusion is a thermo-mechanical process. The material models are temperature dependent. Thermo-mechanical simulations are required for accurate prediction of the material flow and tool deformation. In these simulations, the change in billet temperature due to plastic deformation and heat transferred through the container and the die can be studied.

Die deformation cause a significant distortion in the die opening. As a result, the dimensions of the profile crosssection change. In order to check the influence of the 
die deformation on the profile crosssection, the change in dimensions of the profile crosssection can be calculated at the end of the FE simulation.

The procedures applied to the coupled method don't show a significant decrease in the computational time. A numerical procedure for efficient simulation of die deformation coupled to aluminum flow must be developed. 
A

\section{Tool parts}

The following pages include the detail drawings of the die and its supporting parts. 


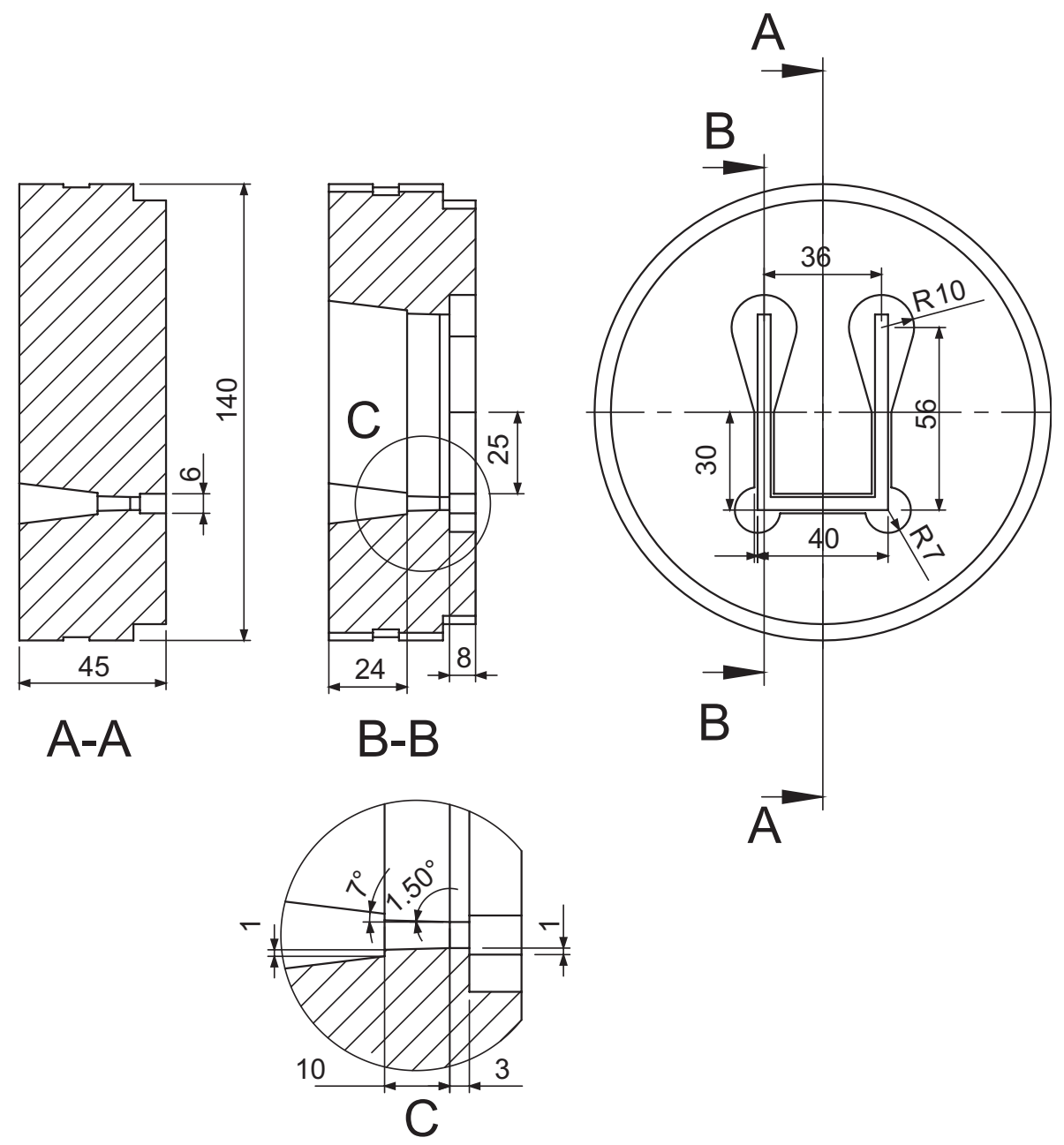

Figure A.1: Die and its section view 


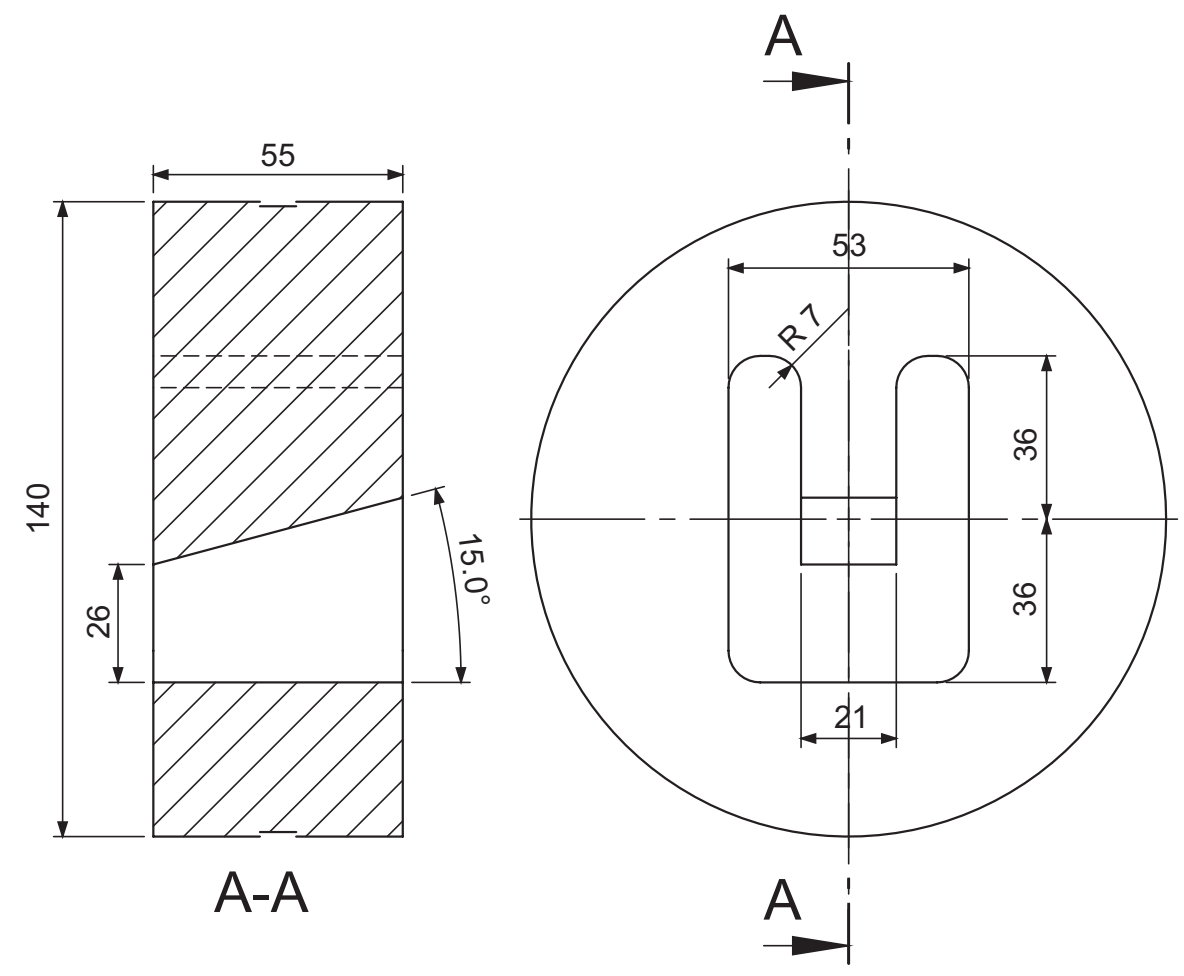

Figure A.2: Front and section view of the backer
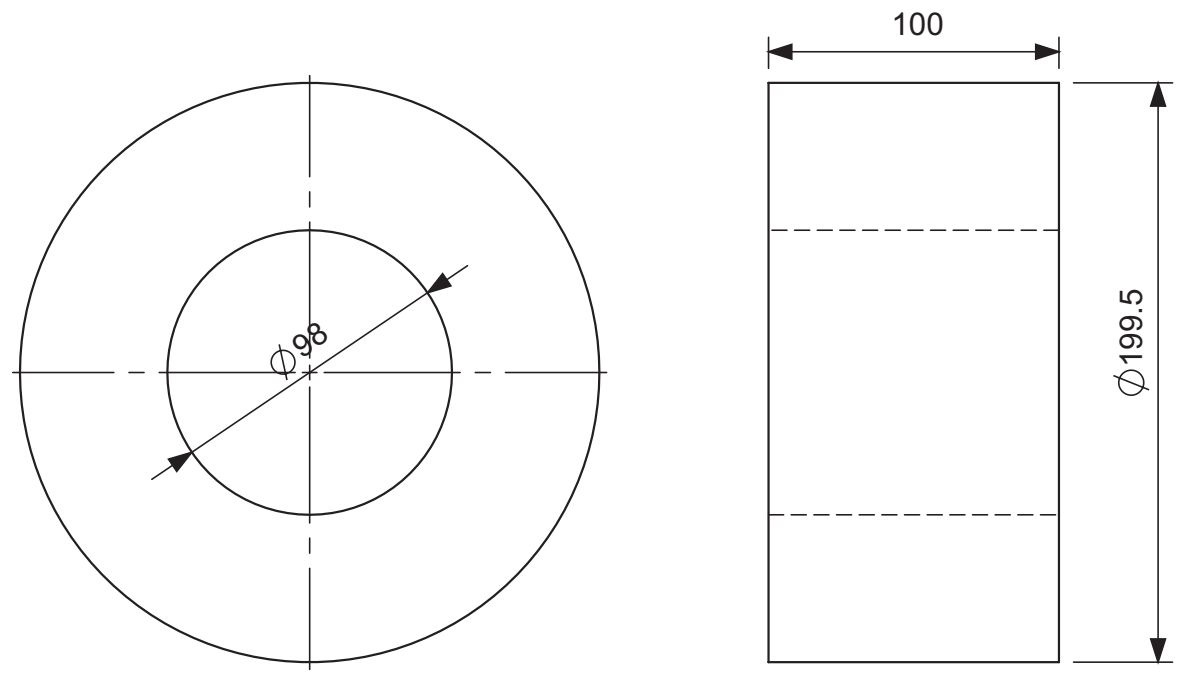

Figure A.3: Front and side view of the bolster 



\section{Results of the $1^{s t}$ round}

The values of the extrusion force, ram speed and angular deflection of the tongue monitored during the $1^{\text {st }}$ round of the experiment are presented in the following table.

Table B.1: Results of the first round

\begin{tabular}{|c|c|c|c|}
\hline $\begin{array}{c}\Delta T \\
{[\mathbf{s e c}]}\end{array}$ & $\begin{array}{c}\text { Ram speed } \\
{[\mathbf{m m} \text { /sec }]}\end{array}$ & $\begin{array}{c}\text { Extrusion force } \\
{[\mathbf{M N}]}\end{array}$ & $\begin{array}{c}\text { Angular deflection } \\
{[\mathbf{m r a d}]}\end{array}$ \\
\hline \multicolumn{3}{|c|}{ First Billet } \\
\hline 0 & 0.0 & 0.06 & 0 \\
182 & 0.0 & 0.06 & 0.63 \\
183 & 0.0 & 1.0 & 0.55 \\
184 & 0.0 & 0.06 & 0.63 \\
187 & 10.77 & 2.98 & 7.28 \\
188 & 3.44 & 2.02 & 7.30 \\
203 & 2.92 & 2.06 & 7.60 \\
248 & 3.76 & 1.47 & 7.80 \\
264 & 6.55 & 1.72 & 8.00 \\
269 & 0.0 & 0.06 & 6.20 \\
273 & 0.0 & 0.06 & 6.46 \\
\hline \multicolumn{5}{|c|}{ Second Billet } \\
\hline 307 & 0.0 & 0.06 & 0.87 \\
310 & 0.0 & 1.0 & 1.0 \\
311 & 0.0 & 0.06 & 0.94 \\
316 & 4.96 & 2.41 & 7.00 \\
331 & 5.3 & 1.95 & 7.37 \\
353 & 5.28 & 1.55 & 7.29 \\
373 & 5.35 & 1.21 & 7.40 \\
376 & 0.0 & 0.06 & 4.86 \\
\hline \multicolumn{5}{|c|}{ Continued on next page } \\
\hline
\end{tabular}


Table B.1 - continued from previous page

\begin{tabular}{|c|c|c|c|}
\hline $\begin{array}{c}\Delta T \\
{[\text { sec }]}\end{array}$ & $\begin{array}{c}\text { Ram speed } \\
{[\mathbf{m m} / \mathbf{s e c}]}\end{array}$ & $\begin{array}{c}\text { Extrusion force } \\
{[\mathbf{M N}]}\end{array}$ & $\begin{array}{c}\text { Angular deflection } \\
{[\mathbf{m r a d}]}\end{array}$ \\
\hline 383 & 0.0 & 0.06 & 4.10 \\
\hline \multicolumn{3}{|c|}{ Third Billet } \\
\hline 410 & 0.0 & 0.06 & 0.94 \\
413 & 0.0 & 0.72 & 1.0 \\
414 & 0.0 & 0.06 & 0.40 \\
417 & 6.97 & 2.60 & 7.12 \\
437 & 5.34 & 1.92 & 6.92 \\
453 & 5.33 & 1.57 & 7.11 \\
476 & 5.36 & 1.20 & 7.19 \\
478 & 0.0 & 0.06 & 7.08 \\
\hline \multicolumn{5}{|c|}{ Fourth Billet } \\
\hline 509 & 0.0 & 0.06 & 0.95 \\
511 & 0.0 & 0.82 & 0.7 \\
512 & 0.0 & 0.06 & 6.23 \\
514 & 0.0 & 2.86 & 7.30 \\
522 & 5.57 & 2.02 & 6.76 \\
543 & 5.31 & 1.66 & 7.03 \\
573 & 5.24 & 1.17 & 7.00 \\
575 & 0.0 & 0.30 & 7.00 \\
581 & 0.0 & 0.06 & 7.00 \\
\hline
\end{tabular}




\section{Material parameters}

\section{C.1 Aluminum alloys}

$$
\bar{\sigma}=\frac{1}{\alpha} \sinh ^{-1}\left(\left(\frac{\dot{\epsilon}}{A} \exp \left(\frac{Q}{R T}\right)\right)^{\frac{1}{n}}\right)
$$

\begin{tabular}{|c|c|c|c|c|c|}
\hline Alloy & $\mathrm{n}$ & $\mathrm{Q}[\mathrm{J} / \mathrm{mol}]$ & $\mathrm{A}\left[\mathrm{sec}^{-1}\right]$ & $\mathrm{R}[\mathrm{J} / \mathrm{K} . \mathrm{mol}]$ & $\alpha\left[\mathrm{MPa}^{-1}\right]$ \\
\hline 6060 & 4.22 & 187900 & $7.38 \mathrm{E} 11$ & 8.314 & 0.052 \\
\hline 6063 & 5.4 & 140000 & $6.0 \mathrm{E} 09$ & 8.314 & 0.04 \\
\hline $6082-O^{1}$ & 2.976 & 153000 & $2.39 \mathrm{E} 08$ & 8.314 & 0.052 \\
\hline $6082-O^{2}$ & 6.88 & 199960 & $1.16099 \mathrm{E} 15$ & 8.314 & 0.019 \\
\hline
\end{tabular}

Table C.1: Constants in Sellars-Tegart equation for some aluminum alloys (1 and 2 are denoted for constants used in benchmarks that were held in 2007 and 2009)

\section{C.2 Tool steel}

\begin{tabular}{|c|c|c|c|c|}
\hline $\begin{array}{c}\text { Temperature } \\
\mathrm{C}^{\circ}\end{array}$ & $\begin{array}{c}\text { Young's Modulus } \\
\mathrm{GPa}\end{array}$ & $\begin{array}{c}\text { Yield stress } \\
\mathrm{MPa}\end{array}$ & $\begin{array}{c}\text { Ultimate stress } \\
\mathrm{MPa}\end{array}$ & Poisson's ratio \\
\hline 500 & 176 & 850 & 1150 & 0.29 \\
\hline
\end{tabular}

Table C.2: Material constants of the tool [29] 



\section{References}

[1] A. H. van den Boogaard, J. Huétink, and A. D. Rietman. Iterative solvers in forming process simulations. In Simulation of Materials Processing: Theory, Methods and Applications, pages 219-224, Balkema, Rotterdam, 1998. NUMIFORM 98.

[2] A. J. Koopman, H. J. M. Geijselaers, and J. Huétink. A SUPG approach for determining frontlines in aluminum extrusion simulations and a comparison with experiments. Zaragoza, Spain, 2007. Esaform.

[3] A. K. Noor, H. A. Kamel, and R. E. Fulton. Substructuring techniques-status and projections. Computers and Structures, 8:621-632, 1978.

[4] B. Bourqui, A. Huber, C.Moulin, A.Brunetti, and Y.Krhenbuhl. Improved weld seam quality using 3D FEM simulation in correlation with practice. Brescia, 2002. The First EAA Extruders Division Congress.

[5] B. J. E. van Rens, W. A. M. Brekelmans, and F. P. T. Baaijens. Modelling friction near sharp edges using a Eulerian reference frame: Application to aluminium extrusion. International Journal for Numerical Methods in Engineering, 54:453471, 2002.

[6] W. A. M. Brekelmans. A simulation method for the die compaction of granular materials. PhD thesis, Eindhoven University of Technology, Eindhoven, Netherlands, 1989.

[7] C. W. Jowet, G. Hay, and N. Parson. Upset. Orlando, USA, 2004. Extrusion Technology.

[8] D. Pietzka, N. Ben Khalifa, and L. Donati. Extrusion benchmark 2009experimental analysis of deflection in extrusion dies. Advances on hot extrusion simulation of light alloys, pages 19-26, 2009.

[9] H. G. Mooi, P. T. G. Koenis, and J. Huétink. An effective split of flow and die deformation calculations of aluminum extrusion. Materials Processing Technology, (88):67-76, 1999. 
[10] H. Sano, T. Ishikawa, and Y. Yoshida. Study on metal flow in extruded billet. Orlando, Florida, USA, 2004. International Extrusion Technology Seminar.

[11] H. Valberg. Experimental techniques to characterize large plastic deformations in unlubricated hot aluminum extrusion. Advances on Hot Extrusion and Simulation of Light Alloys, pages 17-24, 2007.

[12] A. M. H. Hadoush. Efficient simulation and process mechanics of incremental sheet forming. PhD thesis, University of Twente, Enschede, Netherlands, 2010.

[13] J. Huétink. On the simulation of thermo-mechanical forming processes. $\mathrm{PhD}$ thesis, University of Twente, Enschede, 1986.

[14] J. F. Abel and M. S. Shephard. An algorithm for multipoint constraints in finite element analysis. International Journal for Numerical Methods in Engineering, 14:464-467, 1979.

[15] J. J. Despoy, R. M. Kelly, and J. D. McKay. The advantages of aluminum extrusions compared with some competitive materials and methods of forming. Chicago, Illinois, USA, 1988. Extrusion Technology.

[16] J. Lof and Y. Blokhuis. Fem simulations of the extrusion of complex thin-walled aluminum sections. Journal of Materials Processing Technology, 122:344-354, 2002 .

[17] J. M. Gere and S. P. Timoshenko. Mechanics of Materials. PWS, 4 edition, 1997.

[18] J. van de Langkruis, J. Lof, and W. H. Kool. Comparison of experimental AA6063 extrusion trials to 3D numerical simulations, using a general solute-dependent constitutive model. Computational Materials Science, 18:381-392, 2000.

[19] K. Park and D. Y. Yang. Mismatching refinement with domain decomposition for the analysis of steady-state metal forming. International Journal for Numerical Methods in Engineering, 48:1089-1106, 2000.

[20] A. J. Koopman. Analysis tool for the design of aluminum extrusion dies. PhD thesis, University of Twente, Enschede, Netherlands, 2009.

[21] L. Donati and L. Tomesani. Latest advances in extrusion technology and simulation in Europe and second extrusion benchmark. Bologna, Italy, 2007. University of Bologna.

[22] L. Donati, N. Ben Khalifa, L. Tomesani, and A. E. Tekkaya. Comparison of different FEM code approaches in the simulation of the die deflection during aluminum extrusion. Brescia, Italy, 2010. Esafom.

[23] L. Donati, N. Khalifa, and L. Tomesani. Evaluation of different fe simulation codes in the stress analysis of extrusion dies. Brescia, Italy, 2010. ESAFORM.

[24] L. Nannini and G. Fioravanti. News on 2000's press technology NBE burp cycle. Chicago, 1996. Extrusion Technology. 
[25] R. A. Lingbeek. Virtual tool reworking. PhD thesis, University of Twente, Enschede, 2008.

[26] J. Lof. Developments in finite element simulations of aluminum extrusion. $\mathrm{PhD}$ thesis, University of Twente, Enschede, Netherlands, 2000.

[27] M. Lefstad, P. T. Moe, and S. St $\phi$ ren. Thin strip aluminum extrusion - pressure, temperature and deflection recordings of the extrusion die. Kraków, 2002. ESAFORM.

[28] P. T. Moe. Pressure and Strain Measurement During Hot Extrusion of Aluminum. PhD thesis, NTNU, Trodheim, 2005.

[29] H. Mooi. Finite element simulations of aluminum extrusion. PhD thesis, University of Twente, Enschede, Netherlands, 1996.

[30] MUMPS, http://mumps.enseeiht.fr/. MUltifrontal Massively Parallel Solver, (MUMPS 4.9.2), Users guide, November 2009.

[31] N. Ben Khalifa and A. Erman Teckkaya. Advances in extrusion technology and simulation. Dortmund, Germany, 2009. Technical University of Dortmund, Institute of Forming Technology and Lightweight Construction.

[32] P. T. Moe and S. St $\phi$ ren. A technique for measuring pressure on the die face during extrusion. Kraków, 2002. ESAFORM.

[33] P. T. Moe, S. St $\phi$ ren, and J. Huétink. Advances in Material Forming, chapter Hot metal extrusion. Springer, Paris, 2007.

[34] R. D. Cook, D. S. Malkus, M. E. Plesha, and R. J. Witt. Concepts and applications of finite element analysis. John Wiley and Sons, fourth edition, 2001.

[35] R. H. Dodds and L. A. Lopez. Substructuring in linear and nonlinear analysis. International Journal for Numerical Methods in Engineering, 15:583-597, 1980.

[36] R. Thackray, R. Dashwood, and H. McShane. Simulation of the effect of tooling and billet condition on bulk and surface metal flow during extrusion. Chicago, USA, 2000. International Extrusion Technology Seminar.

[37] S. Abtahi and T. Welo. Interface mechanisms on the bearing surface in extrusion. Chicago, USA, 1996. International Extrusion Technology Seminar.

[38] P. K. Saha. Aluminum extrusion technology. ASM International, 1 edition, 2000.

[39] San-Chen Chang and Tsung-Wu Lin. Constraint relation implementation for finite element analysis from an element basis. Advanced Engineering Software, 10:191-194, 1988.

[40] T. Sheppard. Extrusion of Aluminum Alloys. Kluwer Academic Publishers, 2 edition, 1999. 
[41] H. C. Stoker. Developments of the Arbitrary Lagrangian-Eulerian method in non-linear solid mechanics. PhD thesis, University of Twente, 1999.

[42] Sun Microsystems, Inc, www.sun.com. Sun Performance Library, Users' Guide, July 2009.

[43] Jan Sundqvist. An application of ADINA to the solution of fluid-structure interaction problems. Computers and Structures, pages 793-807, 1983.

[44] T. Belytschko, W. Liu, and B. Moran. Nonlinear finite elements for continua and structures. John Wiley and Sons Ltd, 2000.

[45] T. Hatzenbichler, B. Buchmayr, and A. Umgeher. A numerical sensitivity study to determine the main influence parameters on the back-end defect. Materials Processing Technology, (182):73-78, 2007.

[46] T. Miyamura, H. Noguchi, and R. Shioya. Elastic-plastic analysis of nuclear structures with millions of dofs using the hierarchical domain decomposition method. Nuclear Engineering and Design, 212:335-355, 2002.

[47] T. Mori, N. Takatsuji, K. Matsuki, T. Aida, K. Murotani, and K. Uetoko. Measurement of pressure distribution on die surface and deformation of extrusion die in hot extrusion of 1050 aluminum rod. Materials Processing Technology, pages 421-425, 2002.

[48] T. Yoneyama and M. Takahashi. Measurement of pressure and friction on the container surface during aluminum hot extrusion. Orlando, USA, 2004. Extrusion Technology.

[49] S. Tverlid. Modeling of friction in the bearing channel of dies for extrusion of aluminum sections. PhD thesis, NTNU, Trondheim, 1998.

[50] G. van Ouwerkerk. CAD implementation of design rules for aluminum extrusion dies. PhD thesis, University of Twente, 2009.

[51] W. Assaad and H.J.M. Geijselaers. 3-D numerical simulation of direct aluminum extrusion and die deformation. Orlando, Florida, USA, 2008. International Extrusion Technology Seminar.

[52] W. Assaad and H.J.M. Geijselaers. Boundary conditions applied on bearing corner in direct aluminum extrusion. International Journal of Material Forming, $2: 77-80,2009$.

[53] W. Assaad and H.J.M. Geijselaers. Measuring the deformation of a flat die by applying a laser beam on a reflecting surface. Advances on Hot Extrusion and Simulation of Light Alloys, pages 197-204, 2009.

[54] H. Wisselink. Analysis of guillotining and slitting. PhD thesis, University of Twente, 2000.

[55] Y. T. Keum, I. H. Ahn, and M. H. Song. Simulating of stamping process of automotive panel considering die deformation. Detroit, USA, 2005. NUMISHEET. 